\title{
The effectiveness of an education and activation programm in acute and sub-acute shoulder complaints presented in general practice
}

Citation for published version (APA):

de Bruijn, C. P. C. (2008). The effectiveness of an education and activation programm in acute and subacute shoulder complaints presented in general practice. [Doctoral Thesis, Maastricht University]. Universiteit Maastricht. https://doi.org/10.26481/dis.20080306cb

Document status and date:

Published: 01/01/2008

DOI:

$10.26481 /$ dis.20080306cb

Document Version:

Publisher's PDF, also known as Version of record

Please check the document version of this publication:

- A submitted manuscript is the version of the article upon submission and before peer-review. There can be important differences between the submitted version and the official published version of record.

People interested in the research are advised to contact the author for the final version of the publication, or visit the DOI to the publisher's website.

- The final author version and the galley proof are versions of the publication after peer review.

- The final published version features the final layout of the paper including the volume, issue and page numbers.

Link to publication

\footnotetext{
General rights rights.

- You may freely distribute the URL identifying the publication in the public portal. please follow below link for the End User Agreement:

www.umlib.nl/taverne-license

Take down policy

If you believe that this document breaches copyright please contact us at:

repository@maastrichtuniversity.nl

providing details and we will investigate your claim.
}

Copyright and moral rights for the publications made accessible in the public portal are retained by the authors and/or other copyright owners and it is a condition of accessing publications that users recognise and abide by the legal requirements associated with these

- Users may download and print one copy of any publication from the public portal for the purpose of private study or research.

- You may not further distribute the material or use it for any profit-making activity or commercial gain

If the publication is distributed under the terms of Article 25fa of the Dutch Copyright Act, indicated by the "Taverne" license above, 
THE EFFECTIVENESS OF AN EDUCATION AND ACTIVATION PROGRAM IN ACUTE AND SUB-ACUTE SHOULDER COMPLAINTS PRESENTED IN GENERAL PRACTICE

Camiel Peter Carol De Bruijn 
Coverdesign en layout: BiFab, Bianca Fraats 
THE EFFECTIVENESS OF AN EDUCATION AND ACTIVATION PROGRAM

IN ACUTE AND SUB-ACUTE SHOULDER COMPLAINTS

PRESENTED IN GENERAL PRACTICE

\section{PROEFSCHRIFT}

Ter verkrijging van de graad van doctor

aan de Universiteit Maastricht

op gezag van de Rector Magnificus

Prof. Mr. G.P.M.F. Mols

volgens het besluit van het College van Decanen,

in het openbaar te verdedigen

op donderdag 6 maart 2008 om 14.00 uur

door

Camiel Peter Carol De Bruijn 


\section{Promotores:}

Prof. dr. G.J. Dinant

Prof. dr. W.J.A. van den Heuvel

Prof. dr. R.A. de Bie

Co-promotor:

Dr. G.J.M.G. van der Heijden (Juliuscentrum, Universiteit Utrecht)

Beoordelingscommissie:

Prof. dr. G.H.I.M. Walenkamp (voorzitter)

Prof. dr. J.F.M. Metsemakers

Prof. dr. M.H. Prins

Prof. dr. J.W.S. Vlaeyen

Dr. D.A.W.M. van der Windt (Vrije Universiteit, Amsterdam) 


\section{Content}

$\begin{array}{ll}1 . & \text { Introduction }\end{array}$

2. Design 15

3. Method 31

4. Clinical effectiveness of the intervention 45

5. Cost-effectiveness of the intervention 65

6. Patient recruitment 85

7. General discussion 103

$\begin{array}{ll}\text { Summary } & 115\end{array}$

$\begin{array}{ll}\text { Samenvatting } & 127\end{array}$

$\begin{array}{ll}\text { Dankwoord } & 139\end{array}$

About the author 143 


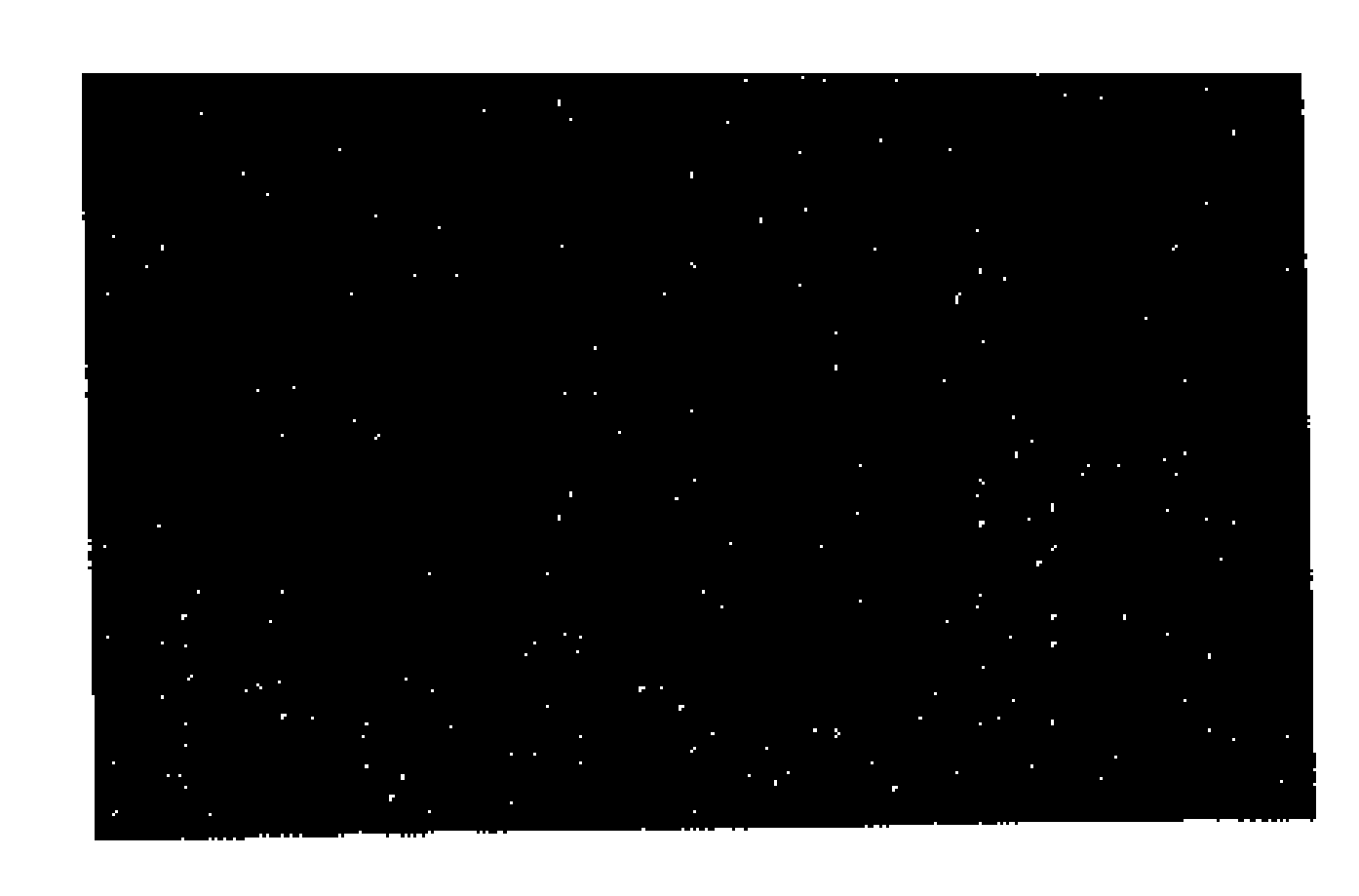

Introduction

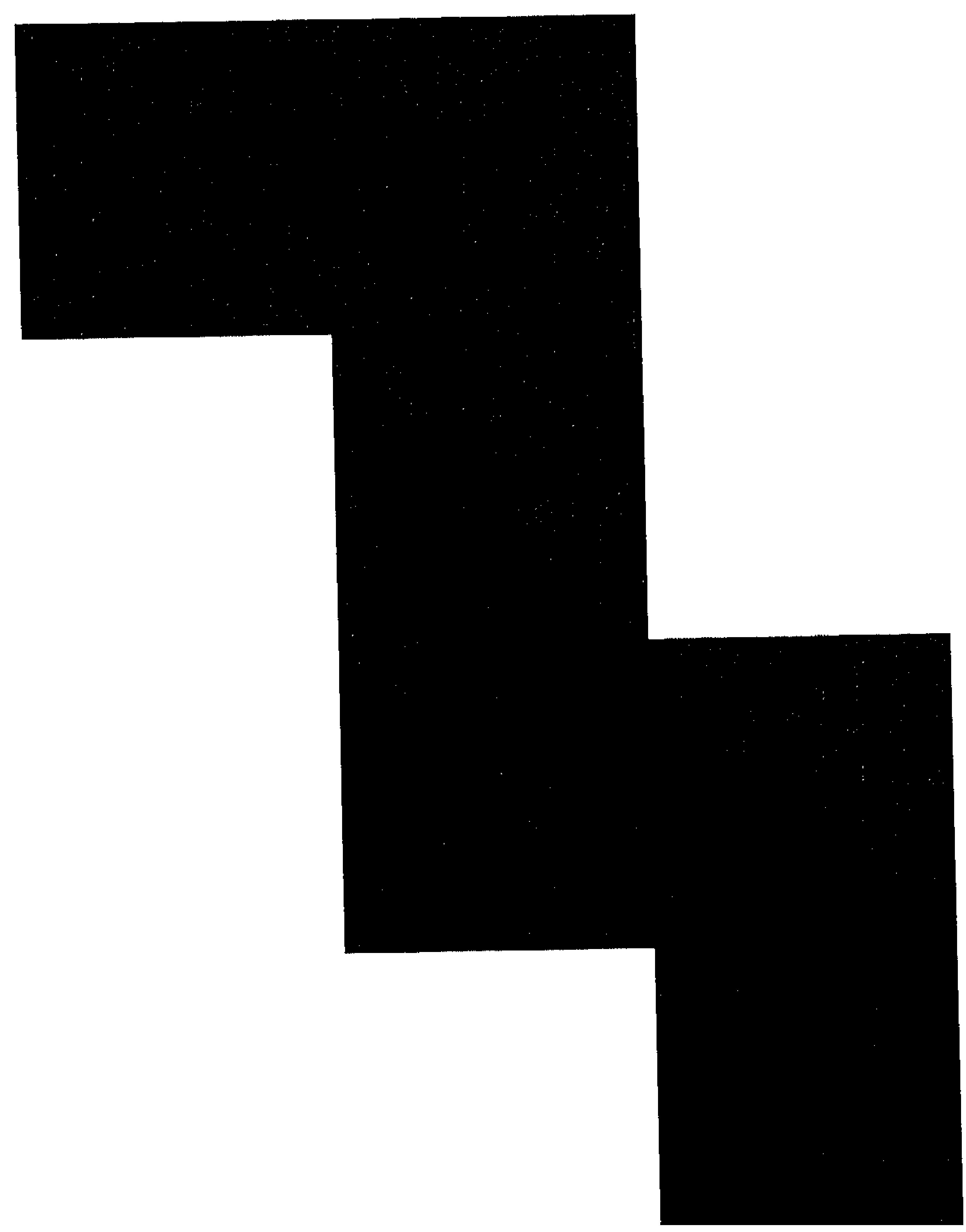




\section{INTRODUCTION}

This thesis presents the results of a randomised clinical trial evaluating an education and activation programme for patients with shoulder complaints in general practice. This first, introductory chapter presents the rationale behind the education and activation programme, resulting in the research questions. The last part of the introduction provides an outline of the thesis.

\section{PAIN IS INEVITABLE. SUFFERING IS OPTIONAL}

'Pain is inevitable. Suffering is optional.' That is what the Dalai Lama ${ }^{1}$ once said about pain. Since wisdom is not in words but in actions, people all over the world are trying to reduce suffering. And since researchers are people too, it is hardly surprising that they try to contribute to this goal.

Pain and suffering are very common in health care. Modern man often expects healthcare to eliminate the inevitable pain in order to avoid suffering, and the biomedical approach usually applied in health care requires a successful elimination of the pain to reduce the suffering. Such high expectations are, however, not always met, resulting in continued pain and possibly even more suffering.

\section{BIOPSYCHOSOCIAL MODEL}

Although the Dalai Lama stated that suffering is optional, many patients may disagree. Suffering is only optional if a patient is provided with tools to confront the suffering. The biomedical approach offers patients few such tools, and patients tend to become dependent on healthcare professionals. The introduction of the biopsychosocial model by Engel initiated the development of new treatments providing patients with tools to confront the suffering themselves. The biopsychosocial model suggests that not only biological determinants but also psychosocial determinants play a role in disease or illness [1].

Previous studies have indicated that therapies aimed at coping with psychosocial determinants are promising instruments for the prevention of

\footnotetext{
${ }^{1}$ Spiritual and political leader of Tibet and Nobel Peace Prize winner
} 
chronic musculoskeletal pain [2-6]. Psychosocial determinants influence cognitions and behaviours. Cognitions refer to the way patients think about their pain and what the pain means to them, in terms of thoughts, beliefs, attitudes and self-efficacy expectations [7], whereas behaviour refers to the patients' observable actions [8]. Psychosocial determinants may cause a patient to develop inadequate cognitions and maladaptive behaviours, which are known to play a role in the persistence of musculoskeletal disorders [9-11].

\section{SHOULDER COMPLAINTS}

The annual incidence of shoulder complaints (SCs) in patients seen by general practitioners (GPS) in the Netherlands lies between 15 and 25 patients per 1000 registered with a GP [12]. Half of these patients report persistent SCs after six months, in spite of usual care. The International Association for the Study of Pain considers complaints lasting more than three months to be chronic, which thus applies to these patients $[13,14]$.

\section{USUAL CARE OF SHOULDER COMPLAINTS}

Usual care of SCs in general practice is mainly aimed at reduction or elimination of the pain. This biomedical approach to shoulder complaints is advocated in the clinical guidelines published by the Dutch College of General Practitioners [15]. The approach seems effective in about half of all patients with a new episode, resulting in the absence of persistent SCs after six months [13]. Apparently, pain is inevitable in the other half of SC patients, resulting in continued, chronic suffering.

\section{THE EDUCATION AND ACTIVATION PROGRAMME}

To reduce the proportion of patients reporting chronic SCs after six months, a new intervention has been developed. This intervention, the education and activation programme (EAP), aims to prevent the development of inadequate cognitions and maladaptive behaviours in the early stages of the SCs. The EAP complements the biomedical approach in usual care with a psychosocial approach aimed at cognitions and behaviours. Its underlying hypothesis is that cognitions and behaviours are susceptible to change in the early stages of SCs 
and need only a brief intervention to be redirected towards adequate cognitions and adaptive behaviour. The EAP is administered by trained GPs or a specially trained ambulant therapist.

\section{THE EAP TRIAL}

To evaluate the effect of the EAP on the prevention of chronic SCs 26 weeks after the first presentation in general practice, a randomised clinical trial was set up and performed. For the purpose of this trial, chronic SCs were operationalised as patients reporting functional limitations or reporting themselves to be not recovered from the SCs after 26 weeks. Patients consulting their GP in the acute and subacute stages of SCs, that is, with SCs having lasted for less than 3 months, were allocated at random to either EAP as an addition to usual care (UC), or to UC only. A cost-effectiveness analysis was conducted alongside the randomised clinical trial.

\section{RESEARCH QUESTIONS}

The core of this thesis reports on the randomised clinical trial (RCT), which was designed to answer the main research question:

Is an EAP in addition to usual care more effective in reducing the proportion of patients reporting persistent SCs after six months than usual care alone?

Additional research questions were concerned with the programme's costeffectiveness, comparing the observed difference in costs with the clinical effectiveness, and with the performance of trained GPs, using videotaped consultations. Furthermore, we evaluated the effect of the patient recruitment strategy on outcome.

\section{DUTCH SHOULDER DISABILITY STUDY}

This trial was part of the Dutch Shoulder Disability Study, a comprehensive prognostic cohort study on shoulder complaints, involving a number of randomised controlled trials in subcohorts.

The aim of the prognostic cohort study was to develop a clinical prediction rule consisting of a limited number of prognostic factors to predict the risk of persistent SCs after 6 weeks and 6 months. The performance of the prediction 
rule proved satisfactory at 6 weeks but poor at 26 weeks, and is awaiting additional testing in a daily practice setting [16].

The first RCT in the Dutch Shoulder Disability Study compared manipulative therapy as an add-on to usual care (UC) with UC alone in patients with SCs and dysfunction of the shoulder girdle, and found a significant effect in favour of the manipulative therapy after 12 and 52 weeks [17]. The second RCT evaluated the effectiveness of a behavioural graded exercise therapy programme for patients with chronic SCs compared to UC. The outcome of this RCT was ambiguous, as a significant effect in favour of the experimental group was found after 12 and 52 weeks for one outcome variable, but the change in the other outcome measure failed to reach the required level of significance [18]. The results of the third RCT are presented in this thesis. A costeffectiveness study was done for all RCTs $[19,20]$.

\section{OUTLINE OF THIS THESIS}

The design of the randomised clinical trial and the content of the EAP are described in chapter 2. The EAP is administered by trained GPs, and the quality of this intervention has been evaluated using video observations (chapter 3). The clinical effectiveness and cost-effectiveness of the EAP are described in chapters 4 and 5. Patients were recruited by GPs and through advertisements in local newspapers, and the effects of these two recruitment strategies on the outcome of the study are described in chapter 6 . The general discussion, chapter 7, discusses practical and methodological issues, as well as practical implications and recommendations for future research. 


\section{REFERENCES}

1. Engel, G.L., The need for a new medical model: a challenge for biomedicine. Science, 1977. 196(4286): p. 129-36.

2. Linton, S.J., Prevention with special reference to chronic musculoskeletal disorders, in Psychosocial Factors in Pain, R.J. Gatchel and D.C. Turk, Editors. 1999, Guilford Publications: New York. p. 374-389.

3. Mitchell, R.I. and G.M. Carmen, Results of a multicenter trial using an intensive active exercise program for the treatment of acute soft tissue and back injuries. Spine, 1990. 15(6): p. 514-21.

4. Lindstrom, I., et al., The effect of graded activity on patients with subacute low back pain: a randomized prospective clinical study with an operant-conditioning behavioral approach. Phys Ther, 1992. 72(4): p. 279-90; discussion 291-3.

5. Haig, A.J., et al., Aggressive early medical management by a specialist in physical medicine and rehabilitation: effect on lost time due to injuries in hospital employees. J Occup Med, 1990. 32(3): p. 241-4.

6. Malmivaara, A., et al., The treatment of acute low back pain--bed rest, exercises, or ordinary activity? N Engl J Med, 1995. 332(6): p. 351-5.

7. Wit, R.d., et al., Assessment of pain cognitions in cancer patients with chronic pain. Journal of Pain and Symptom Management, 2001. 22(5): p. 911-924.

8. Fordyce, W.E., Behavioral methods for chronic pain and illness. 1976, Saint Louis: C. V. Mosby Company.

9. Linton, S., A systematic review of psychological risk factors for back and neck pain. Spine, 2000. 25: p. 1148-1156.

10. Turk, D.C. The role of demographic and psychosocial factors in transition from acute to chronic pain. in 8th World Congress on Pain, Progress in Pain Research and Management. 1997: IASP Press.

11. Weiser, S. and C. Cedraschi, Psychosocial issues in the prevention of chronic low back pain - A literature review. Bailliere's Clinical Rheumatology, 1992. 6(3): p. 657-684.

12. Sobel, J.S. and J.C. Winters, Shoulder complaints in general practice. 1996, Rijksuniversiteit Groningen. 
13. Windt, D.A.v.d., et al., Shoulder disorders in general practice: prognostic indicators of outcome. $\mathrm{Br} J$ Gen Pract, 1996. 46(410): $\mathrm{p}$. 519-23.

14. Merskey, $H$. and N. Bogduk, IASP pain terminology, in Classification of Chronic Pain, H. Merskey and N. Bogduk, Editors. 1994, IASP Press: Seattle. p. 209-214.

15. Winters, J.C., et al., NHG-standaard schouderklachten. Huisarts en Wetenschap, 1999. 42(5): p. 222-231.

16. Kuijpers, T., et al., Clinical prediction rules for the prognosis of shoulder pain in general practice. Pain, 2006. 120(3): p. 276-85.

17. Bergman, G.J., et al., Manipulative therapy in addition to usual medical care for patients with shoulder dysfunction and pain: a randomized, controlled trial. Ann Intern Med, 2004. 141(6): p. 432-9.

18. Geraets, J.J., et al., Effectiveness of a graded exercise therapy program for patients with chronic shoulder complaints. Aust $J$ Physiother, 2005. 51(2): p. 87-94.

19. Bergman, G.J.D., et al., Economic evaluation, in Manipulative therapy for shoulder complaints in general practice, G.J.D. Bergman, Editor. 2004: Groningen. p. 63-77.

20. Geraets, J.J., et al., Cost-effectiveness of a graded exercise therapy program for patients with chronic shoulder complaints. Int J Technol Assess Health Care, 2006. 22(1): p. 76-83. 

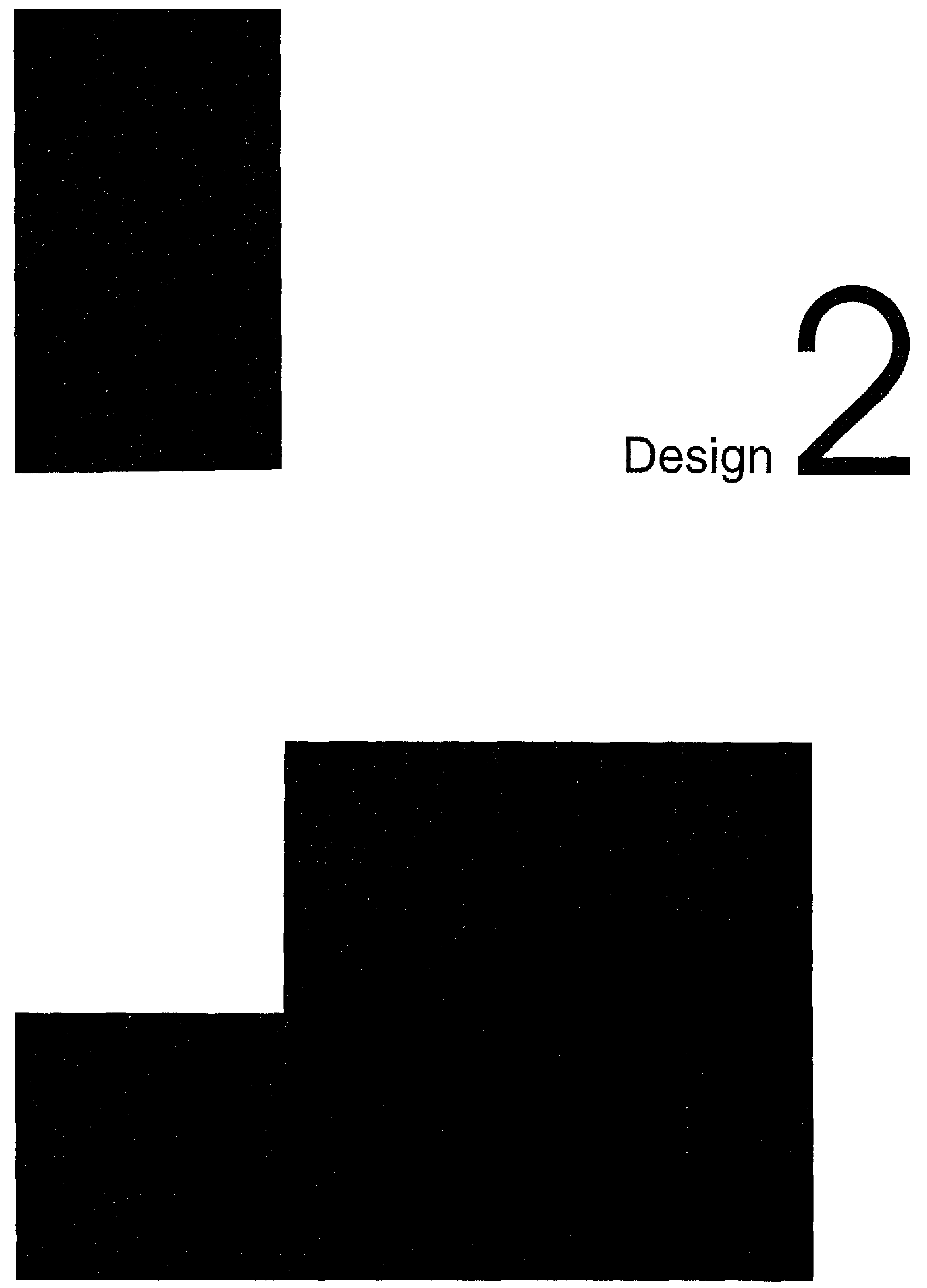

published as:

De Bruijn C, De Bie RA, Geraets J, Goossens M, Köke A, Van den Heuvel W, Van der Heijden G, Dinant GJ. Evaluation of an education and activation programme to prevent chronic shoulder complaints: design of an RCT. BMC Family Practice 2005;6:7 www.biomedcentral.com/1471-2296/6/7 


\section{ABSTRACT}

Background: About half of all newly presented episodes of shoulder complaints (SC) in general practice are reported to last for at least six months. Early interventions aimed at the psychological and social determinants of SC are not common in general practice, although such interventions might prevent the development of chronic SC.

The Education and Activation Programme (EAP) consists of an educational part and a time-contingent activation part. The aim of the EAP is to provide patients with the proper cognitions by means of education, and to stimulate adequate behaviour through advice on activities of daily living.

Design: The article describes the design of a randomised clinical trial (RCT) to evaluate the effectiveness and cost-effectiveness of an EAP in addition to usual care, compared to usual care only, in the prevention of chronic SC after six months. It also describes the analysis of the cost and effect balance. Patients suffering from SC for less than three months are recruited in general practice and through open recruitment. $A$ trained general practitioner or a trained therapist administers the EAP.

Primary outcome measures are patient-perceived recovery, measured by selfassessment on a seven-point scale, and functional limitations in activities of daily living. Questionnaires are used to study baseline measures, prognostic measures, process measures and outcome measures.

Discussion: The inclusion of patients in the study lasted until December $31^{\text {st }}$ 2003. Data collection is to end in June 2004. 


\section{BACKGROUND}

\section{Shoulder complaints}

Shoulder complaints (SC) have been defined by Sobel \& Winters [1] as pain localised in the region of the deltoid muscle, the acromioclavicular joint, the superior part of the trapezoid muscle and the scapula. Radiation of the pain to the arm as well as limitation of the motion of the upper arm and/or the shoulder girdle may be present [1].

SC are characterised by pain in the area between the base of the neck and the elbow, at rest or when elicited by movement of the upper arm (fig. 1).
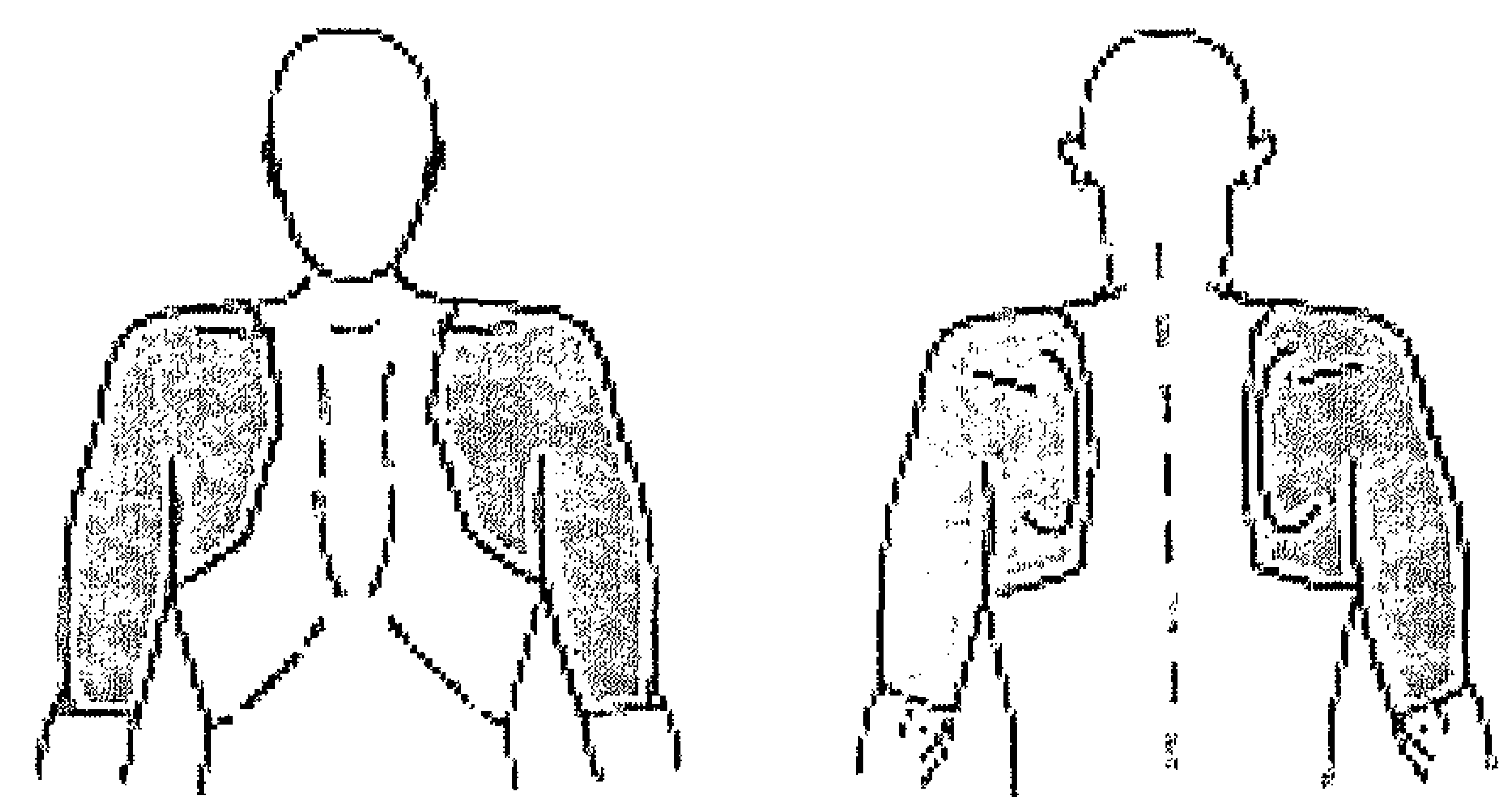

Figure 1: Area between the base of the neck and the elbow

Musculoskeletal disorders, of which SC constitute the second largest group after low back disorders, account for the second largest share in healthcare costs and represent the largest group of work-related diseases in the Netherlands [2].

\section{Shoulder complaints in general practice}

The point prevalence of SC in the general population in the Netherlands has recently been estimated at $21 \%$ [3]. In a British study a lower point prevalence of $14 \%$ has been found [4]. The annual incidence of SC as seen by general practitioners (GPS) in the Netherlands lies between 15 and 25 patients per 1000 registered general practice patients[1]. About half of all newly presented episodes in general practice are reported to last for at least six months, while 40 percent of the newly presented episodes result in disability in terms of activities of daily living after one year [5]. 
The International Association for the Study of Pain (IASP) regards persistent or recurring pain lasting less than three months as acute pain, whereas more than three months of persistent or recurring pain is considered to be chronic pain [6]. The study by van der Windt [5] showed that, according to this cut-off criterion, $51 \%$ of patients with a newly presented episode of SC in general practice develop chronic SC, that is, complaints lasting more than three months.

The Dutch College of General Practitioners provides clinical guidelines for the treatment of SC [7]. These guidelines, however, do not include treatment aimed at psychosocial factors such as maladaptive behaviour and inadequate cognitions, known to play a role in the development and persistence of chronic musculoskeletal diseases [8-10]. Treatments addressing such factors are mentioned in the guidelines, but only as a last resort, when the biomedical approach has proved ineffective in reducing the pain.

To date, early interventions aimed at the psychological and social determinants of SC are not common in general practice, although such interventions in the early stages of the SC might prevent the development of chronic complaints [11].

\section{Early intervention in general practice}

We hypothesised that an intervention concentrating on psychological and social determinants in the early stages of SC would prevent the development of inadequate cognitions and maladaptive behaviour, ensuring that such inadequate cognitions and behaviour do not play a role in the development of chronic SC later on.

The term cognitions refers to the way patients think about their pain and what the pain means to them, in terms of thoughts, beliefs, attitudes and self-efficacy expectations [12], whereas behaviour refers to the patients' observable actions [13].

Patients' cognitions and behaviour should thus be influenced so as to become adequate cognitions and adaptive behaviour. A relatively brief treatment in the early stages of SC, administered by a trained therapist, may be expected to be effective in preventing the development of chronic SC. The Education and Activation Programme (EAP) that formed the subject of the present study is such an early intervention. 


\section{Aim of the study}

This paper describes the design of a study to evaluate the clinical effectiveness of an early EAP aimed at using psychological and behavioural factors to prevent chronic SC. In addition, the study is to evaluate the balance between costs and effects. EAP in patients with acute SC is to be compared with treatment according to the Dutch College of General Practitioners guidelines. The Medical Ethics Committee of the Institute for Rehabilitations Research in association with Rehabilitation Foundation Limburg has approved the design of the study presented here. Funding was obtained from the Netherlands Organisation for Scientific Research.

This paper describes also the rationale and content of the EAP.

\section{Education and Activation Programme}

Previous studies have indicated that cognitive behavioural therapies aimed at bio-psychosocial factors are promising instruments for the prevention of chronic musculoskeletal pain [11]. The EAP focuses on the same elements as cognitive behavioural therapies, but is applied at an earlier stage than such therapies [14]. Whereas the latter focus mainly on the elimination of inadequate cognitions and maladaptive behaviour after they have already developed in the course of the SC, the EAP focuses on guiding the patient towards adequate pain behaviour and reinforcing this behaviour at an early stage of the SC.

The aim of the EAP is to prevent the development of inadequate cognitions and maladaptive behaviour in patients with acute SC.

Education is used to maintain or induce adequate cognitions by providing information that is tailored to questions that patients have about their SC. Health care educators frequently assume that giving information equals comprehension, which should automatically translate into changed behaviours as the knowledge is applied [15]. According to Hussey, however, simply receiving a message hardly correlates with understanding it [16]. Effective learning also requires the active participation of the patient[17].

Since inadequate cognitions and maladaptive behaviours are not yet fully developed in patients with acute SC, the focus of the EAP is not on restructuring inadequate cognitions or modifying maladaptive behaviour, but on maintaining or inducing the proper cognitions by education and on maintaining or inducing adequate behaviour by giving advice on activities of daily living. 
Adequate behaviour is considered to be behaviour in which the patient remains active. A comprehensive description of the EAP is given in the Design section.

\section{DESIGN}

\section{Patients}

Patients are recruited by GPS and in the open population by advertising in local newspapers.

Patients are eligible for inclusion in the Randomised Clinical Trial (RCT) if they consult their own GP or respond to adverts in a local newspaper with a new episode of SC that has lasted no longer than three months, at rest or when elicited by movement in the shoulder area.

Patients are included if they are 18 years or older and living in the south of the Netherlands. Only newly presented episodes of SC are considered, that is, patients who have not consulted their GP and have not been treated for their SC in the preceding three months. Additional exclusion criteria are given in table 1.

\footnotetext{
Exclusion criteria

- other episodes of SC in the 12 months preceding the consultation with the GP

- prior fractures and/or surgery of the shoulder

- (suspected) referred pain from internal organs

- SC with a confirmed extrinsic cause

- inability to complete a questionnaire independently

- presence of dementia or other severe psychiatric abnormalities

Table 1: Exclusion criteria

\section{Randomised Clinical Trial}

A Randomised Clinical Trial (RCT) with a six-month follow-up is used to evaluate the effectiveness and cost-effectiveness of an EAP to prevent chronicity in patients with acute SC, compared to usual care.

A computer-generated random sequence table is used to randomise the patients to EAP or usual care. Neither the patient nor the GP, nor the trained therapist, can be blinded for the allocated treatment. The trained therapist is also the researcher coordinating the RCT and conducting the data analysis, but is blinded for treatment allocation during the data analysis. The allocation code will be revealed only after the data analysis has been completed.
} 


\section{Treatments}

Usual care (UC) is applied according to the Dutch College of General Practitioners guidelines for SC (version 1999)[7]. Management during the first two weeks consists of a wait-and-see policy with information and advice about shoulder complaints, possibly supplemented with analgesics or nonsteroidal anti-inflammatory drugs. If this approach has little or no effect, up to three corticosteroid injections can be given. Physiotherapy is considered for complaints persisting after six weeks or more. If the SC persist, referral to a hospital-based specialist may be considered.

The focus of the EAP is to maintain or induce the proper cognitions by education and to stimulate adequate behaviour by means of advice on activities of daily living. Table 2 shows the components of the EAP. The EAP is administered by specially trained GPs or an ambulant therapist (CDB) trained to provide the EAP. The ambulant therapist administers the EAP when no trained GP is available in the living area of the patient.

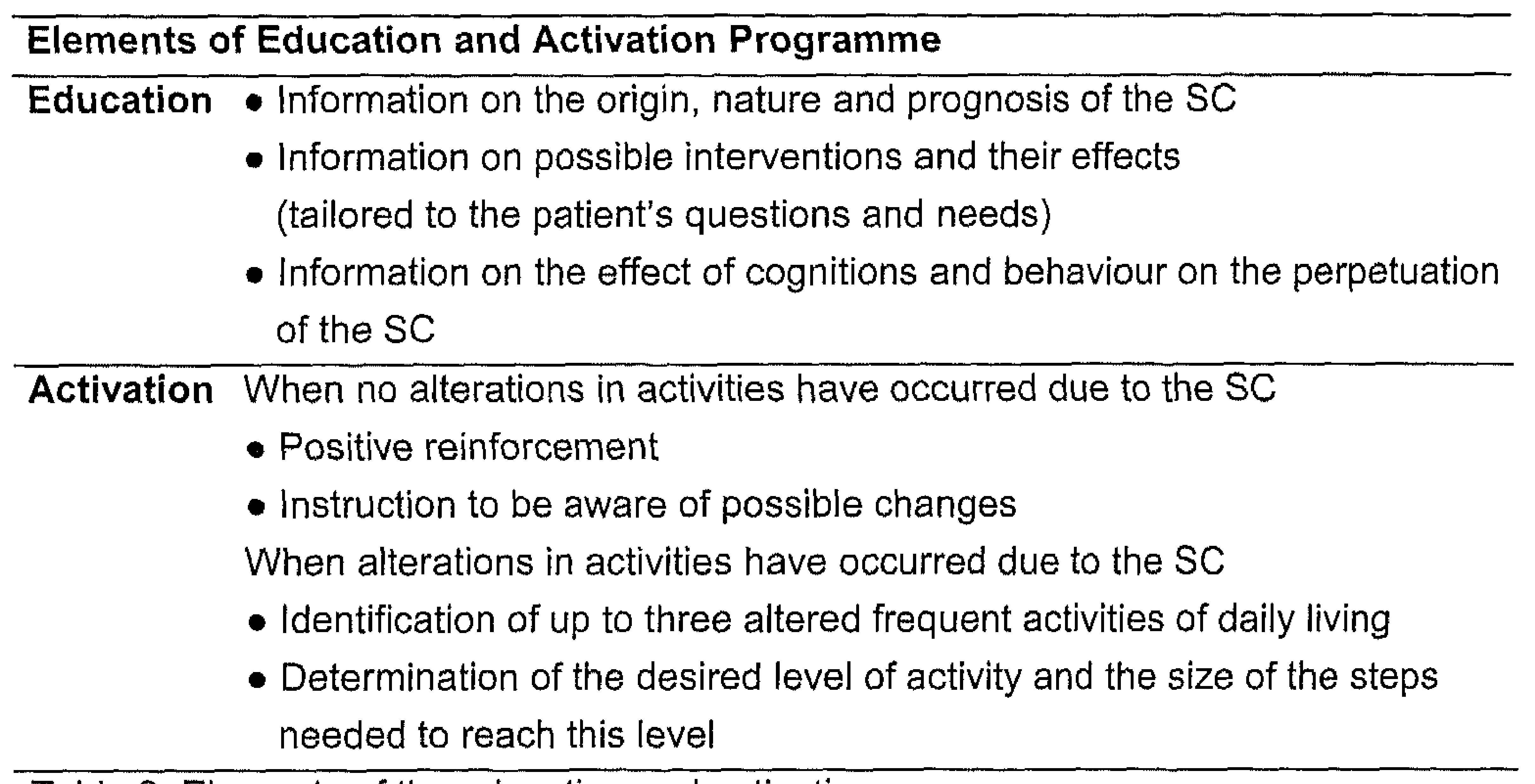

Table 2: Elements of the education and activation programme

The EAP consists of a minimum of two sessions and a maximum of six followup sessions over a period of six weeks. Each session may last up to 20 minutes. The first and second sessions are organised in the general practice setting by the trained GP, or at the patient's home by the ambulant EAP therapist. The other sessions are provided by telephone. 


\section{Education}

The first part of the EAP has an educational purpose, and focuses on information about the origin, nature and prognosis of the $\mathrm{SC}$, possible interventions and their effects, the impact on activities of daily living and its consequences and the patient's own possibility to contribute to recovery. This information is tailored to the patients' questions and needs and is based on the information available in the Dutch College of General Practitioners guidelines for SC.

In addition, the effect of cognitions and behaviour on the perpetuation of the $\mathrm{SC}$ is clarified to the patient by an example. If possible, this example refers to a condition or circumstance the patient has experienced, such as a broken bone or back pain. The patient is helped by the trained GP or the trained therapist to explore whether his or her thoughts about the SC are justified. Negative patterns of thinking are modified into adequate and accurate thoughts.

\section{Activation}

The second part of the EAP consists of a time contingent activation programme, based on the principles of operant learning. It focuses on gradually increasing activities of daily living, despite the pain.

Potential avoidance of activities is countered by reinforcement of continuation or resumption of usual activities.

Positive reinforcement is used to stimulate patients with a normal activity pattern, in spite of their SC, to continue their activities. This positive reinforcement may be enough to achieve continuation of the desired activities [13]. These patients are also instructed to be aware of possible changes in their activities that could lead to undesirable behaviour such as reduced use of the affected shoulder.

Patients who have reduced their normal activities are helped to identify up to three frequent activities of daily living that they have reduced as a result of the SC. These activities are stepwise gradually increased to the desired level of activity in a time-contingent manner. The desired level of activity and the magnitude of the increases are determined and agreed upon by the EAP therapist and the patient.

The patient and the EAP therapist also plan a progress evaluation, which is used to positively reinforce the patient's behaviour if the gradual increase has 
been correctly implemented or to adjust the magnitude of the increases if the original objectives prove too optimistic.

\section{Measurements}

The first outcome measure is the perceived recovery of the patient. Patients are considered to be recovered when they report to be much improved or fully recovered, on an 7-point ordinal scale, after six months.

The second outcome measure is that of functional limitations in activities of daily living. This variable is assessed by a 16 -item questionnaire, the shoulder disability questionnaire (SDQ)[18], with a scoring range of 0 to 16 . A reduction of the score on this questionnaire implies a reduction in functional limitations. The outcome measures are recorded at 6,12 and 26 weeks after randomisation. The SDQ is also measured at baseline. A cost diary [19] is used to assess health care utilisation, direct non-medical costs and indirect costs. A complete overview of baseline measures, prognostic measures, process measures and outcome measures is given in table 3 .

\begin{tabular}{ll}
\hline & VARIABLE \\
\hline Baseline measures & Demographic variables \\
& - Age \\
- Gender & - Employment status \\
& Specific disease characteristics \\
& - Affected side \\
& - Possible cause of shoulder complaints \\
& - Duration of complaints \\
& - History of shoulder complaints \\
& Co-morbidity \\
& Physical activity \\
& Workload \\
& Treatment credibility and preference \\
\hline Prognostic measures & Mobility of glenohumeral joint \\
& - HIB (hand in back), HIN (hand in neck), passive exorotation \\
& - Active and passive abduction \\
& Mobility of cervicothoracal spine \\
& Severity of main complaint \\
& Psychosocial variables \\
\hline
\end{tabular}




\begin{tabular}{|c|c|}
\hline & $\begin{array}{l}\text { - Anxiety } \\
\text { - Depression } \\
\text { - Somatisation } \\
\text { - Sistress } \\
\text { - Di } \\
\text { Job content }\end{array}$ \\
\hline Outcome measures & Perceived recovery of complaints \\
\hline$T=1,2,3$ & Functional limitations to daily activities ${ }^{3}$ \\
\hline $\begin{array}{l}\text { Process measures } \\
T=0,1,2,3\end{array}$ & $\begin{array}{l}\text { Psychosocial variables } \\
\text { - Kinesiophobia }{ }^{4} \\
\text { - Fear avoidance and beliefs }{ }^{5} \\
\text { - Catastrophising } \\
\text { - Coping with pain } \\
\text { - Internal locus of control } \\
\text { - External locus of control } \\
\text { Global assessment } \\
\text { Shoulder pain }^{5} \\
\text { General health }^{8}\end{array}$ \\
\hline $\begin{array}{l}\text { Cost } \\
T=0-26 \text { weeks }\end{array}$ & $\begin{array}{l}\text { Health care utilisation } \\
\text { Direct non-medical costs } \\
\text { Indirect costs }\end{array}$ \\
\hline
\end{tabular}

Table 3: Variables

\section{Data Analysis}

The statistical analysis will be carried out according to the 'intention-to-treat' principle. Differences between groups, with $95 \%$ confidence intervals, will be calculated for each outcome measure. The study groups will be compared by an independent samples t-test for changes since baseline for continuous outcome variables and the chi-square test for categorical outcome variables. In addition, the corresponding baseline value for each continuous outcome will be used as a covariate.

The analysis will be repeated taking any loss-to-follow-up into account by applying a sensitivity analysis in which all patients who are lost to follow-up are

\footnotetext{
${ }^{2}$ Four-Dimensional Symptoms Questionnaire [23]

${ }^{3}$ Shoulder Disability Questionnaire [18]

${ }^{4}$ Tampa Scale for Kinesiophobia - Dutch version (partly) [25]

${ }^{5}$ Fear Avoidance and Beliefs Questionnaire - Dutch version (partly) [26]

${ }^{6}$ Pain Coping and Cognition List [27]

${ }^{7}$ Shoulder Pain Score [28]

${ }^{8}$ Generic Health Related Quality of Life [29]

${ }^{9}$ Cost Diary [19]
} 
first considered to show the largest observed improvement and then the largest observed deterioration in outcome measures.

The analyses of the difference in change for the outcomes at three and six months will account for the repeated measures character of the data. Baseline characteristics that are a priori considered to be possible prognostic factors for outcome variables, as well as post-randomisation differences between the groups, will be handled as potential confounders. Their influence will be evaluated by means of multivariable regression analyses. In the case of confounding, adjusted effect estimates will also be reported.

\section{Sample size}

About half of all newly presented episodes of SC in general practice are reported to last for at least six months. A number needed to treat of 4.5 after six months is considered clinically relevant. This implies an absolute reduction of $22 \%$ of the proportion of patients with SC after six months. With a two-sided alpha of 0.05 and a statistical power $(1-\beta)$ of $0.80,70$ patients per treatment group are needed to detect a difference in favour of the EAP compared to usual care after six months.

\section{Embedding in the Dutch Shoulder Disability Study}

This RCT is part of the Dutch Shoulder Disability Study, a comprehensive prognostic cohort study on SC, with randomised controlled interventions in subcohorts. The Dutch Shoulder Disability Study is funded by the Netherlands Organisation for Scientific Research (NWO, grant number 904-65-901).

\section{DISCUSSION}

\section{Reasons for publishing a study design}

There are several reasons to publish a study design before the results are available. The main reason is that it provides an opportunity to counteract publication bias, that is, the phenomenon whereby a study producing positive results is more likely to be published than a study showing no difference between the study groups $[20,21]$. Hence, if the design is published but not the results, the study can still be included in a systematic review because data can be retrieved from the researcher [22]. 
Another reason is that it gives researchers the opportunity to reflect upon the study design independently of the results. When results run counter to the researchers' expectations, methodological flaws are usually examined. But when the results are in line with expectations, methodological flaws are more likely to be overlooked. [20]

The third reason arises from the tendency among randomised controlled studies to deviate from their original designs, mainly because of practical problems. Such deviations from the study design may affect the study results. Publishing the study design forces researchers to test its implementation and to answer for any deviations from the design.

Finally, this article offers us an opportunity to describe the rationale and content of the intervention in greater detail than the methods section of an article reporting the results of the RCT would do[22].

\section{Applicability in general practice}

The EAP is a brief intervention that can easily be administered by GPs in addition to the usual care according to the guidelines. This might give GPs an instrument to prevent the development of chronic SC in the early stages of the complaints by focusing on psychological and social determinants.

\section{Time schedule}

The inclusion of patients in the study lasted until December $31^{\text {st }}$ 2003. Data collection will be completed in June 2004. Currently, 108 patients have been included and are being followed up. 


\section{REFERENCES}

1. Sobel, J.S. and J.C. Winters, Shoulder complaints in general practice. 1996, Rijksuniversiteit Groningen.

2. Picavet, H.S.J., H.W.V.v. Gils, and J.S.A.G. Schouten, Klachten van het bewegingsapparaat in de nederlandse bevolking. 2000, Rijksinstituut voor Volksgezondheid en Milieu: Bilthoven.

3. Picavet, H.S.J. and J.S.A.G. Schouten, Musculoskeletal pain in the netherlands: prevalences, consequences and risk groups, the $\mathrm{DMC}(3)$ study. Pain, 2003. 102: p. 167-178.

4. Bongers, P.M., The cost of shoulder pain at work. British Medical Journal, 2001. 322: p. 64-65.

5. Windt, D.A.v.d., et al., Shoulder disorders in general practice: prognostic indicators of outcome. $\mathrm{Br} J$ Gen Pract, 1996. 46(410): $\mathrm{p}$. 519-23.

6. Merskey, $\mathrm{H}$. and N. Bogduk, IASP pain terminology, in Classification of Chronic Pain, H. Merskey and N. Bogduk, Editors. 1994, IASP Press: Seattle. p. 209-214.

7. Winters, J.C., et al., NHG-standaard schouderklachten. Huisarts en Wetenschap, 1999. 42(5): p. 222-231.

8. Linton, S., A systematic review of psychological risk factors for back and neck pain. Spine, 2000. 25: p. 1148-1156.

9. Turk, D.C. The role of demographic and psychosocial factors in transition from acute to chronic pain. in 8th World Congress on Pain, Progress in Pain Research and Management. 1997: IASP Press.

10. Weiser, S. and C. Cedraschi, Psychosocial issues in the prevention of chronic low back pain - A literature review. Bailliere's Clinical Rheumatology, 1992. 6(3): p. 657-684.

11. Linton, S.J., Prevention with special reference to chronic musculoskeletal disorders, in Psychosocial Factors in Pain, R.J. Gatchel and D.C. Turk, Editors. 1999, Guilford Publications: New York. p. 374-389.

12. Wit, R.d., et al., Assessment of pain cognitions in cancer patients with chronic pain. Journal of Pain and Symptom Management, 2001. 22(5): p. $911-924$. 
13. Fordyce, W.E., Behavioral methods for chronic pain and illness. 1976, Saint Louis: C. V. Mosby Company.

14. Turner, J.A. and F.J. Keefe, Cognitive-behavioral therapy for chronic pain, in Pain; an updated review, M. Max, Editor. 1999. p. 523-533.

15. Davis, P., et al., Evaluation of a rheumatoid arthritis patient education program: impact on knowledge and self-efficacy. Patient Education and Counseling, 1994. 24: p. 55-61.

16. Hussey, L.C., Strategies for effective patient education material design. journal of cardiovascular nursing, 1997. 11(2): p. 37-46.

17. Padberg, R.M. and L.F. Padberg, Strengthening the effectiveness of patient education: applying principles of adult education. Oncol Nurs Forum, 1990. 17: p. 65-69.

18. Heijden, G.J.M.G.v.d., P. Leffers, and L.M. Bouter, Development and responsiveness of the shoulder disability questionnaire. Journal of Clinical Epidemiology, 1999.

19. Goossens, M.E.J.B., et al., The cost diary: a method to measure direct and indirect costs in cost-effectiveness research. Journal of Clinical Epidemiology, 2000. 53: p. 688-695.

20. Dickersin, K., The existence of publication bias and risk factors for its occurrence. JAMA, 1990. 263: p. 1385-1389.

21. Eastbrook, P.J., et al., Publication bias in clinical research. Lancet, 1991. 337: p. 867-872.

22. Ostelo, R.W.J.G., et al., Behavioral-graded activity compared with usual care after first-time disk surgery: considerations of the design of a randomized clinical trial. Journal of Manipulative Physiol Ther, 2000. 23(5): p. 312-319.

23. Terluin, B., et al., The four-dimensional symptom questionnaire (4DSQ): a validation study of a multidimensional self-report questionnaire to assess distress, depression, anxiety and somatization. BMC Psychiatry, 2006. 6: p. 34.

24. Terluin, B., De vierdimensionale klachtenlijst (4DKL) in de huisartspraktijk. De Psycholoog, 1998: p. 18-24.

25. Vlaeyen, J.W.S., et al., Fear of movement/(re)injury in chronic low back pain and its relation to behavioral performance. Pain, 1995. 62: p. 363372. 
26. Vendrig, A., P. Deutz, and I. Vink, Nederlandse vertaling en bewerking van de fear-avoidance beliefs questionnaire. Nederlands Tijdschrift voor Pijn en Pijnbestrijding, 1998. 18(1): p. 11-14.

27. Berg, S.S.-v.d., et al., Pijn coping en cognitie lijst. 1999.

28. Winters, J., et al., A shoulder pain score: a comprehensive questionnaire for assessing pain in patients with shoulder complaints. Scandinavian Journal of Rehabilitation Medicine, 1996. 28: p. 163-167.

29. Brooks, R., EuroQol: The current state of play. Health Policy, 1996. 37 : p. 53-72. 

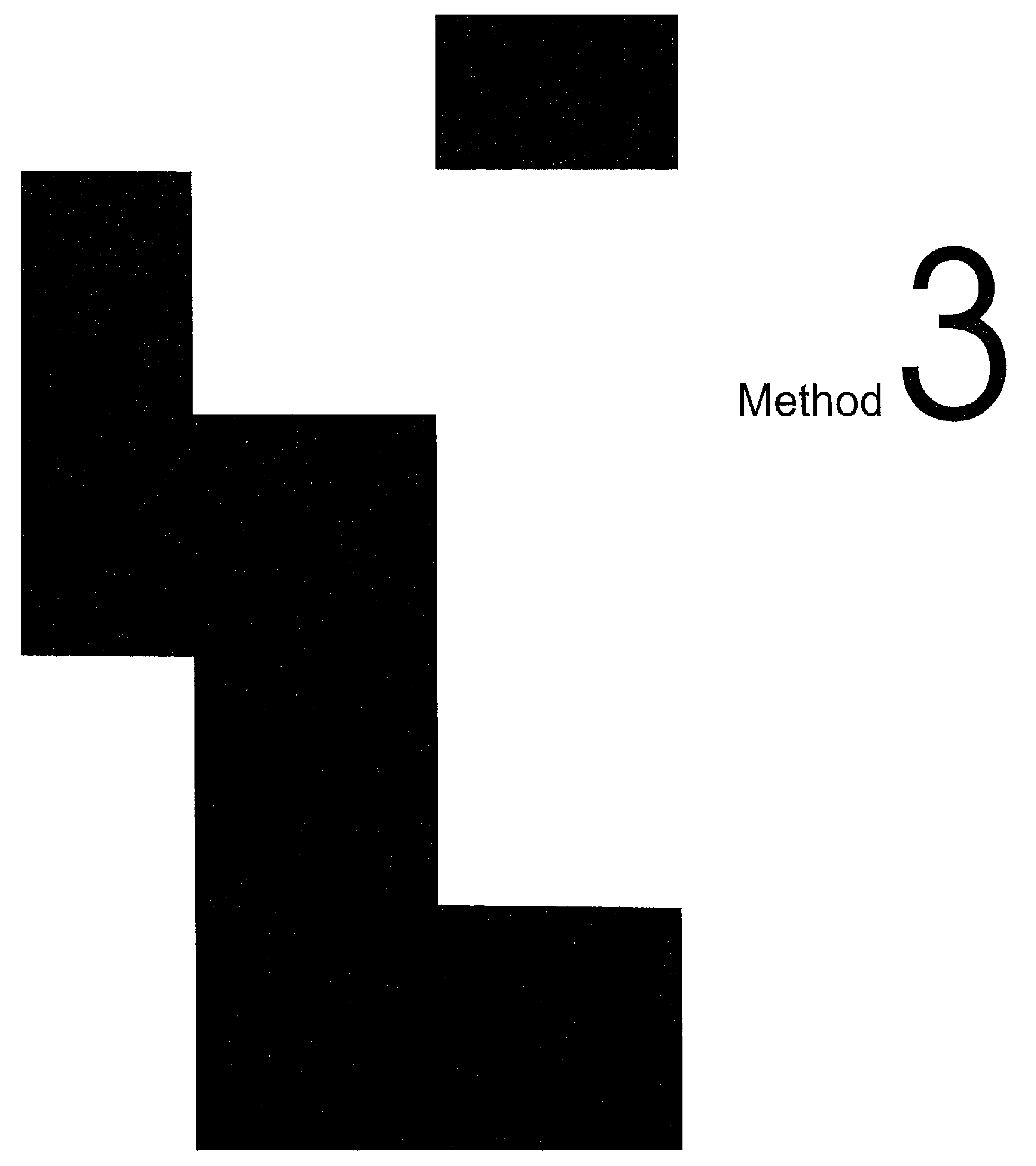

published as:

De Bruijn C, De Bie RA, Geraets J, Goossens M, Köke A, Van den Heuvel W, Dinant GJ. General practitioners apply the usual care for shoulder complaints better than expected analysis of videotaped consultations. BMC Family Practice 2007;8:13 www.biomedcentral.com/1471-2296/8/13 


\section{ABSTRACT}

Background: The education and activation program (EAP) is a newly developed intervention to prevent the development of chronic shoulder complaints (SCS). Trained general practitioners (GPS) administer the EAP. The EAP addresses inadequate cognitions and maladaptive behavior related to the SCs. The effect of the EAP is evaluated in a randomized clinical trial.

The aim of the present study is to use videotaped consultations to study (1) the performance of trained GPs administering the EAP and (2) the presence of key features of the EAP already embedded in usual care (UC).

Methods: Five trained GPs were videotaped while treating a standardized patient with EAP. Additionally, five GPS administering UC were videotaped. Two blinded observers evaluated the videotapes in relation to key features of the EAP which were scored on the EAP checklist.

Results: The mean total score on the EAP checklist was 4.7 (SD $=2.9$ ) for the UC group and $7.1(S D=2.1)$ for the EAP group. Neither group reached a score higher than 8 , which was considered to reflect an acceptable number of key EAP features.

Discussion: Our comparison of the presence of key features of EAP shows that the UC and EAP groups differed less than was expected. GPs in the UC group performed above expectation, with a mean total score of 4.7. Moreover, the low number of key features present in the EAP group may very well have led to a reduced effectiveness of the EAP. The results of this study can be used to optimize the training of GPs using the EAP. 


\section{BACKGROUND}

Previous studies have shown that the actual performance of general practitioners (GPs) is not directly related to their competence [1]. This implies that training of GPs to implement a newly developed intervention may not or only partly result in the desired performance in daily practice. The performance of GPs educated to implement an intervention should be closely monitored for any deviations from the protocol.

About half of the newly presented episodes of shoulder complaints (SCs) in general practice are reported to last for at least six months, while 40 percent of the newly presented episodes result in disability in terms of activities of daily living after one year [2]. To date, early interventions aimed at the psychological and social determinants of SCs are not common in general practice, although such interventions in the early stages of the SCs might prevent the development of chronic complaints [3].

The education and activation program (EAP) is a newly developed intervention addressing psychological and social determinants of SCs which can be applied to prevent the development of chronic SCs [4]. GPs are trained to administer this intervention. A randomized clinical trial evaluating the effectiveness of the EAP compared to only usual care (UC) failed to showed an effect after 26 weeks [4]. The absence of an effect questioned whether this could be attributed to 1) protocol deviations in the actual implementation of the EAP by the GPs or to 2) the contrast between EAP and UC was not as large as assumed.

The EAP emphasizes a psychosocial approach to SCs whereas the usual approach, as described in the guidelines of the Dutch College of General Practitioners (DCGP) is mainly biological [5]. On the other hand, GPs are familiar with a psychosocial approach in conditions such as low back pain and irritable bowl syndrome [6] [7]. Positive experiences with such approaches may induce GPs to apply a psychosocial approach in SCs as well. If this is the case, the EAP may be of less value than expected.

The aim of the present study is to obtain an indication of the performance of the trained GPs by analyzing video taped consultations. Direct observation of the consultations using video was preferred over indirect observation by chart audit, since indirect observation is more susceptible to recall bias, especially in patient education [8]. The number of key features of the EAP present in the 
consultations is used as an indication of the performance and adherence to the EAP.

Furthermore, videotaped consultations of the GPS in the UC group are analysed for the presence of key features of the EAP. The aim of this analysis is to see whether features exclusively attributed to the EAP were already embedded in daily general practice.

\section{METHODS}

\section{Study design}

Five GPs who had been trained during a three-hour training session to apply the EAP and five GPs who had received no training were video taped during a consultation with a standardized patient. The EAP training had consisted of an introduction to the background and use of the EAP, after which the key features of the EAP were further trained in role-plays supervised by CDB and AK. After the GPS' performance had been videotaped, it was evaluated by two blinded observers using a checklist to score the presence of key features of the EAP. Copies of the videotapes were available to the observers giving them the opportunity to replay the videotape at their own convenience.

All GPs were videotaped in their own consulting room after a brief introduction to the standardized patient. Time between the training and the videotaped consultation with a standardized patient varied between three and six months. Trained GPs was offered a period of at least three months to get acquainted with the EAP. After this period, patient recruitment started for the randomized clinical trial. Patients were allocated at random to either the EAP group or the UC group within a period of 18 months.

\section{Standardized patient}

Standardized patients are simulated or actual patients that have been carefully coached to present their illness in a standardized way [9]. The female standardized patient simulating the SCs in this study had received a two-hour instruction during which her role had been worked out using role-plays. She is a professional standardized patient who takes part in the medical training curriculum of the Faculty of Medicine of Maastricht University. 


\section{Education and activation program}

The EAP attempts to steer cognitions and behaviors related to SCs in a desired direction to avoid the development of inadequate cognitions and maladaptive behaviors which are known to play a role in the persistence of musculoskeletal complaints [10-12]. Interventions aimed at these cognitions and behaviors are promising instruments to prevent musculoskeletal pain from becoming chronic $[3,13-16]$. Cognitions refer to the way patients think about their SCs and what these complaints mean to them, in terms of thoughts, beliefs, attitudes and self-efficacy expectations [17], whereas behavior refers to patients' observable actions [18].

The educational part of the EAP consists of tailored information intended to remove the worries and questions patients have regarding their SCs. The trained GP helps the patient to explore whether his or her thoughts about the SC are adequate. Negative patterns of thinking are modified into adequate and accurate thoughts. The activation part aims to assist patients in the continuation or resumption of activities affected by the SCs. This part is based on the principles of operant learning and aims for a gradual increase of activities of daily living despite the pain $[18,19]$.

A successful EAP should be able to reduce the impact of inadequate cognitions and maladaptive behaviors impacting on patients' perception of the SCs resulting in a shorter duration of the SCs. Furthermore, patients should be able to handle future episodes of SCs more adequately also resulting in a shorter duration. In contrast, usual care focuses mainly on pain reduction. If this reduction cannot be achieved, or only partly, patients may not be well prepared to cope with their SCs.

The EAP consists of a minimum of two sessions and a maximum of six followup sessions over a period of six weeks. Each session may last up to 20 minutes. The first and second sessions are organised in the general practice setting by the trained GP. The other sessions are provided by telephone.

\section{The EAP checklist}

The EAP checklist consists of 15 dichotomous (yes/no) items relating to verbal expressions, focusing on the presence of key features of the EAP (table 1).

Key features of the educational part include a discussion of the physical cause of the SCs, preconceptions, prognosis, treatment preferences, and expectations. Information and advice provided during the educational part also 
relate to the events resulting in SCs (cause of complaints). The GP who applies the EAP has to identify preconceptions about the cause and origin of the SCs and has to alter these preconceptions if they are incorrect or reinforce them if they are correct. Inadequate expectations about prognosis and treatment have to be identified and altered if necessary. The aim of the educational part of the EAP is to provide the patients with a realistic image of prognosis and treatment effect. Therefore, the information should be tailored to patients' specific needs and is to be used either to alter incorrect thoughts or to reinforce correct thoughts. The activation part of EAP focuses on changes in activities of daily living resulting from the SCs. Patients are advised to continue or resume their activities despite the pain. In addition to this advice, the adverse effects of inactivity are discussed with the patients. Activities indicated by the patients to be affected by the SCs are closely monitored during the subsequent consultations. Agreements are made about the resumption or gradual increase of these activities, using a time contingent approach. In this approach, resumption or increase of activities occurs irrespective of pain experience but according to preset goals in time.

\section{Analysis}

A total score on the EAP checklist is calculated by counting the affirmative items ('yes' = key feature is present), yielding a score between 0 and 15 points. Although the checklist's construct validity and reliability have not been determined, its face validity is considered to be high, since the items are based on the key features of the EAP. In the view of the developers of the EAP, a score equal to or higher than 8 indicates that an acceptable number of key EAP features was observed.

Additional items (table 1) relate to the presence of pain-contingent treatments aiming to reduce the shoulder pain. These pain-contingent treatments are part of the UC treatment according to the Dutch guidelines [5].

Mean total scores were calculated for each group, using the mean total scores of the two observers. In addition, mean item scores were computed for each group.

Data from the EAP checklist were analyzed for inter-observer variability by the kappa statistics method for observers, as outlined by Fleiss [20]. 


\section{RESULTS}

In total 5 trained GPs in the EAP group and 5 non-trained GPs in the UC group participated. Mean age of GPs in the EAP group was $48.0(\mathrm{SD}=7.8)$ and 45.6 $(S D=11.7)$ in the UC group. GPs in the EAP group had $19.4(S D=9.2)$ years of experience as a GP. GPs in the UC group had $16.8(S D=11.4)$ years of experience.

The kappa value for the inter-observer variability between the observers using the EAP checklist was 0.618 , indicating substantial agreement between the observers [21].

The mean total score on the EAP checklist was 4.7 (SD =2.9) in UC group and $7.1(S D=2.1)$ in the EAP group. Although neither group reached a score higher than 8 (which was considered to reflect an acceptable number of key features), the EAP group thus scored higher than UC group.

Comparing each group at item level for the key features (table 1) shows that the proportion of items observed in the consultations by the EAP group equalled or surpassed that in the UC group for all but one item (number 12). Items 1, 3, 9 and 12 were observed in at least $50 \%$ of the consultations in the UC group, while the EAP group had scores of at least $50 \%$ for items $1,3,4,5$, 9,11 , and 12 .

On item-level, a difference of $40 \%$ or more in favor of the EAP group was observed for the items 4,5 , and 9 . The differences between the two groups with regard to the other items were less consistent, with differences of less than $40 \%$.

Pain-contingent treatments were more likely to be applied by the UC group (table 1), which complies with current treatment guidelines. All GPs in UC group used medication as part of the treatment, whereas $60 \%$ of the GPs in the EAP group used medication. 


\begin{tabular}{|c|c|c|c|c|}
\hline \multicolumn{2}{|c|}{$\begin{array}{l}\text { Item } \\
\text { number }\end{array}$} & Description & UC group & $\begin{array}{r}\text { EAP group } \\
(\%)\end{array}$ \\
\hline $\begin{array}{l}\text { Key features } \\
\text { of the EAP }\end{array}$ & 1 & $\begin{array}{l}\text { Discuss the physical cause of the } \\
\text { complaints }\end{array}$ & 80 & 80 \\
\hline & 2 & $\begin{array}{l}\text { Explore the patient's thoughts on the } \\
\text { physical cause }\end{array}$ & 0 & 20 \\
\hline & 3 & $\begin{array}{l}\text { Explore the patient's thoughts on the } \\
\text { events resulting in SCs (origin) }\end{array}$ & 100 & 100 \\
\hline & 4 & $\begin{array}{l}\text { Verify that the patient understands and } \\
\text { agrees with the explanation of the } \\
\text { cause of the complaints }\end{array}$ & 30 & 70 \\
\hline & 5 & $\begin{array}{l}\text { Discuss the prognosis with attention for } \\
\text { the patient's thoughts }\end{array}$ & 10 & 60 \\
\hline & 6 & $\begin{array}{l}\text { Explore and discuss the patient's } \\
\text { thoughts on pain and activities }\end{array}$ & 10 & 10 \\
\hline & 7 & $\begin{array}{l}\text { Explore and discuss the patient's } \\
\text { treatment preferences }\end{array}$ & 10 & 10 \\
\hline & 8 & $\begin{array}{l}\text { Involve the patient in the choice of the } \\
\text { treatment }\end{array}$ & 20 & 20 \\
\hline & 9 & $\begin{array}{l}\text { Aim the activation at specific activities } \\
\text { affected by the SCs }\end{array}$ & 50 & 90 \\
\hline & 10 & $\begin{array}{l}\text { Give concrete recommendations on } \\
\text { activities }\end{array}$ & 40 & 40 \\
\hline & 11 & $\begin{array}{l}\text { Discuss the recommendations with the } \\
\text { patient }\end{array}$ & 20 & 50 \\
\hline & 12 & $\begin{array}{l}\text { Explain the aim of intervention to the } \\
\text { patient }\end{array}$ & 80 & 70 \\
\hline & 13 & Discuss limiting factors in treatment & 0 & 10 \\
\hline & 14 & Discuss feasibility with the patient & 0 & 20 \\
\hline & 15 & Make time-contingent agreements & 20 & 40 \\
\hline $\begin{array}{l}\text { Pain-contingent } \\
\text { treatments }\end{array}$ & 16 & Treatment aimed at pain reduction & 90 & 70 \\
\hline & 17 & Medication as part of treatment & 100 & 60 \\
\hline & 18 & Use other pain reduction interventions & 40 & 40 \\
\hline
\end{tabular}

Table 1: Presence of key EAP items in \% of consultations observed, for the EAP and UC groups 


\section{DISCUSSION}

Video analysis showed that neither the GPs in the EAP group nor those in the UC group reached scores above 8 points on the EAP checklist, a level which we consider to reflect the administration of an acceptable number of key EAP features. GPs in the UC group performed above expectation, with a mean total score of 4.7. This can be explained by experiences with a similar approach in low back pain and irritable bowel syndrome. At item level, key features were present as often or more often in the treatment by the EAP group than in that by the UC group, except for item 12 in which the aim of the intervention is explained to the patient. Pain-contingent treatments were, as expected, more often present in the treatment by the UC group. It has to be admitted, however, that the substantial agreement between the observers, combined with the limited number of videotaped GPs, has reduced the power of this study. Furthermore, observing the presence of key features in the treatment provides no information on the quality of the way they were administered, and this quality may well differ between the two study groups. This fact, and the limited power of the study, implies that the results should be interpreted with caution and can only provide a first indication of the GPs' performance. The contrast between the two groups in terms of key features was rather small, resulting in a smaller difference between treatment groups than desired in the clinical trial comparing the two groups [4]. Moreover, the small number of key features that were seen in the treatment by the EAP group may very well have led to a reduced effectiveness of the EAP.

A comparison of the groups at item level shows that most items were present in both treatment groups, although the majority of the items were more often observed in the EAP group. The UC group administered a high proportion of items referring to the physical cause (item 1), patient's thoughts on origin (item 3 ) and the aim of the intervention (item 12), suggesting that these key features are already embedded in usual care. Assessment of the items administered in the EAP group reveals a wide variety in the presence of key features. Only seven items were present in $50 \%$ or more of the observations, whereas eight items were observed in less than $50 \%$ of the consultations in the EAP group. Item 8 on the patient's involvement in the choice of the treatment and item 14 on feasibility in particular are important factors for long-term success, as patients have to take responsibility for their own recovery in EAP. Several 
reasons can be given for the low presence of these items. One reason may be the briefness of the training, which may not have provided GPs with sufficient tools to administer these items. Acquiring more complex skills in cognitive behavior therapy is not as straightforward for general practitioners as might be assumed [22]. Another reason may be the reluctance among GPs to administer key features whose benefits are not yet clear to them. It should be noted that introducing a new treatment among GPs may require more detailed education about the specific working mechanism of key features, to alter their attitudes and beliefs. Pressure of time in daily practice may also have resulted in GPs leaving out some key features of the EAP. Finally, only the first consultation of a standardized patient was videotaped. Key features not present in this consultation could have been embedded in subsequent consultations but this has not been recorded.

The items of the EAP checklist are based on the key features of the EAP. This makes them valid items. It can be questioned however whether it is realistic to expect observers to differentiate between these key features. The observers reported however no difficulty in differentiating between the key features.

The item on patient's thoughts on origin (item 3) was observed in all consultations in both treatment groups. This suggests that this key feature can not be exclusively attributed to the EAP and is a feature most likely to be present in the majority of consultations in general practice. A similar result is found for the items on the cause of the complaints (item 1) and the aim of the intervention (item 12).

It should be noted that, although described in the guidelines of the DCGP, these guidelines provide no elaboration on these items in which the patient's point of view is explored [5]. This may explain the presence of these key features but the elaboration on these items may differ from the EAP. The EAP checklist is unable to detect this difference in elaboration.

Being videotaped introduces the risk of the Hawthorne-effect. The Hawthorneeffect refers to the tendency to improve performance because of the awareness of being studied [23, 24]. This may have been the case in this study possibly resulting in an overestimation of the performance of the GPs. This has however no effect on the conclusions of this study as the Hawthorne-effect would have occurred in both treatment groups. 


\section{CONCLUSIONS}

This study shows that GPs administering the EAP perform below the desired level while GPS in the UC group already use key features of the EAP in daily practice. This resulted in a smaller difference than anticipated between the UC and EAP group. This may have affected the outcome of the randomized clinical trial comparing these two interventions. However, the impact also depends on the quality of the administration of the key features, which was not measured by the EAP checklist.

We recommend that the EAP training of the GPs should give special attention to those key features that were not sufficiently present in treatments given by the trained GPs in this study. The focus of this attention should be on the cognitions and behavior of the GPs. Whereas patients develop cognitions and behavior by undergoing SCs, GPs develop cognitions and behavior based on their experience in treating SCs. Altering these cognitions and behavior for a new therapy requires more than a training in which the rationale of the EAP is explained. Existing cognitions on treating SCs and the resulting behavior of the GPs should be explored and discussed during this training. 


\section{REFERENCES}

1. Rethans, J.J., et al., Does competence of general practitioners predict their performance? Comparison between examination setting and actual practice. Bmj, 1991. 303(6814): p. 1377-80.

2. Windt, D.A.v.d., et al., Shoulder disorders in general practice: prognostic indicators of outcome. Br J Gen Pract, 1996. 46(410): p. 519-23.

3. Linton, S.J., Prevention with special reference to chronic musculoskeletal disorders, in Psychosocial Factors in Pain, R.J. Gatchel and D.C. Turk, Editors. 1999, Guilford Publications: New York. p. 374-389.

4. Bruijn, C.D., et al., Evaluation of an education and activation programme to prevent chronic shoulder complaints: design of an RCT [ISRCTN71777817]. BMC Fam Pract, 2005. 6(1): p. 7.

5. Winters, J.C., et al., NHG-standaard schouderklachten. Huisarts en Wetenschap, 1999. 42(5): p. 222-231.

6. Faas, A., et al., NHG-standaard M54 lage rugpijn. Huisarts Wet, 1996. 39: p. 18-31.

7. van der Horst, H.E., et al., Managing patients with irritable bowel syndrome in general practice. How to promote and reinforce self-care activities. Patient Educ Couns, 1998. 35(2): p. 149-56.

8. Woodward, C.A., et al., Measurement of physician performance by standardized patients. Refining techniques for undetected entry in physicians' offices. Med Care, 1985. 23(8): p. 1019-27.

9. Beullens, J., et al., The use of standardized patients in research in general practice. Family Practice, 1997. 14(1).

10. Linton, S., A systematic review of psychological risk factors for back and neck pain. Spine, 2000. 25: p. 1148-1156.

11. Turk, D.C. The role of demographic and psychosocial factors in transition from acute to chronic pain. in 8th World Congress on Pain, Progress in Pain Research and Management. 1997: IASP Press.

12. Weiser, $S$. and C. Cedraschi, Psychosocial issues in the prevention of chronic low back pain - a literature review. Bailliere's Clinical Rheumatology, 1992. 6(3): p. 657-684. 
13. Mitchell, R.I. and G.M. Carmen, Results of a multicenter trial using an intensive active exercise program for the treatment of acute soft tissue and back injuries. Spine, 1990. 15(6): p. 514-21.

14. Lindstrom, I., et al., The effect of graded activity on patients with subacute low back pain: a randomized prospective clinical study with an operant-conditioning behavioral approach. Phys Ther, 1992. 72(4): p. 279-90; discussion 291-3.

15. Haig, A.J., et al., Aggressive early medical management by a specialist in physical medicine and rehabilitation: effect on lost time due to injuries in hospital employees. J Occup Med, 1990. 32(3): p. 241-4.

16. Malmivaara, A., et al., The treatment of acute low back pain--bed rest, exercises, or ordinary activity? N Engl J Med, 1995. 332(6): p. 351-5.

17. Wit, R.d., et al., Assessment of pain cognitions in cancer patients with chronic pain. Journal of Pain and Symptom Management, 2001. 22(5): p. 911-924.

18. Fordyce, W.E., Behavioral methods for chronic pain and illness. 1976, Saint Louis: C. V. Mosby Company.

19. Morley, S., C. Eccleston, and A. Williams, Systematic review and metaanalysis of randomized controlled trials of cognitive behaviour therapy and behaviour therapy for chronic pain in adults, excluding headache. Pain, 1999. 80(1-2): p. 1-13.

20. Fleiss, J.A., The measurement of interrater agreement, in Statistical Methods for Rates and Proportions. 1981, Wiley: New York.

21. Landis, J.R. and G.G. Koch, The Measurement of observer agreement for categorical data. Biometrics, 1977. 33: p. 159-174.

22. King, M., et al., Effectiveness of teaching general practitioners skills in brief cognitive behaviour therapy to treat patients with depression: randomised controlled trial. Bmj, 2002. 324(7343): p. 947-50.

23. Leung, W.C., et al., Continued reduction in the incidence of birth trauma and birth asphyxia related to instrumental deliveries after the study period: Was this the Hawthorne effect? Eur J Obstet Gynecol Reprod Biol, 2006.

24. Wickstrom, G. and T. Bendix, The "Hawthorne effect"--what did the original Hawthorne studies actually show? Scand J Work Environ Health, 2000. 26(4): p. 363-7. 


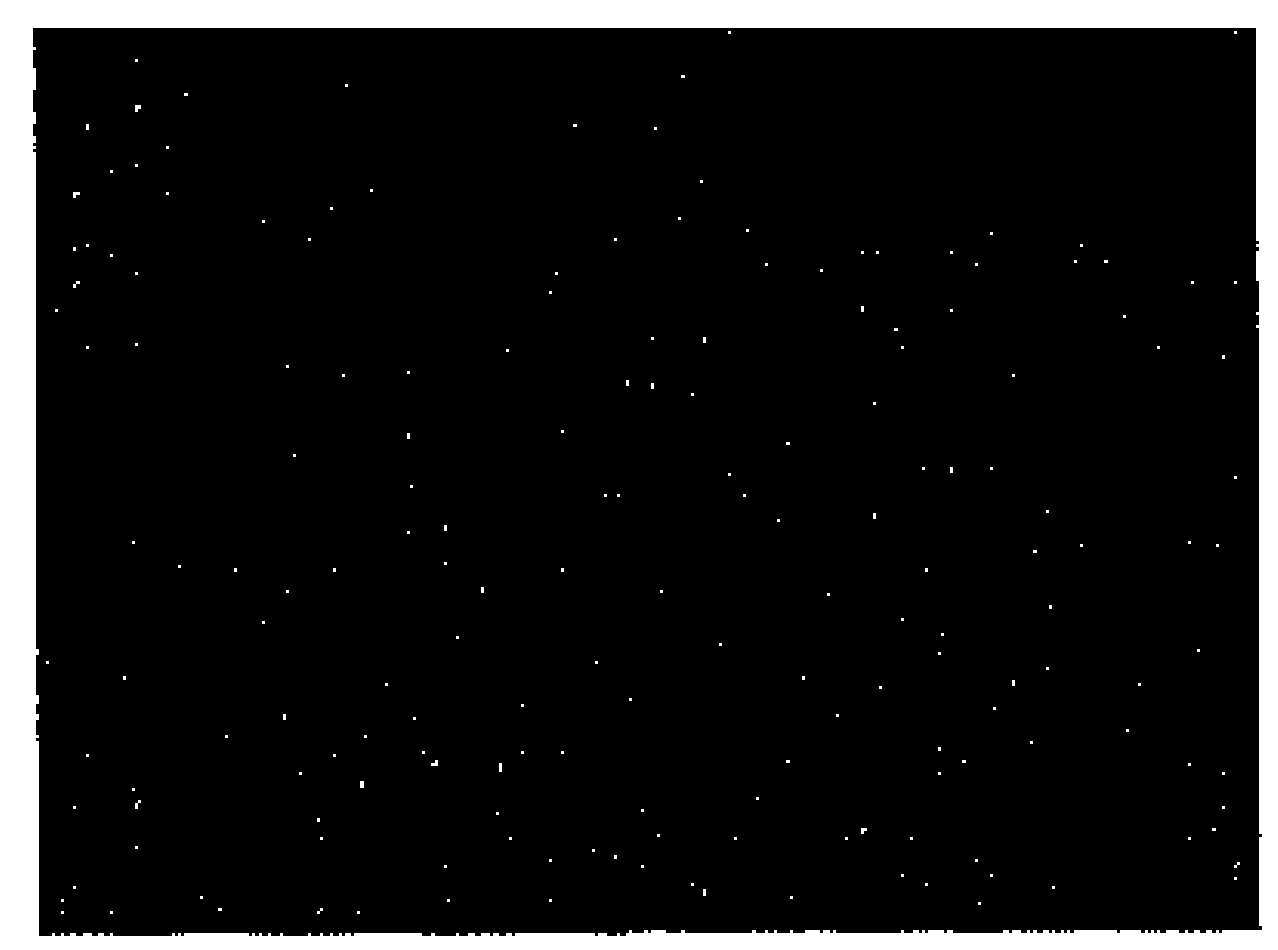

\section{Clinical effectiveness of the intervention}
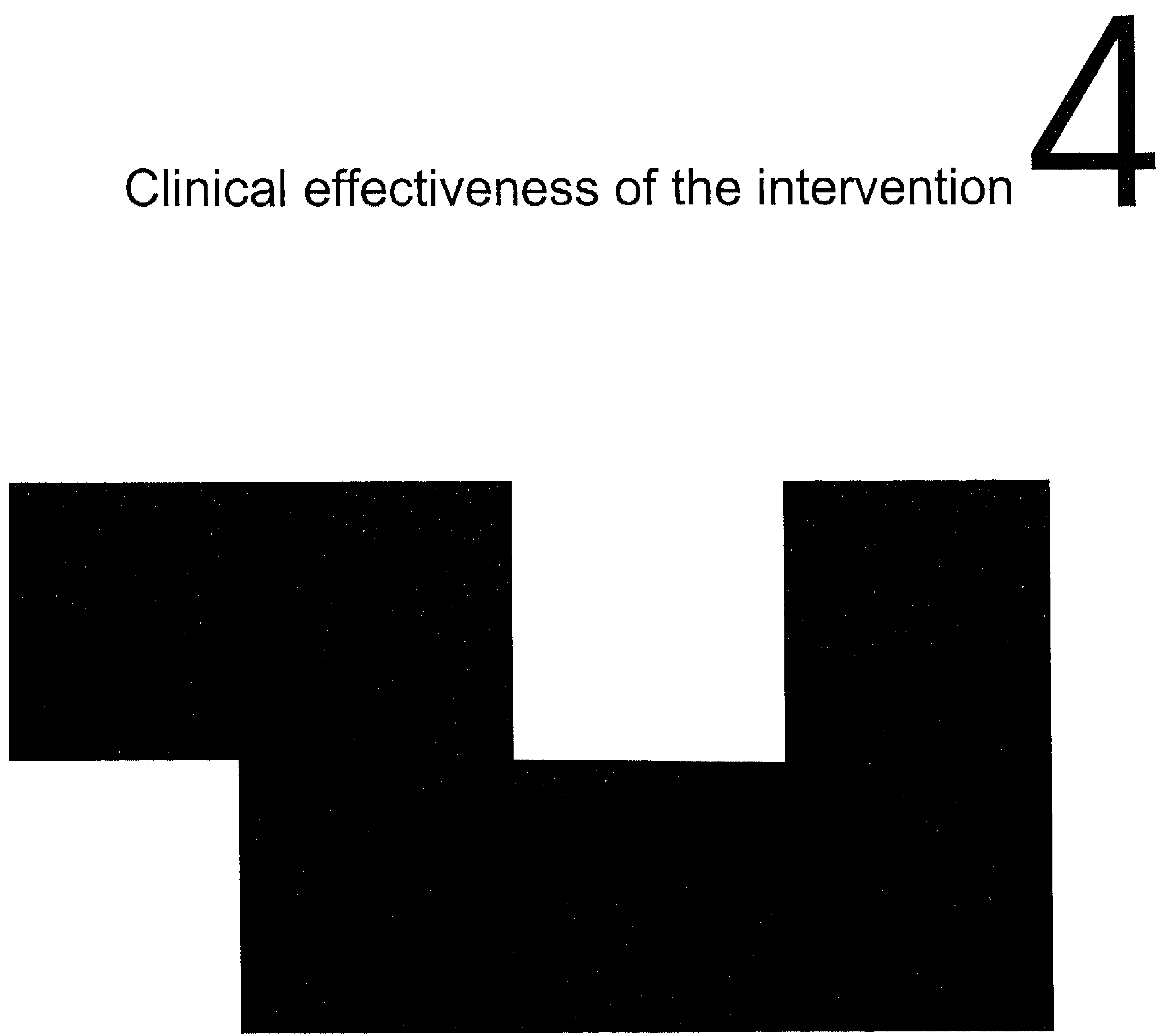

Published as:

De Bruijn C, De Bie RA, Geraets J, Goossens M, Van den Heuvel W, van der Heijden G, Candel M, Dinant GJ. Effect of an education and activation programme on functional limitations and patient-perceived recovery in acute and sub-acute shoulder complaints - a randomised clinical trial. BMC Musculoskeletal Disorders 2007;8:112 www.biomedcentral.com/1471$2474 / 8 / 112$ 


\section{ABSTRACT}

Background: The education and activation programme (EAP) aims at coping with psychosocial determinants to prevent the development of chronic shoulder complaints (SCs). The effect of the EAP on functional limitations and patientperceived recovery after 6 and 26 weeks is evaluated in a randomised clinical trial.

Methods: Patients with SCs present at rest or elicited by movement and lasting no longer than 3 months were allocated at random to either EAP as an addition to usual care (UC), or to UC only. Measurements were taken at baseline and after 6 and 26 weeks and were analysed by means of multilevel analysis for the group effect. EAP was administered by GPs or by an ambulant therapist (CDB). Patients in the UC group were given UC by their own GP.

Results: Multilevel analysis failed to show a significant effect of the EAP on either functional limitations or patient-perceived recovery. Analysis showed coincidentally a relation between catastrophising at baseline and functional limitations.

Conclusions: The EAP has no significant effect on the outcome of SCs after 6 and 26 weeks. The relation between catastrophising at baseline and functional limitations suggests that an intervention focusing specifically on catastrophising may be more successful in reducing functional limitations in the long term. Further research is however needed to evaluate the effect of catastrophising at baseline on the course of SCs.

Trial registration: Current Controlled Trials ISRCTN71777817 


\section{BACKGROUND}

Psychological and social factors are known to play a role in the development and persistence of chronic musculoskeletal diseases [1-3]. Furthermore, previous studies showed that therapies aimed at coping with psychosocial determinants are promising interventions to prevent musculoskeletal pain from becoming chronic [4-8]. Up till now, usual care (UC) in patients with shoulder complaints (SCs) in the Netherlands has mainly focused on the biomedical determinants mentioned in the clinical guidelines of the Dutch College of General Practitioners [9]. Since half of all newly presented episodes of SCs in general practice last for at least six months, a therapy aimed at coping with psychosocial determinants may reduce the proportion of SCs that become chronic [10].

We have therefore developed an education and activation programme (EAP) aimed at coping with psychosocial determinants to prevent the development of chronic SCs. Psychosocial determinants influence cognitions and behaviours. The EAP attempts to steer these cognitions and behaviours in the desired direction to avoid the development of inadequate cognitions and maladaptive behaviours. In this context, cognitions refer to the way patients think about their SCs and what these complaints mean to them, in terms of thoughts, beliefs, attitudes and self-efficacy expectations [11], whereas behaviour refers to the patients' observable actions [12].

Our hypothesis is that in the acute and sub-acute stages of the SCs, cognitions and behaviours are easily susceptible to modification, which means that the EAP can be administered in a brief intervention by specially trained general practitioners (GPs) or a trained ambulant therapist. A randomised clinical trial was set up to evaluate the effect of the EAP as an addition to UC, compared to $U C$ alone, on patient-perceived recovery and changes in functional limitations of activities of daily living after 6 weeks and 26 weeks [13]. This paper presents the results of the randomised clinical trial as regards functional limitations and patient-perceived recovery after 6 and 26 weeks. The trial is part of a national study on shoulder complaints in general practice, which includes a prognostic cohort study with three randomised clinical trials in subcohorts. This study is funded by The Netherlands Organization for Health Research and Development (grant number 940-31-085). 


\section{METHODS}

\section{Study design}

In our randomised clinical trial, patients were allocated at random to either EAP as an addition to UC, or to UC only. Measurements were taken at baseline and after 6 and 26 weeks by a self administered questionnaire. The 6 and 26 weeks questionnaires were sent and returned by mail. The 6 weeks measurement provided information on the immediate effect of the EAP as the EAP had to be administered within the six week period after the baseline measurement. The 26 weeks measurement provided information on the long term effect of the EAP. EAP was administered by GPs or by an ambulant therapist (CDB) if no EAP-trained GP was available near a patient's home. All GPs who provided EAP attended a three-hour training session, in which the EAP was introduced and role-plays were used to train the proper administration of EAP. The GPs received a training manual during this session in which the principles of the EAP were summarized. Patients in the UC group were given UC by their own GP, unless their GP had attended the EAP training. In that case, UC was administered by a colleague from the same GP group practice, to avoid contamination. The design of this study has been described in detail in a previous publication [13].

\section{Patients and procedure}

Eligible patients had consulted their own GP or responded to advertisements in local newspapers calling on people with a new and untreated episode of SCs that had lasted less than three months and produced complaints at rest or complaints elicited by shoulder movement. Patients were included if they were older than 18 years and living in the south of the Netherlands. Additional inclusion and exclusion criteria are given in table 1. 


\begin{tabular}{|c|c|}
\hline Inclusion criteria & Exclusion criteria \\
\hline $\begin{array}{l}\text { - SC present at rest or elicited by } \\
\text { movement } \\
\text { - SC episode lasting no longer than } 3 \\
\text { months } \\
\text { - First episode of SC for } 12 \text { months } \\
\text { - Newly presented episode (no prior } \\
\text { consultations or treatments for this } \\
\text { episode in the previous three months) } \\
\text { - Older than } 18 \text { years } \\
\text { - Living in the south of the Netherlands }\end{array}$ & $\begin{array}{l}\text { - Prior fractures and/or surgery of the } \\
\text { shoulder } \\
\text { - (Suspected) referred pain from internal } \\
\text { organs } \\
\text { - SCs with a confirmed extrinsic cause } \\
\text { - Inability to complete a questionnaire } \\
\text { independently } \\
\text { - Presence of dementia or other severe } \\
\text { psychiatric abnormalities }\end{array}$ \\
\hline
\end{tabular}

Table 1: Inclusion and exclusion criteria

The patient recruitment procedure in the consultation room was designed to minimize the time needed by the GP, since lack of time is often mentioned as one of the main barriers when recruiting patients in general practice [14]. GPs pointed out the existence of the EAP trial to patients with newly presented SCs, checked the inclusion and exclusion criteria and forwarded the patients' personal data by fax to the research centre. The patients had to give written permission for their personal data to be forwarded to the research centre. The GPs were advised to refer patients to the research centre for further information about the EAP trial. Patients responding to the advertisements were first screened by telephone for inclusion and exclusion criteria. Patients meeting the inclusion criteria were subsequently visited by an independent GP involved in the EAP trial (EAP-GP). This EAP-GP provided the patients with a regular consultation for SCs. Personal data of eligible patients were forwarded to the research centre. In both recruitment strategies, the research assistant contacted patients within 2 weeks and took care of final inclusion and randomisation. The baseline questionnaire was handed out and after completion returned to the research assistant.

Blocked and concealed randomisation with blocks of 4 patients was used to allocate patients to either the EAP group or the UC group. An independent researcher used a computer-generated random sequence table to randomise the patients in each block. The seals of the prepared, numbered, opaque, sealed envelopes containing the treatment group were broken by the research 
assistant after eligibility had been verified and the patient had given written informed consent.

\section{Blinding}

Neither the patients nor the GPs, nor the trained ambulant therapist, could be blinded for the allocated treatment. The ambulant therapist was also the researcher coordinating the randomised clinical trial and conducting the data analysis, but he was blinded for treatment allocation during the data analysis. The allocation code was kept by an independent researcher (JG) and was revealed only after data analysis had been completed.

\section{Interventions}

The focus of EAP is to maintain or induce the proper cognitions by education and to stimulate adequate behaviour by means of advice on activities of daily living, using principles of operant conditioning [11]. The programme consists of an educational and an activation part.

The educational part of the EAP consists of tailored information intended to take away the worries and answer questions patient may have regarding their SCs. Special care is taken to structure the information and advice that patients receive from other individuals in their social and health care environment. The information and advice are tailored to the patients' thoughts. Preconceptions on SCs are identified and altered if they are incorrect or reinforced if they are correct. The final aim of the educational part of the EAP is to provide patients with a realistic idea of their prognosis and the effect of treatment.

The activation part aims to assist patients in the continuation or resumption of activities affected by the SCs, despite the pain. The adverse effects of inactivity are discussed with the patients and activities that patients indicate to be affected by the SCs are closely monitored during the subsequent consultations. Schedules are set for the resumption or gradual increase of these activities, using a time-contingent approach, which means that the resumption or increase of activities occurs irrespective of pain experience but according to preset goals in time.

The EAP consists of a minimum of two sessions and a maximum of six followup sessions over a period of six weeks. Each session can last up to 20 minutes. 
UC was administered according to the clinical guidelines of the Dutch College of General Practitioners [9].

\section{Outcome Measures}

The first primary outcome measure, assessed at 6 and 26 weeks after randomisation, was patient-perceived recovery (PPR)[10]. Patients were considered recovered when they reported to be 'much improved' or 'fully recovered', on a 7-point ordinal scale, six weeks after randomisation.

The second primary outcome measure was a change in functional limitations of activities of daily living. This variable was assessed by the 16-item shoulder disability questionnaire (SDQ)[15], with a standardised scoring range of 0 to 100. A lower score on this questionnaire implies lower levels of functional limitations.

Several psychosocial variables were assessed at baseline. Anxiety, depression, somatisation and distress were assessed using the fourdimensional symptoms questionnaire [16, 17]. Catastrophising and coping were assessed by 6-level subscales of the Pain Coping and Cognition List (1: completely disagree; 6: completely agree) [18]. Mean subscale scores of 1 were classified as 'very low' (code $=0$ ), scores between 2 and 6 were classified as elevated (code=1) [18]. Other specific disease variables recorded at baseline were pain intensity, measured on a 10-point visual analogue scale; onset (quick or gradual); affected shoulder and having had prior episodes of SCs lasting at least 1 week.

\section{Sample size}

About half of all newly presented episodes of SC in general practice are reported to last for at least six months. A number needed to treat of 4.5 after 26 weeks is considered clinically relevant. This implies an absolute reduction of $22 \%$ of the proportion of patients with SC after 26 weeks. With a two-sided alpha of 0.05 and a statistical power $(1-\beta)$ of $0.80,82$ patients per treatment group were needed to detect a difference in favour of EAP compared to UC after 26 weeks. 


\section{Data analysis}

The baseline variables of the treatment groups were compared using chisquare tests and an independent samples t-test. Significant differences in baseline variables were considered to be potential confounders. The statistical data analysis was carried out according to the 'intention-to-treat' principle.

Patients attending the same GP cannot be assumed to be fully independent. Similarly, different observations for the same patient with SCs cannot be assumed to be independent either. Multilevel analysis was used to address this dependency due to clustering of data. The effect of treatment group (EAP group $=1$; UC group=0) was analyzed by means of linear multilevel analysis if SDQ was the outcome variable and logistic multilevel analysis if patientperceived recovery was the outcome variable. Three levels of variance were distinguished: GPs, subjects and measurements.

In the linear multilevel analysis, baseline SDQ scores were entered into the model to adjust for differences at baseline. Since none of the patients were recovered at baseline, no adjustment was needed for patient-perceived recovery at baseline in the logistic multilevel analysis. Time of measuring was represented in the model by two dummy variables for the measurements at 6 and 26 weeks. Potential confounders were also entered into the linear and logistic model as independent variables. Finally, the interaction effect between the treatment group and the time of measuring was also included in the model. The multilevel analyses resulted in estimates (and standard errors) of the fixed and random effects. Likelihood ratio (LR) test statistics were used to determine whether the estimates were statistically significant $(p<0.05)$ in the linear multilevel analyses. Wald chi-square tests were used to determine the statistical significance of the estimates in the logistic multilevel analyses. Estimates that did not reach the required level of significance were excluded from the model in a top-down procedure, except for the intervention variable, leaving out the least significant estimates first. For the logistic multilevel analysis, these estimates were converted to odds ratios with their $95 \%$ confidence intervals. All multilevel analyses were performed with MLwiN (version 1.10) $[19,20]$. 


\section{RESULTS}

\section{Patients}

GPs referred a total of 133 patients for participation in the EAP trial, 74 of whom were actually included in the trial. In total, 64 patients responded to the advertisements. Of these, 44 met the selection criteria, as ascertained by a telephone interview. The subsequent visit by the EAP-GP resulted in the final inclusion of 37 patients. A total of 111 patients were thus eventually recruited to participate in the study (figure 1). Three patients dropped out after randomisation without receiving any treatment, and were therefore excluded from further analysis. After 6 weeks, complete data was available for 40 patients $(77 \%)$ in the UC group and 48 patients $(86 \%)$ in the EAP group. After 26 weeks, complete data was available for 35 patients $(67 \%)$ in the UC group and $44(79 \%)$ patients in the EAP group.

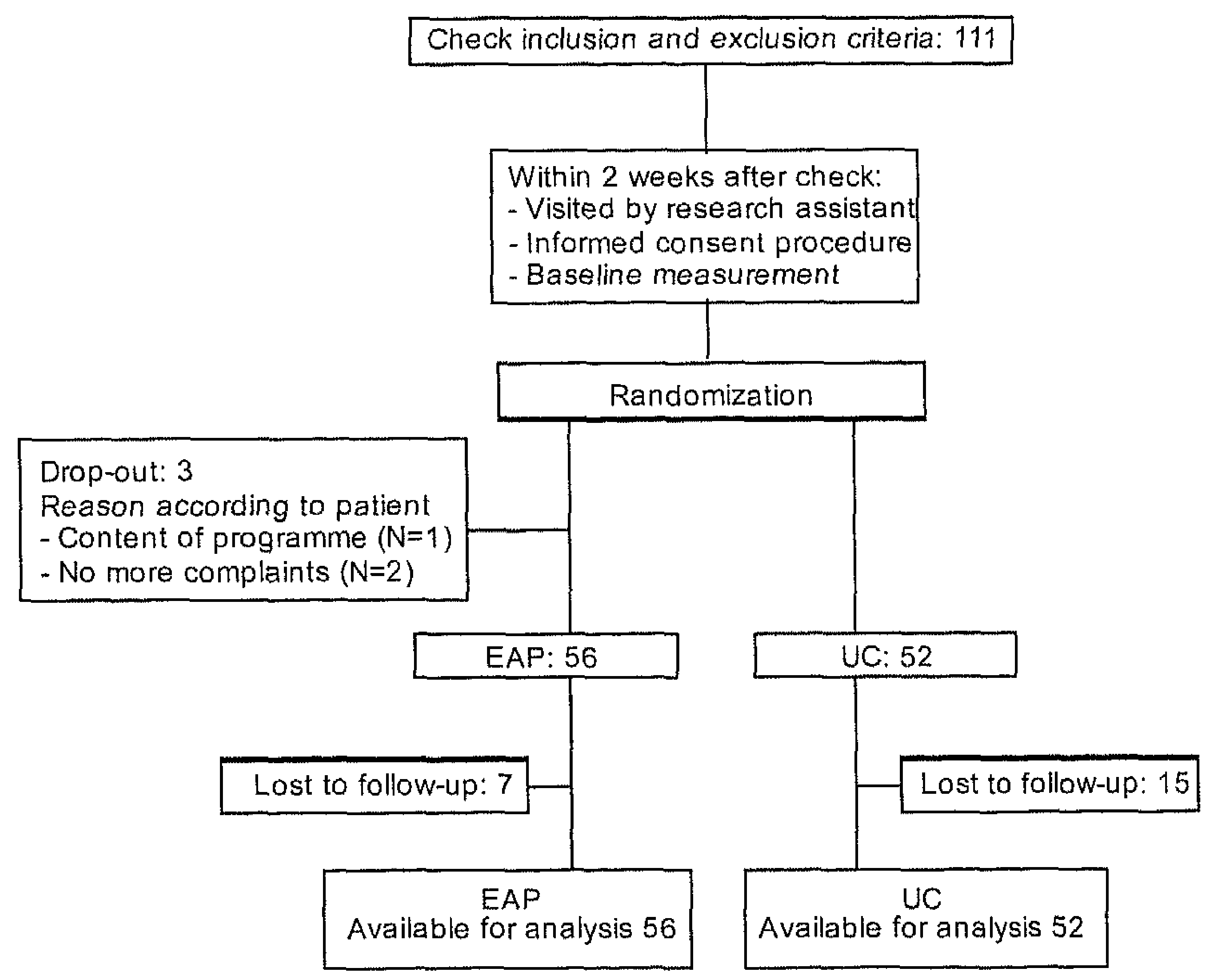

Figure 1: Flow chart 


\section{Baseline variables}

Table 2 shows that there were no statistically significant differences between the two treatment groups at baseline for any of the variables except catastrophising. The effect of baseline differences in catastrophising was evaluated by entering this variable into the multilevel analysis models.

\begin{tabular}{lrrr}
\hline & UC & EAP & p-value \\
\hline Number & 52 & 56 & \\
\hline Demographic variables & $49.9(11.7)$ & $48.4(16.2)$ & 0.572 \\
\hline Age (years)(SD) & 44 & 36 & 0.366 \\
\hline Gender $\%$ (\%) & $5.2(2.3)$ & $5.3(2.2)$ & 0.887 \\
\hline Specific disease variables & 44 & 54 & 0.286 \\
\hline Pain intensity T0 (mean + SD) & $42-52-6$ & $41-57-2$ & 0.538 \\
\hline Onset (quick) (\%) & 42 & 49 & 0.482 \\
\hline Affected shoulder (Left/right/both) (\%) & & & \\
\hline Prior episodes of SCs lasting at least 1 week & & & \\
(\% yes) & $60.8(24.1)$ & $67.1(24.0)$ & 0.175 \\
\hline Outcome variable & 49 & & \\
\hline SDQ score at baseline (mean and SD) & 12 & 8 & 0.022 \\
\hline Psychosocial variables & $79-17-4$ & $80-18-2$ & 0.815 \\
\hline Catastrophising (\% very low) & $94-2-4$ & $91-7-2$ & 0.357 \\
\hline Coping (\% very low) & $100-0-0$ & $100-0-0$ & - \\
\hline Distress categories (low-medium-high; \%) & $85-11-4$ & $82-18-0$ & 0.231 \\
\hline Depression categories (low-medium-high; \%) & & &
\end{tabular}

Table 2: Baseline variables

\section{Multilevel analyses}

Estimates with their standard error and levels of significance are presented in table 3 for the linear multilevel analyses of the SDQ scores. The interaction terms between the two dummy variables and the group variable did not reach significance and were excluded from the final model in the top-down procedure. This implies that the potential effect of treatment group was similar at both post measurements. In the final model, treatment group turned out to have no effect at either of the measurements. Catastrophising at baseline and 
baseline SDQ scores were significantly and positively related to SDQ scores at both post measurements. Time dummy 1 and time dummy 2 were significantly and negatively related to SDQ scores, suggesting that SDQ score, representing the level of functional limitations, decreases as time progresses.

\begin{tabular}{lrr}
\hline Variable & Estimate (SE) & p-value \\
\hline Fixed parameter & & \\
\hline Treatment group & $3.44(4.98)$ & 0.4916 \\
\hline Time dummy 1 (6 weeks) $^{10}$ & $-8.18(3.24)$ & $0.0116^{11}$ \\
\hline Time dummy 2 (26 weeks) & $-17.26(4.03)$ & $0.0000^{11}$ \\
\hline Catastrophising at baseline & $6.84(5.10)$ & 0.0000 \\
\hline SDQ score at baseline & $0.53(0.11)$ & 0.0000 \\
\hline Random effects & & \\
\hline Variance at patient level & & \\
\hline - Time dummy1 & $819.03(133.67)$ & $0.0000^{11}$ \\
\hline - Time dummy 2 & $1227.20(205.03)$ & $0.0000^{11}$ \\
\hline
\end{tabular}

Table 3: Results of the linear multilevel analysis of SDQ

Estimates with their standard errors and levels of significance for the logistic multilevel analyses of the PPR are presented in table 4. Data were interpreted by converting estimates to odds ratios (ORs). The top-down procedure resulted in the exclusion of the interaction terms from the logistic model. This implies that the potential effect of treatment group was similar for both post measurements. In the final analysis model, the treatment group had a nonsignificant ( $p=0.1784$ ) effect on patient-perceived recovery. A significant effect was found for time dummy 1 and time dummy 2 , indicating a significant effect on PPR of the time elapsed since baseline. Baseline levels of catastrophising did not have a significant effect on the PPR and were excluded from the final analysis model.

10 This variable has the code 1 for 6 weeks and 0 otherwise 11 Based on the Wald statistic

12 This variable has the code 1 for 26 weeks and 0 otherwise 


\begin{tabular}{|c|c|c|c|c|}
\hline Variable & Estimate (SE) & OR & $95 \% \mathrm{Cl}$ & $p$-value \\
\hline Fixed parameter & & & & \\
\hline Treatment group & $0.85(0.63)$ & 2.34 & {$[0.68 ; 8.00]$} & $0.1784^{13}$ \\
\hline Time dummy 1 (6 weeks $)^{14}$ & $1.24(0.45)$ & 3.46 & {$[1.43 ; 8.33]$} & $0.0056^{13}$ \\
\hline Time dummy $2(26 \text { weeks })^{15}$ & $2.60(0.49)$ & 13.46 & {$[5.16 ; 35.16]$} & $0.0000^{13}$ \\
\hline
\end{tabular}

Table 4: Results of the logistic multilevel analysis of patient-perceived recovery

\section{DISCUSSION}

Multilevel analysis using either Shoulder Disability Questionnaire (SDQ) scores or PPR as the outcome variable failed to show a significant effect of the EAP. Baseline levels of catastrophising were significantly and positively related to functional limitations. Patient-perceived recovery (PPR), on the other hand, was not significantly related to baseline levels of catastrophising. A significant effect of time was found for both outcome variables.

The positive and significant correlation between functional limitations and elevated levels of catastrophising at baseline suggests the existence of a relation between the two. Such a relation is plausible, as catastrophising refers to 'an exaggerated negative orientation toward pain stimuli and pain experience' [21-23]. This may cause patients with SCs to be more reluctant to use their shoulder, resulting in increased functional limitations.

In view of this, it is remarkable that no relation was found between catastrophising and patient-perceived recovery, since negative orientation is expected to affect the perception of the SCs as well. Such a relation between catastrophising and the chronic pain experience has indeed been found in patients with low back pain [24-28]. Furthermore, Kuijpers et al. also found an association between catastrophising at baseline and PPR after 6 weeks in patients with SCs. A possible explanation for the absence of a relation in our analysis may have been the dichotomous nature of the outcome measure making it difficult to detect a relation between catastrophising and patientperceived recovery.

The relation between catastrophising and functional limitations at baseline and the absence of a relation with patient-perceived recovery raises some

13 Based on the Wald statistic

14 This variable has the code 1 for 6 weeks and 0 otherwise

15 This variable has the code 1 for 26 weeks and 0 otherwise 
questions. Why does the EAP have no effect on functional limitations, even though one of its aims is to change catastrophising cognitions? On the other hand, the absence of a relation with patient-perceived recovery raises the question whether it is worthwhile to intervene on catastrophising cognitions if no relation is found between the two although it is also possible that the absence of such a relation can be attributed to the dichotomous nature of the outcome measure.

At the start of this study, little was known about the specific effect of psychosocial determinants in SCs, although interventions aiming to modify these determinants, such as cognitive behavioural programs were considered to be promising for musculoskeletal pain in general [4-8]. We developed the EAP to fill a gap in UC, which focuses mainly on biomedical determinants. The EAP uses techniques used in cognitive behavioural therapy that were expected to benefit patients in the early stages of SCs. Furthermore, GPs had to be able to apply these techniques after a brief training whereas cognitive behavioural programs are usually administered by specialized therapists.

The lack of information on specific psychosocial determinants of SCs made us develop a generic intervention addressing several psychosocial determinants, of which catastrophising cognitions is only one. This generic nature of the EAP may be the reason that we found no effect on outcome. Although this study shows that catastrophising at baseline is related to one of the outcome measures, namely functional limitations, catastrophising cognitions are not the main focus of the EAP. Another reason for the absence of an effect of the EAP may be that other, unknown, determinants are more closely related to SCs. This view is supported by the absence of a relation between catastrophising at baseline and patient-perceived recovery, suggesting that the relation between catastrophising and outcome is not as straightforward as expected.

It should be noted that the relation between catastrophising at baseline and functional limitations was a coincidental finding of this study. Baseline levels of catastrophising were initially entered into the multilevel models to adjust for baseline differences between study groups. A study by van der Windt et al. showed that higher levels of catastrophising in patients with longer symptom duration are significantly associated with persistent symptoms [29].Further study is needed to evaluate the effect of catastrophising in SCs and the possibilities of interventions focusing on catastrophising. 
The significant effect of time on outcome suggests that SCs are likely to improve over time regardless of the intervention. This positive effect of time is found in other studies as well [10, 30-32]. Identifying patients with this favourable natural course in the early stages of SCs appears to be difficult [33]. Otherwise, the effectiveness of any intervention could be improved by focussing on the patients at risk. Further study is needed to identify factors predicting a favourable natural course in the early stages.

Analysis of videotaped consultations showed that not all key features of the EAP were applied by the trained GPS [34]. Furthermore, GPs administering UC were already including some key features exclusively attributed to the EAP in their UC. This may have reduced the contrast between the treatment groups.

Ours appears to be the first study addressing psychosocial determinants in patients with acute and sub-acute SCs in general practice. A recent study evaluating a similar intervention in patients with low back pain in general practice also found no effect [35].

Outcome measures were collected using self reported questionnaires. Both patient perceived recovery and functional limitations may thus be influenced by the state of mind of the patient reporting the outcome. From this point of view, outcome measures reflect the patient's subjective perspective whereas an objective measure would be unbiased by the patient's state of mind. We preferred a subjective outcome over an objective outcome as we wanted to evaluate the effectiveness of the intervention from the patient's perspective.

The effect of the EAP on total costs related to SCs is evaluated using bootstrap analysis [36]. This analysis showed that the EAP is more effective but at higher costs. Furuthermore, healthcare utilisation showed no difference between the study groups. It should be noted that a bootstrap analysis is specifically designed to evaluate the cost-effectiveness of an intervention. The multilevel analysis presented in this paper is able to determine the isolated effect of the EAP.

Recruitment by GPs fell short of our expectations. Therefore we opted for an alternative strategy using advertisements. This introduces the risk of selection bias. However, a comparison of baseline values (not presented) showed no differences between the recruitment methods. Even more, entering recruitment method as a variable in the multilevel analysis showed no significant effect of recruitment method on outcome (not presented in this paper). It appeared that GPs recruiting patients were less accurate in checking the inclusion and 
exclusion criteria. This resulted in a higher exclusion rate of patients referred for participation in the trial by GPS.

It may be questioned whether a brief training is sufficient to enable GPs to administer the EAP as prescribed. Our hypothesis was that patients' cognitions and behaviours in the acute and sub-acute stages of the SCs are susceptible to modification. We may have underestimated, however, that cognitions and behaviours by the GPs towards SCs were less susceptible to modification, and that the GPs might require a more intense training to become thoroughly acquainted with the key features of the EAP. This may have affected the quality of the EAP administered by the GPs.

Based on our sample size calculation, we needed 82 patients per treatment group. However, patient recruitment fell short of our expectations. Eventually, 56 patients were included in the EAP group and 52 patients were included in the UC group. This resulted in a reduction of the power of this study. A posthoc power calculation indicated a statistical power of 0.63 , compared to the intended power of 0.80 . This power reduction increases the risk of a 'false negative' finding in this study.

Although complete data was available for $67 \%$ of the patients in the UC group and $79 \%$ of the patients in the EAP group, multilevel analysis made it possible to use all data available of the 52 patients in the UC group and 56 patients in the EAP group. The difference in available complete data between groups may be influenced by the fact that patients were not blinded. It is likely that patients in the UC group were less inclined to complete participation in the study after being allocated to UC.

\section{CONCLUSION}

Multilevel analysis shows that the EAP has no significant effect on the outcome of SCs. A coincidental finding of this study was the relation between catastrophising at baseline and functional limitations. This relation suggests that an intervention focusing specifically on catastrophising may be more successful in reducing functional limitations in the long term. In contrast, the EAP addresses catastrophising as one of several psychosocial determinants of SCs. The effect of an intervention focusing on catastrophising may be improved by selecting patients with elevated levels of catastrophising at 
baseline. Further research is needed to evaluate the effect of catastrophising at baseline on the course of SCs. 


\section{REFERENCES}

1. Linton S: A systematic review of psychological risk factors for back and neck pain. Spine 2000, 25:1148-1156.

2. Turk DC: The role of demographic and psychosocial factors in transition from acute to chronic pain. In 8th World Congress on Pain, Progress in Pain Research and Management. Edited by Jensen TS, Turner JA, Z. W-H. IASP Press; 1997: 185-213.

3. Weiser $S$, Cedraschi $C$ : Psychosocial issues in the prevention of chronic low back pain - a literature review. Bailliere's Clinical Rheumatology 1992, 6:657-684.

4. Linton SJ: Prevention with special reference to chronic musculoskeletal disorders. In Psychosocial Factors in Pain. Edited by Gatchel RJ, Turk DC. New York: Guilford Publications; 1999: 374-389

5. Mitchell RI, Carmen GM: Results of a multicenter trial using an intensive active exercise program for the treatment of acute soft tissue and back injuries. Spine 1990, 15:514-521.

6. Lindstrom I, Ohlund C, Eek C, Wallin L, Peterson LE, Fordyce WE, Nachemson AL: The effect of graded activity on patients with subacute low back pain: a randomized prospective clinical study with an operantconditioning behavioral approach. Phys Ther 1992, 72:279-290; discussion 291-273.

7. Haig AJ, Linton P, Mclntosh M, Moneta L, Mead PB: Aggressive early medical management by a specialist in physical medicine and rehabilitation: effect on lost time due to injuries in hospital employees. $J$ Occup Med 1990, 32:241-244.

8. Malmivaara A, Hakkinen $U$, Aro $T$, Heinrichs $M L$, Koskenniemi $L$, Kuosma E, Lappi S, Paloheimo R, Servo C, Vaaranen V, et al.: The treatment of acute low back pain--bed rest, exercises, or ordinary activity? N Engl J Med 1995, 332:351-355.

9. Winters JC, Jongh ACD, Windt DAWMvd, Jonquiere $M$, Winter AFD, Heijden GJMGvd, Sobel JS, Goudswaard AN: NHG-standaard schouderklachten. Huisarts en Wetenschap 1999, 42:222-231.

10. Windt DAvd, Koes BW, Boeke AJ, Deville W, Jong BAD, Bouter LM: Shoulder disorders in general practice: prognostic indicators of outcome. Br J Gen Pract 1996, 46:519-523. 
11. Wit Rd, Dam Fv, Litjens M, H. HA-S: Assessment of pain cognitions in cancer patients with chronic pain. Journal of Pain and Symptom Management 2001, 22:911-924.

12. Fordyce WE: Behavioral methods for chronic pain and illness. Saint Louis: C. V. Mosby Company; 1976.

13. Bruijn CD, de Bie R, Geraets J, Goossens M, Koke A, van den Heuvel W, van der Heijden G, Dinant GJ: Evaluation of an education and activation programme to prevent chronic shoulder complaints: design of an RCT [ISRCTN71777817]. BMC Fam Pract 2005, 6:7.

14. Prout H, Butler C, Kinnersley P, Robling M, Hood K, Tudor-Jones R: A qualitative evaluation of implementing a randomized controlled trial in general practice. Fam Pract 2003, 20:675-681.

15. Heijden GJMGvd, Leffers P, Bouter LM: Development and responsiveness of the shoulder disability questionnaire. Journal of Clinical Epidemiology 1999.

16. Terluin B, van Marwijk HW, Ader HJ, de Vet HC, Penninx BW, Hermens ML, van Boeijen CA, van Balkom AJ, van der Klink JJ, Stalman WA: The four-dimensional symptom questionnaire (4DSQ): a validation study of a multidimensional self-report questionnaire to assess distress, depression, anxiety and somatization. BMC Psychiatry 2006, 6:34.

17. Terluin B: De vierdimensionale klachtenlijst (4DKL) in de huisartspraktijk. De Psycholoog 1998:18-24.

18. Berg SS-vd, Vlaeyen J, Kuile Mt, Spinhoven P, Breukelen Gv, KoleSnijders A: Pijn coping en cognitie lijst. 1999.

19. Rasbash J, Browne W, Goldstein H, Yang M, Plewis I, Healy M, Woodhouse G, Draper D, Langford I, Lewis T: A user's guide to MLwiN (Second Edition). London: Institute of Education University of London; 2000.

20. Rasbash J, Browne W, Healy M, Cameron B, Charlton C: MLwiN. 1.10.0007 edition. London: Multilevel Models Project Institute of Education; 2001.

21. Chaves JF, Brown JM: Spontaneous cognitive strategies for the control of clinical pain and stress. J Behav Med 1987, 10:263-276. 
22. Geisser ME, Robinson ME, Keefe FJ, Weiner ML: Catastrophizing, depression and the sensory, affective and evaluative aspects of chronic pain. Pain 1994, 59:79-83.

23. Sullivan MJL, Bishop SR, Pivik J: The pain catastrophizing scale: development and validation. Psychol Assess 1995, 7:524-532.

24. Crombez G, Vlaeyen JWS, Heuts PHTG, Lysens R: Pain-related fear is more disabling than pain itself: evidence on the role of pain-related fear in chronic back pain disability. Pain 1999, 80:329-339.

25. Crombez G, Vervaet L, Lysens R, Baeyens F, Eelen P: Avoidance and confrontation of painful, back-straining movements in chronic back pain patients. Behav Modif 1998, 22:62-77.

26. Main CJ, Waddell G: A comparison of cognitive measures in low back pain: statistical structure and clinical validity at initial assessment. Pain 1991, 46:287-298.

27. Vlaeyen JWS, Seelen HAM, Peters M, Jong Pd, Aretz E, Beisiegel E, Weber WEJ: Fear of movement/(re)injury and muscular reactivity in chronic low back pain patients: an experimental investigation. Pain 1999, 82:297-304.

28. Vlaeyen JWS, Kole-Snijders AMJ, Boeren RGB, Eek Hv: Fear of movement/(re)injury in chronic low back pain and its relation to behavioral performance. Pain 1995, 62:363-372.

29. van der Windt DA, Kuijpers $T$, Jellema $P$, van der Heijden GJ, Bouter LM: Do psychological factors predict outcome in both low back pain and shoulder pain? Ann Rheum Dis 2006.

30. Winters JC, Jorritsma W, Groenier $\mathrm{KH}$, Sobel JS, Jong BM-d, Arendzen $\mathrm{HJ}$ : Treatment of shoulder complaints in general practice: long term results of a randomised, single blind study comparing physiotherapy, manipulation, and corticosteroid injection. British Medical Journal 1999, 318:1395-1396.

31. Geraets JJ, Goossens ME, de Groot IJ, de Bruijn CP, de Bie RA, Dinant GJ, van der Heijden G, van den Heuvel WJ: Effectiveness of a graded exercise therapy program for patients with chronic shoulder complaints. Aust J Physiother 2005, 51:87-94.

32. Kuijpers $T$, van der Windt DA, van der Heijden GJ, Bouter LM: Systematic review of prognostic cohort studies on shoulder disorders. Pain 2004, 109:420-431. 
33. Kuijpers $T$, van der Windt DA, Boeke AJ, Twisk JW, Vergouwe $Y$, Bouter LM, van der Heijden GJ: Clinical prediction rules for the prognosis of shoulder pain in general practice. Pain 2006, 120:276285.

34. De Bruijn C, de Bie R, Geraets J, Goossens M, Koke A, van den Heuvel W, Dinant GJ: General practitioners apply the usual care for shoulder complaints better than expected--analysis of videotaped consultations. BMC Fam Pract 2007, 8:13.

35. Jellema $P$, van der Windt DA, van der Horst HE, Twisk JW, Stalman WA, Bouter LM: Should treatment of (sub)acute low back pain be aimed at psychosocial prognostic factors? Cluster randomised clinical trial in general practice. Bmj 2005, 331:84.

36. De Bruijn C, Goossens M, de Bie R, Ament A, Geraets J, Dinant GJ: Cost-effectiveness of an education and activation program for patients with acute and subacute shoulder complaints compared to usual care. Int J Technol Assess Health Care 2007, 23:80-88. 


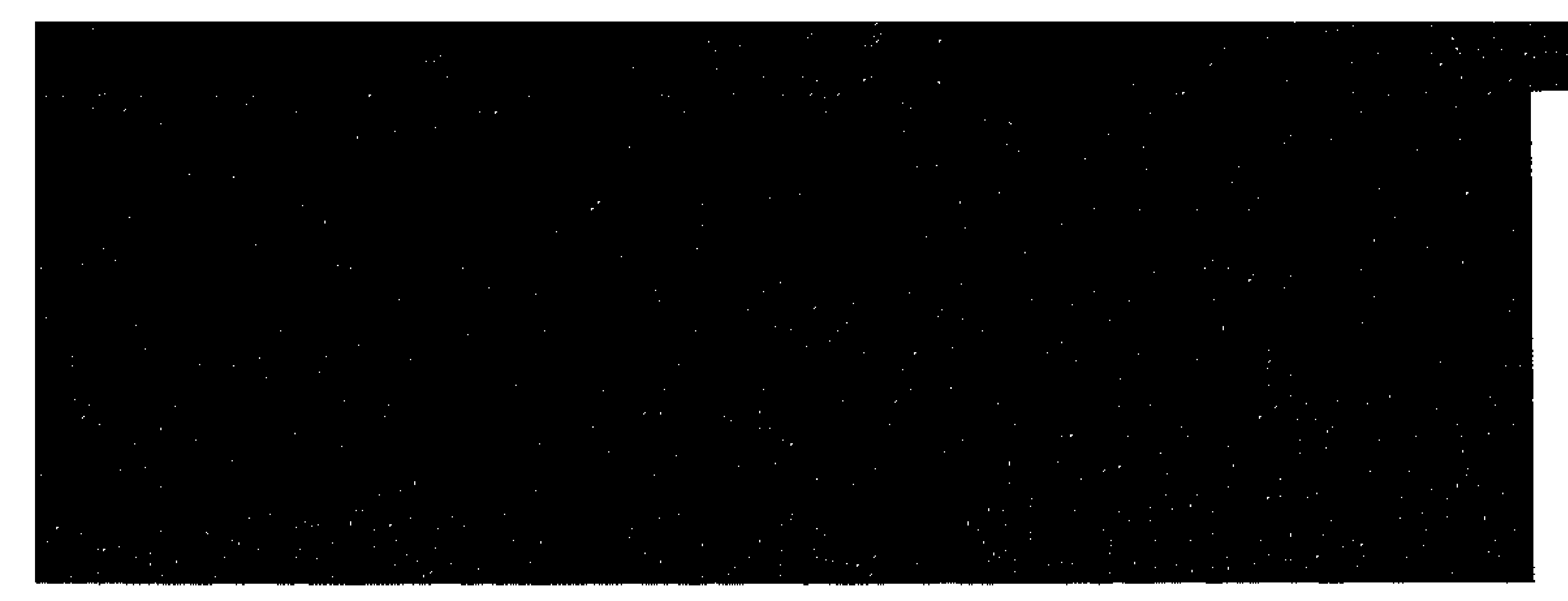

\section{Cost-effectiveness of the intervention}

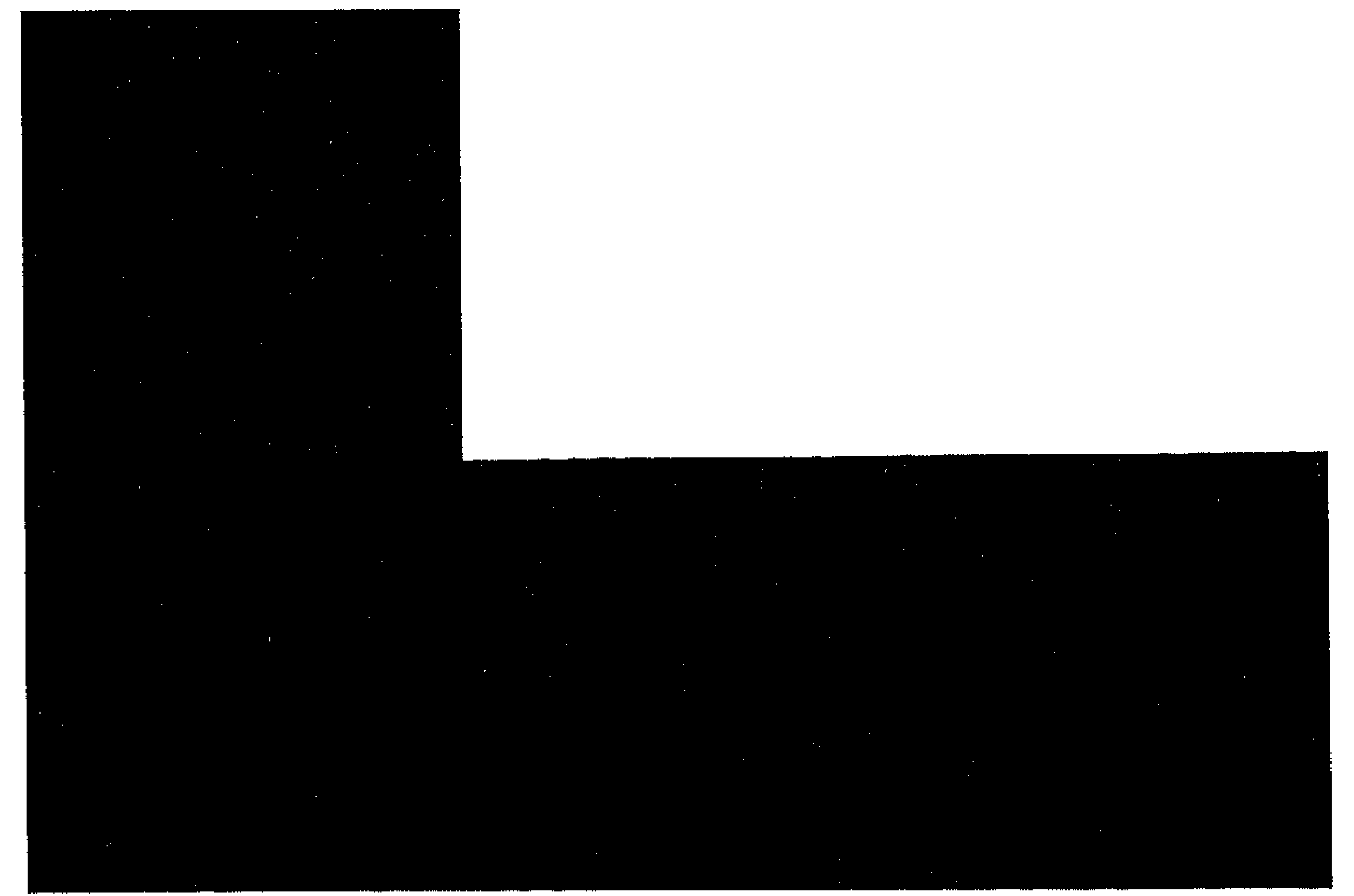

\section{Published as:}

De Bruijn C, Goossens M, De Bie RA, Ament A, Geraets J, Dinant GJ. Costeffectiveness of an education and activation program for patients with acute and subacute shoulder complaints compared to usual care. International Journal of Technology Assessment in Health Care 2007;23:1-9 


\section{ABSTRACT}

Objectives: Shoulder complaints (SCs) constitute the second largest group of musculoskeletal disorders after low back pain. The economic burden in terms of costs of healthcare use and costs due to work absenteeism underlines the need for a cost-effectiveness analysis of the interventions involved. The education and activation program (EAP) is a newly developed early intervention to prevent the development of chronic SCs. A cost-effectiveness analysis should provide more information on the effect of an EAP on total costs related to SCs.

Methods: We conducted a cost-effectiveness analysis alongside a randomized clinical trial comparing the effectiveness of the EAP in addition to usual care (EAP group) with that of usual care alone (UC group) in terms of preventing chronicity in patients with acute SCs. The aim of the cost-effectiveness analysis was to compare the observed difference in costs with the clinical effectiveness (i.e., patient-perceived recovery after 26 weeks), using bootstraps.

Results: The comparison of total costs between treatment groups showed no significant ( $p=.077$ ) difference after 26 weeks. The majority (82 percent) of the cost-effect pairs after bootstrap analysis were located in the northeast quadrant, suggesting more effect but at higher costs.

Conclusions: In view of the clinical relevance of the clinical outcomes and the considerable costs needed to achieve this, it can be concluded that the EAP is currently not cost-effective. 


\section{BACKGROUND}

Shoulder complaints (SCs) constitute the second largest group of musculoskeletal disorders after low back pain (19). Musculoskeletal disorders in general account for the second largest share in healthcare costs in the Netherlands (16). Additionally, Swedish insurance data show that, in 1994, approximately 18 percent of total paid sick leave for musculoskeletal disorders were related to neck-shoulder problems [17]. Hence, the economic burden in terms of costs of healthcare use and costs due to work absenteeism underlines the need for a cost-effectiveness analysis of the interventions involved.

SCs are characterized by pain in the area between the base of the neck and the elbow, at rest or when elicited by movement of the upper arm. The selfreported point prevalence of shoulder pain in the Netherlands is 20.9 percent [19]. Approximately half of the newly presented episodes in general practice are reported to last at least 6 months, and 40 percent of the newly presented episodes result in disability in terms of activities of daily living after 1 year [21]. The minority (less than 25 percent) of the patients in whom low back pain develops into a chronic condition generate more than 80 percent of the total costs $[11 ; 24]$. In view of this finding, preventing a chronic condition in the early stages may be an efficient cost-reducing tool. Because approximately half of the newly presented episodes of SCs also develop into a chronic condition lasting more than 6 months, it is likely that costs of SCs are not normally distributed either, with a minority of the patients generating a majority of the total costs. Hence, an early intervention preventing chronic SCs may reduce total costs related to SCs by reducing costs generated in the chronic stage of SCs by a minority of patients.

The education and activation program (EAP) is a newly developed early intervention to prevent the development of chronic SCs. The EAP aims to prevent the development of inadequate cognitions and maladaptive behaviors known to play a role in the persistence of musculoskeletal disorders [15;20;25]. Trained general practitioners (GPs) administer the EAP in addition to usual care (UC).

A successful EAP should reduce the proportion of patients with chronic SCs reporting not to be recovered after 26 weeks. Even a small reduction in this proportion should result in a reduction of total costs, especially because 
patients with chronic SCs are likely to generate the majority of the total costs related to SCs.

A cost-effectiveness analysis should provide more information on the effect of an EAP on total costs related to SCs. We conducted a cost-effectiveness analysis alongside a randomized clinical trial comparing the effectiveness of the EAP in addition to usual care (EAP group) with that of usual care alone (UC group) in terms of preventing chronicity in patients with acute SCs.

The aim of the cost-effectiveness analysis described in this study was to compare the total costs generated over a period of 26 weeks in both study groups. Additionally, the observed difference in costs was related to the clinical effectiveness (patient-perceived recovery after 26 weeks) in the two study groups, using bootstraps.

\section{METHODS}

\section{Study Design}

The design of the randomized clinical trial on which the cost-effectiveness study was based has previously been described in detail [6]. After inclusion in the study, patients with an episode of SCs that had lasted no longer than 3 months were randomly allocated to either the EAP group or the UC group. Before randomization and 26 weeks after randomization, patients were assessed for clinical outcomes.

\section{Patients}

The study population included patients older than 18 years, living in the south of the Netherlands, and suffering from SCs that had lasted up to 3 months. Only newly presented episodes of SCs were considered, that is, patients who had not consulted their general practitioner (GP) in the previous 3 months for SCs and had not been treated for their SCs in the preceding 3 months. Reasons for exclusion were as follows: other episodes of SCs in the 12 months preceding the consultation with the GP, prior fractures and/or surgery of the shoulder, actual or suspected referred pain from internal organs, SCs with a confirmed extrinsic cause, inability to complete a questionnaire independently, and presence of dementia or other severe psychiatric abnormalities. 


\section{Treatments}

Patients in the UC group received usual care (UC) according to the Dutch College of General Practitioners guidelines for SCs (version 1999) [28]. This care consists of a wait-and-see policy during the first 2 weeks with information and advice about shoulder complaints, possibly supplemented with analgesics or nonsteroidal anti-inflammatory drugs. If this approach has little or no effect, up to three corticosteroid injections can be given. Physiotherapy is considered for complaints persisting after 6 weeks or more. If the SCs persist, referral to a hospital-based specialist may be considered.

Patients in the EAP group received UC and an additional EAP. The aim of this program was to prevent the development of inadequate cognitions and maladaptive behaviors by maintaining or inducing proper cognitions and stimulating adequate behavior. Education was used to maintain or induce the proper cognitions (e.g., ideas and expectations about origin, duration, and treatment effects). Adequate behavior was stimulated by means of advice on activities of daily living, using principles of operant conditioning [9]. The program consisted of a minimum of two sessions and a maximum of six followup sessions over a period of 6 weeks. Each session could last up to 20 minutes.

The EAP was administered by specially trained GPs or a specially trained ambulant therapist (Cd.B.) if no trained GP was available in the area where the patient lived. UC was administered by the patient's own GP unless the GP had been trained to provide the EAP. In that case, UC was administered by a colleague of the GP, to avoid contamination of the UC treatment.

\section{Clinical Outcomes}

The clinical effectiveness after 26 weeks was measured using "patientperceived recovery." This combined outcome measure considers patients to be recovered when they either report to be "much improved" or "very much improved" on a 7-point scale or they report to be cured on a dichotomous question ("Are you fully recovered from your shoulder complaints?" Yes/no.) [21]. The EQ-5D was used to rate generic health-related quality of life for the cost-effectiveness analysis [5]. Data recorded at baseline included demographic variables and specific disease variables such as pain intensity (10-point visual analogue scale), onset (quick or slow), affected shoulder, and prior episodes of SCs lasting at least 1 week. 


\section{Costs}

Cost data were collected from a societal perspective, using a cost diary assessing direct healthcare costs and direct non-health-related costs [12]. The diary was presented in a booklet form covering a period up to 6 weeks. Patients were asked to complete four cost diaries prospectively in four periods, lasting a total of up to 24 weeks after inclusion in the study. Cost data of the final cost diary were extrapolated to calculate the costs of the last 2 weeks to report costs over a period of 26 weeks ( 6 months) and be consistent with the clinical outcomes.

Direct healthcare costs included treatment by a GP, physiotherapist, manual therapist, occupational therapist, "Mensendieck" or "Cesar" exercise therapist, or complementary health therapist (e.g., acupuncturist); visits to a consultant in orthopedic surgery, neurology, rheumatology, or rehabilitation medicine; professional home care; prescribed medication; and hospitalization. Direct nonhealthcare costs included costs of paid and unpaid help, purchased aids, and over-the-counter medications.

The costs of direct healthcare utilization were calculated by multiplying the number of visits with the rates presented in table 1 [18]. The additional direct healthcare costs of prescribed medication were based on the rates used by the Dutch Health Care Insurance Board [23].

The costs of direct non-healthcare utilization were calculated by multiplying the hours of home care, home help, or help from partner/relatives/friends with the rates presented in table 1 [18]. The additional direct non-healthcare costs of over-the-counter medication were based on the prices used by the Health Care Insurance Board [23].

Indirect costs refer to the value of the production lost due to SCs-related absence from paid and unpaid work. Indirect costs for paid work were calculated using the friction cost method (with a friction period of 154 days) [13]. For unpaid work, such as housework, costs were estimated at a shadow price of $€ 8.30$ [18]. 


\begin{tabular}{lr}
\hline Costs & Cost $(€)$ \\
\hline Direct healthcare costs per contact & \\
\hline General practitioner [19] & 20.20 \\
\hline Physiotherapist [19] & 22.75 \\
\hline Manual therapist [19] & 32.20 \\
\hline Exercise therapist [19] & 23.00 \\
- Mensendieck or Cesar & \\
- Occupational therapist & 56.00 \\
\hline Specialist & \\
- Orthopedist & \\
- Neurologist & \\
- Rheumatologist & \\
- Rehabilitation physician & 20.00 \\
\hline Acupuncturist & 26.70 \\
\hline Osteopath & 12.70 \\
\hline Direct non-healthcare costs per hour & 8.30 \\
\hline Home care [19] & \\
\hline Home help [19] & \\
\hline Help from partner/relatives/friends [19] & \\
\hline
\end{tabular}

Table 1: Costs applied in the economic evaluation of treatments for patients with shoulder complaints

The costs of the EAP are part of the direct healthcare costs. The calculation of the costs of the EAP used only the frequency and duration of the consultations by the ambulant therapist, because no data were available for the GPs providing the EAP.

Costs of the individual EAP administered by the ambulant therapist are based on the total duration of the program, where 10 minutes equal a regular consultation in general practice at a rate of $€ 20.20$. Costs of treatments administered by the trained GPs are based on the mean treatment duration of the EAP administered by the ambulant therapist at a rate of $€ 20.20$ per 10 minutes. 


\section{Analyses}

Clinical outcome measures were analyzed according to the intention-to-treat principle. Between-group changes since baseline of continuous outcome variables were analyzed using an independent samples $t$-test for changes since baseline. The Chi-squared test was used for categorical outcome variables. Additional analysis was conducted on imputed data. The "last observation carried forward" method was used to impute missing values in clinical outcomes.

The primary cost-effectiveness analysis was performed on imputed cost data. Missing cost data were replaced using last value carried forward imputation for individual cost data. Cost data for patients who returned less than one cost diary and patients for whom the first cost diary was missing were excluded from the analysis. Because we expected the majority of the costs to be incurred during the first cost period, missing the first cost diary would result in bias, and imputation using last value carried forward was not possible for this cost diary.

Because cost data per patient are typically highly skewed, we used bootstrap estimation to derive a 95 percent confidence interval for the mean difference in total costs due to SCs and the mean difference in clinical effectiveness between the groups [3;8]. Bootstrap estimation is based on random sampling ( 1,000 replications) with replacement of several of the patients in the trial, using the original data [4].

The incremental cost-effectiveness ratios (ICER), calculated by dividing the difference in direct costs for the two treatment groups by the difference in effect between the two groups, were calculated for each bootstrap replicate [7]. The bootstrapped cost-effect pairs were graphically represented on a costeffectiveness plane [2]. Acceptability curves show the probability that a treatment is cost-effective at a specific ceiling ratio [22].

We performed a sensitivity analysis on total costs, excluding the indirect costs, to evaluate the effect of these indirect costs on the cost-effectiveness. Furthermore, a sensitivity analysis was applied to patients who completed all cost diaries. 


\section{RESULTS}

\section{Patients}

In the randomized clinical trial, fifty-two patients were allocated at random to the UC group and fifty-six to the EAP group. Returning less than one cost diary and/or not returning the first cost diary resulted in the exclusion from the cost analysis of fifteen patients in the UC group and thirteen patients in the EAP group. Imputed cost data were available for thirty-seven patients in the UC group and forty-three patients in the EAP group. Baseline characteristics of patients included in the cost analysis were not significantly different between treatment groups (table 2), and baseline characteristics of patients excluded from the cost analysis were not significantly different from those of patients included in the cost analysis (not presented).

\begin{tabular}{lrrr}
\hline & UC group & EAP group & $p$ value \\
\hline Number & 37 & 43 & \\
\hline Demographic variables & & & \\
\hline - Age (years) (SD) & $48.7(11.6)$ & $48.5(17.0)$ & .969 \\
\hline - Gender o (\%) & 30 & 42 & .260 \\
\hline - Paid work (\%) & 57 & 71 & .174 \\
\hline Specific disease variables & & & \\
\hline - Pain intensity T0 (mean + SD) & $5.0(2.4)$ & $5.1(2.3)$ & .856 \\
\hline - Onset (quick) (\%) & 46 & 50 & .719 \\
\hline - Affected shoulder (left/right/both) (\%) & $46 / 49 / 5$ & $34 / 63 / 3$ & .391 \\
\hline - Prior episodes of SCs lasting at least 1 week (\%) & 43 & 52 & .410 \\
\hline Outcome variables & & & \\
\hline - EQ-5D (mean + SD) & $.72(.17)$ & $.71(.16)$ & .775 \\
\hline
\end{tabular}

Table 2: Baseline characteristics

\section{Cost Diaries}

Complete cost data were available for twenty-seven (52 percent) patients in the UC group and thirty-two (57 percent) patients in the EAP group. Overall, 326 of 432 (75 percent) cost diaries were completed and returned. 


\section{Clinical Outcomes}

The comparison of patient-perceived recovery between treatment groups showed no significant difference for patients for whom complete cost data were available (table 3). Nor was there a significant difference in patient-perceived recovery between the treatment groups for patients for whom imputed cost data were available. Similar results were found for changes in the EQ-5D score (table 4). Mean changes in EQ-5D were very small in both treatment groups, suggesting that the EQ-5D is not sensitive enough to detect changes in generic health-related quality of life in this population.

\begin{tabular}{lccccr}
\hline Patient perceived recovery & & & & \\
\hline & UC & & EAP & \\
\hline & $N$ & Yes & $N$ & Yes & Pearson Chi-square \\
& & $(\%)$ & & $(\%)$ & $p$ value \\
\hline Complete cost data available & 27 & 56 & 32 & 66 & .429 \\
\hline Imputed cost data available & 37 & 58 & 43 & 69 & .325 \\
\hline
\end{tabular}

Table 3. Patient-perceived recovery after 26 weeks

\begin{tabular}{|c|c|c|c|c|c|c|c|c|c|}
\hline \multicolumn{10}{|l|}{$E Q-5 D$} \\
\hline & \multicolumn{3}{|c|}{$\overline{U C}$} & \multicolumn{3}{|c|}{ EAP } & \multicolumn{3}{|c|}{ Differences between groups } \\
\hline & $N$ & Mean & $\overline{S D}$ & $N$ & Mean & SD & $\begin{array}{l}\text { Mean } \\
\text { difference }\end{array}$ & $95 \% \mathrm{Cl}$ & $\begin{array}{l}p \\
\text { value }\end{array}$ \\
\hline $\begin{array}{l}\text { Complete } \\
\text { cost data } \\
\text { available }\end{array}$ & 27 & .092 & .25 & 32 & .062 & .32 & .031 & $\begin{array}{c}-.12- \\
.18\end{array}$ & .689 \\
\hline $\begin{array}{l}\text { Imputed } \\
\text { cost data } \\
\text { available }\end{array}$ & 37 & .083 & .26 & 43 & .074 & .28 & .009 & $\begin{array}{c}-.12- \\
.13\end{array}$ & .881 \\
\hline
\end{tabular}

Table 4. Mean change in EQ-5D per treatment group after 26 weeks, compared to baseline 


\section{Costs}

\section{EAP Costs}

EAP administered by the ambulant therapist consisted of an average of 2.0 visits $(S D=.8)$ and .7 consultations by phone $(S D=.7)$. The average time invested in a patient (both visits and consultations by phone) was 55 minutes $(S D=31)$. The ambulant therapist administered the EAP to thirty-three patients, of whom twenty-five were included in the cost analysis. Mean costs per person of the EAP administered by the ambulant therapist were $€ 111$ (SD $=63$ ). These costs were also used to calculate the costs of the EAP administered by the trained GPs.

\section{Direct Healthcare and Direct Non-healthcare Costs}

The volumes per treatment group for the various categories of direct healthcare and non-healthcare utilization after imputation are shown in table 5. The volumes were comparable for the two treatment groups, and there were no statistically significant differences between the groups. Use of home care or home help was reported in neither of the study groups.

\begin{tabular}{lrrr}
\hline Type of utilization & $\begin{array}{r}\text { UC group } \\
(n=37)\end{array}$ & $\begin{array}{r}\text { EAP group } \\
(n=43)\end{array}$ & $\begin{array}{r}p \\
\text { value }^{16}\end{array}$ \\
\hline Direct health care & & & \\
\hline General practitioner (no. of visits) & $1.1(1.4)$ & $1.4(1.6)$ & .344 \\
\hline Physiotherapist (no. of visits) & $6.2(9.2)$ & $3.9(8.7)$ & .252 \\
\hline $\begin{array}{l}\text { Exercise therapist (Mensendieck, Cesar, } \\
\text { occupational therapist, manual therapist) (no. of visits) }\end{array}$ & $.5(2.4)$ & $.8(3.3)$ & .577 \\
\hline $\begin{array}{l}\text { Specialist (orthopedist, neurologist, } \\
\text { rheumatologist, rehabilitation physician) (no. of visits) }\end{array}$ & $.3(1.0)$ & $.3(.9)$ & .795 \\
\hline Acupuncturist (no. of visits) & $.0(.0)$ & $.4(1.7)$ & .185 \\
\hline Direct non-health care & & & \\
\hline Home care (hours) & $.0(.0)$ & $.0(.0)$ & - \\
\hline Home help (hours) & \multicolumn{1}{c}{$\begin{array}{l}.0(.0) \\
\text { Help from partner/relatives/friends (hours) }\end{array}$} & $.0(.0)$ & - \\
\hline
\end{tabular}

Table 5. Mean (SD) direct healthcare and non-healthcare utilization per patient after imputation and per treatment group, over a 26-week period

${ }^{16}$ Mann-Whitney test 
Mean direct healthcare costs, direct non-healthcare costs, and indirect costs after 26 weeks did not differ significantly between the UC group and the EAP group for complete cases (not presented). Imputation of missing cost data (table 6) also failed to show a significant difference between treatment groups, although the difference in mean total costs came close to the level of significance $(p=.077)$.

\begin{tabular}{lrrrrr}
\hline Costs & $\begin{array}{r}\text { UC group } \\
(n=37)\end{array}$ & $\begin{array}{r}\text { EAP group } \\
(n=43)\end{array}$ & & UC EAP & \\
& Mean & Mean & Mean & $(95 \%$ Cl) & $p$ value \\
& $($ SD $)$ & $($ SD $)$ & difference & & \\
\hline Direct health- & 195 & 260 & -65 & $(-177-48)$ & .254 \\
care costs $(€)$ & $(248)$ & $(255)$ & & & \\
\hline Direct non-health- & 34 & 30 & 5 & $(-36-45)$ & .823 \\
care costs $(€)$ & $(105)$ & $(77)$ & & & \\
\hline Indirect costs $(€)$ & 236 & 1,087 & -851 & $(-1,834-133)$ & .089 \\
& $(843)$ & $(3,079)$ & & & \\
\hline Total costs $(€)$ & 465 & 1,376 & -911 & $(-1,923-101)$ & .077 \\
& $(981)$ & $(3,132)$ & & & \\
\hline
\end{tabular}

Table 6: Mean direct healthcare costs (SD) per treatment group after 26 weeks

\section{Cost-Effectiveness Analysis}

Total costs after imputation were used for further cost-effectiveness analysis. The ICER for the comparison of patient-perceived recovery between UC and EAP was $€ 8,501$. This implies that an investment of $€ 8,501$ is needed for every additional recovered patient in the EAP group, compared with the UC group, after 26 weeks.

Mean ICER after 1,000 bootstrap replications was $€ 7,933$ (95 percent confidence interval [Cl], $€ 675-€ 15,192$ ). The majority (82 percent) of the costeffect pairs for patient-perceived recovery are located in the northeast quadrant of the cost-effectiveness plane, suggesting that EAP is more effective but at higher costs. Sixteen percent of the cost-effect pairs are located in the northwest quadrant, suggesting that the EAP is less effective at higher costs (inferior).

Figure 1 shows the incremental cost-effectiveness acceptability curve for patient-perceived recovery. This curve shows the probability that the EAP is 
cost-effective at a certain cost ceiling ratio. For example, at a cost ceiling ratio of $€ 10,000$, the probability that the EAP is cost-effective is 53 percent. The results of the cost-effectiveness study for the EQ-5D are not presented in this study, because the minimal changes in clinical effectiveness of this outcome variable provide no additional information when analyzed in a costeffectiveness analysis.

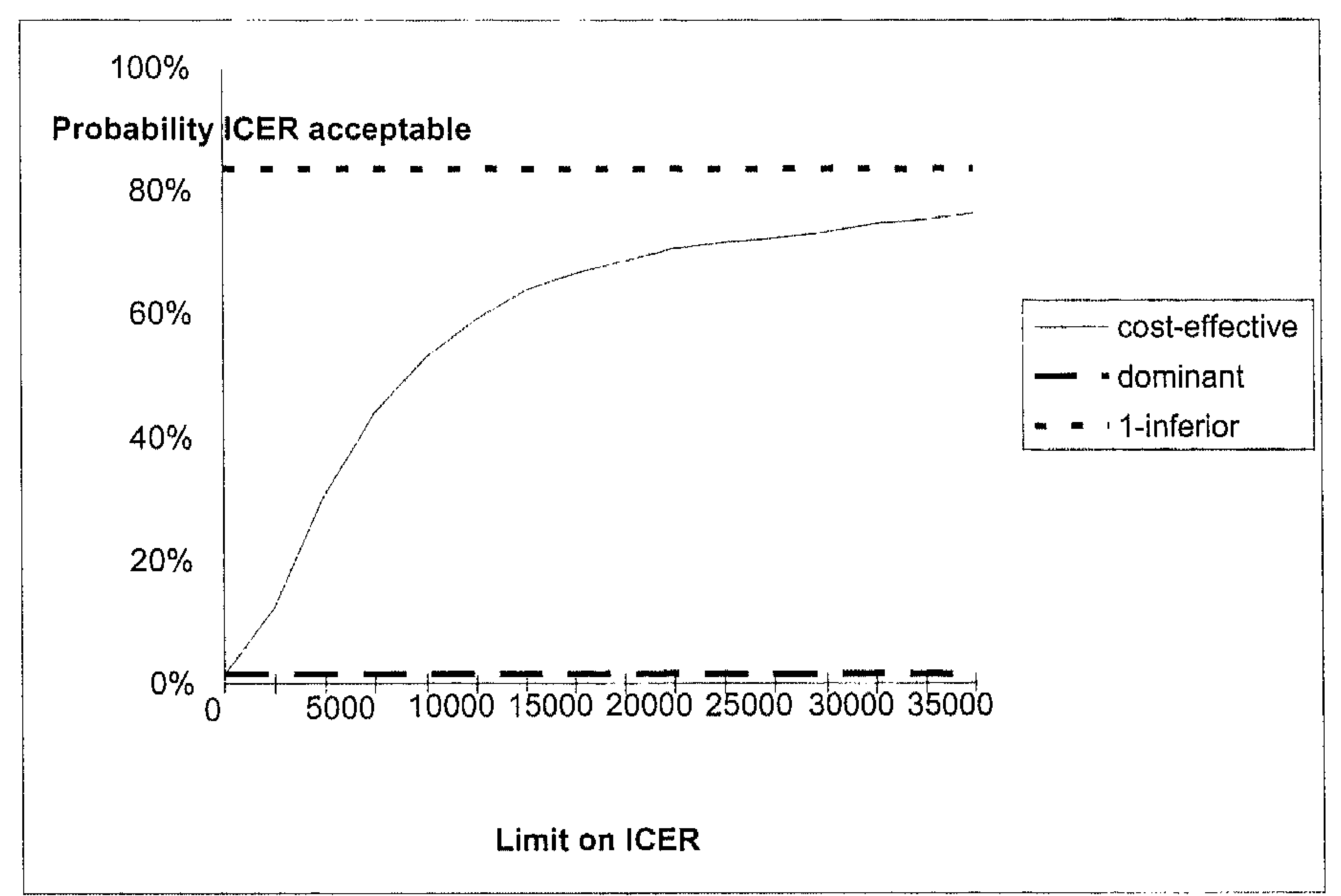

Figure 1: Cost-effectiveness acceptability curve for patient-perceived recovery. ICER, incremental cost-effectiveness ratios.

\section{Sensitivity Analysis}

\section{Indirect Costs}

Indirect costs were strongly influenced by a minority of the patients. Seventy percent of the indirect costs (mainly due to production losses) were generated by three patients in the EAP group, whereas three patients in the UC group generated 83 percent of the indirect costs.

Omitting indirect costs from the bootstrap analysis reduced the mean ICER of patient-perceived recovery to $€ 164$ (95 percent $\mathrm{Cl}, €-201$; $€ 529$ ). The majority of the cost-effect pairs for patient-perceived recovery are located in the northeast quadrant of the cost-effectiveness plane ( 68 percent), and 13 percent of the cost-effect pairs were located in the inferior northwest quadrant. The 
cost-effectiveness acceptability curve without the indirect costs is presented in Figure 2. Without indirect costs, the probability that the EAP is cost-effective was 82 percent at a cost ceiling ratio of $€ 10,000$.

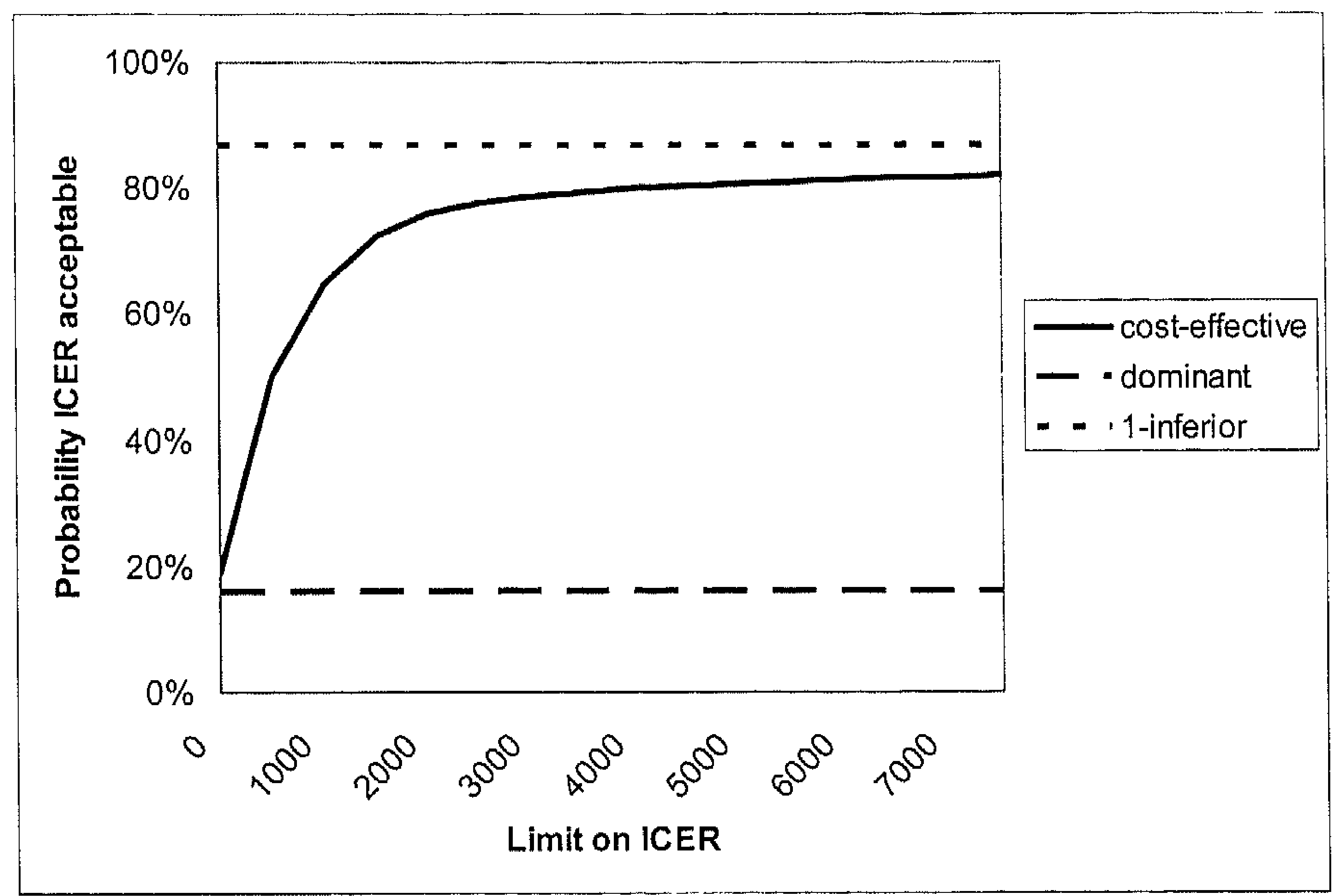

Figure 2: Cost-effectiveness acceptability curve for patient-perceived recovery without indirect costs. ICER, incremental cost-effectiveness ratios.

\section{Complete Cost Diaries}

Bootstrap analysis of cases that completed and returned all cost diaries shows that the majority (76 percent) of the cost-effective pairs are located in the northeast quadrant of the cost-effectiveness plane for total costs. The ICER for patient-perceived recovery increased to $€ 12,517$.

\section{DISCUSSION}

Our comparison of total costs between treatment groups showed no significant difference $(p=.077)$ after 26 weeks, although mean total costs in the EAP group were considerably higher. These higher mean costs are illustrated by an ICER for patient-perceived recovery of $€ 8,501$, suggesting that an additional $€ 8,501$ is needed to help one additional patient in the EAP group recover after 26 weeks. 
The majority ( 82 percent) of the cost-effect pairs after bootstrap analysis are located in the northeast quadrant of the cost-effectiveness plane, suggesting greater effect but at higher costs. The cost-effectiveness acceptability curve shows that considerable investments are needed to increase the probability that the EAP is cost-effective. To achieve a probability of 53 percent that the EAP is cost-effective would require an investment of $€ 10,000$ to help one additional patient in the EAP group recover.

The EAP is an early intervention intended to prevent the development of chronic SCs. Additional costs incurred for all patients with a new episode of SCs should be compensated by costs avoided in the future by patients likely to develop chronic SCs at baseline. In this study, however, the future was restricted to a period of 26 weeks. Avoided costs after this period are not known from the literature or recorded in this study. Although our conclusions are based on a period of 26 weeks, it should be noted that accounting for the costs avoided after this period might have altered the conclusions.

Bergman et al. [1] calculated an ICER for patient-perceived recovery of $€ 19,773$ for every additional recovered patient treated with manipulative therapy as an add-on to usual care, compared with usual care only. In this perspective, the mean ICER of $€ 7933$ we found after bootstrap analysis is fairly low. No other data on cost-effectiveness in relation the patient perceived recovery were found in the literature.

We believe, however, that final conclusions on the cost-effectiveness of the EAP should be based on common sense rather than comparison with other studies, especially because the outcome measure chosen in this study has rarely been used in cost-effectiveness studies and the literature offers few opportunities for comparison. Additional costs of $€ 10,000$ to achieve a probability of 53 percent that the EAP is cost-effective are simply too high for such a low probability. Furthermore, these additional costs are needed to help only one additional patient in the EAP group recover. This is, however, not a clinically relevant improvement. Achieving a clinically relevant improvement, which was defined in the randomized clinical trial that this cost-effectiveness study accompanied as a number needed to treat (NNT) of 4.5 , would require an even greater investment [6]. Clinical outcomes (table 3) show even more clearly that this clinical effectiveness was not achieved in the present study (NNT = 9). Based on this, we consider EAP not to be cost-effective when compared with usual care. 
The EQ-5D does not seem to be sensitive enough to detect changes in generic health-related quality of life in patients with SCs. Other studies using the EQ$5 \mathrm{D}$ for patients with SCs have found similar results $[1 ; 10]$.

Not all cost diaries were completed and returned. With an overall return rate of 75 percent, imputation was needed to complete cost diaries lost to follow-up. The problem of loss to follow-up of cost diaries is well-known and imputation is considered to be feasible and valid [12]. Missing values were imputed using the "last observation carried forward" method. This strategy may have caused a slight overestimation of the costs, because it can be expected that costs fall over time as patients improve. This effect is delayed by the "last observation carried forward" method.

Mean indirect costs (due to work absenteeism) were higher in the EAP group, but these costs were strongly influenced in both study groups by a minority of the patients. The sensitivity analysis showed that omitting these costs from the bootstrap analysis reduced the mean ICER to only $€ 164$. The probability that the EAP is cost-effective at a cost ceiling ratio of $€ 10,000$ thereby increased to 82 percent. This sensitivity analysis shows the drastic impact of indirect costs on the results of the cost-effectiveness analysis. We believe, however, that omitting indirect costs from the cost-effective analysis results in an incomplete view of the costs related to SCs. This study shows that indirect costs are likely to exceed total costs in conditions with relatively low direct costs and in conditions with a high proportion of patients not engaged in paid work.

Patients were included in this study regardless of their risk status at baseline. The reason for this approach was the absence of a valid prediction instrument at the start of this study. Selecting patients with an elevated risk of developing chronic SCs may improve the clinical effectiveness and cost-effectiveness of the EAP. Additional costs of the EAP at the start of a new episode of SCs would only be incurred for patients most likely to generate costs in the future without the EAP. A recent study shows, however, that it remains difficult to predict the long-term outcome of SCs in general practice [14].

The quality of the EAP administration has been studied in another study using video analyses of consultations with standardized patients. This study showed that the quality of EAP administration by the GPs was not as good as expected. Furthermore, the GPs in the UC group also appeared to administer features exclusively attributed to the EAP. This reduced the difference between treatment groups and possibly explains the smaller clinical effectiveness. 


\section{CONCLUSION}

There was no significant difference in mean total costs between the EAP and UC treatment groups. Bootstrap analysis showed that considerable costs are needed to increase the probability that the EAP is cost-effective. Indirect costs strongly affect the outcome of the cost-effectiveness analysis.

In view of the clinical relevance of the outcomes and the considerable costs needed to achieve this, it can be concluded that the EAP is not cost-effective at this moment. Selecting patients with an elevated risk of developing chronic SCs may improve the cost-effectiveness, but no valid prediction instrument is currently available.

\section{POLICY IMPLICATIONS}

Based on the results presented in this study, it should be concluded that the EAP is not ready to be implemented in daily practice. The cost-effectiveness of the EAP may improve when patients with an elevated risk of developing SCs can be detected in the early stages of the SCs. These patients are most likely to benefit from the EAP. Further study is, however, needed to be able to select these patients in the early stages of the SCs and to evaluate the effect of the EAP on this selection of patients. 


\section{REFERENCES}

1. Bergman GJD, Tulder, MW, Winters, JC et al. Economic evaluation. In: Bergman GJD, ed. Manipulative therapy for shoulder complaints in general practice. Amsterdam: Groningen; 2004:63-77.

2. Black WC. The CE plane: A graphic representation of costeffectiveness. Med Decis Making. 1990;10:212-214.

3. Briggs $\mathrm{AH}$, Gray AM. Handling uncertainty when performing economic evaluation of healthcare interventions. Health Technol Assess. 1999;3:1-134.

4. Briggs $A H$, Wonderling $D E$, Mooney $C Z$. Pulling cost-effectiveness analysis up by its bootstraps: A non-parametric approach to confidence interval estimation. Health Econ. 1997;6:327-340.

5. Brooks R. EuroQol: The current state of play. Health Policy. 1996;37:53-72.

6. Bruijn $C D$, de Bie R, Geraets J. Evaluation of an education and activation programme to prevent chronic shoulder complaints: Design of an RCT (ISRCTN71777817). BMC Fam Pract. 2005;6:7.

7. Chaudhary MA, Stearns SC. Estimating confidence intervals for costeffectiveness ratios: an example from a randomized trial. Stat Med. 1996;15:1447-1458.

8. Efron B, Tibshirani RJ. An introduction to the bootstrap. 1993. New York: Chapmann and Hall.

9. Fordyce WE. Behavioral methods for chronic pain and illness. Saint Louis: C.V. Mosby Company; 1976.

10. Geraets JJ, Goossens ME, de Bruijn CP. Cost-effectiveness of a graded exercise therapy program for patients with chronic shoulder complaints. Int J Technol Assess Health Care. 2006;22:76-83.

11. Goossens M, Evers SMAA. Economic evaluation in back pain interventions. J Occup Rehabil. 1997;7:15-32.

12. Goossens ME, Rutten-van Molken MP, Vlaeyen JW, van der Linden SM. The cost diary: A method to measure direct and indirect costs in cost-effectiveness research. J Clin Epidemiol. 2000;53:688-695.

13. Koopmanschap MA, Rutten FF, van Ineveld BM, van Roijen L. The friction cost method for measuring indirect costs of disease. $J$ Health Econ. 1995;14:171-189. 
14. Kuijpers $T$, van der Windt DA, Boeke AJ, et al. Clinical prediction rules for the prognosis of shoulder pain in general practice. Pain. 2006;120:276-285.

15. Linton S. A systematic review of psychological risk factors for back and neck pain. Spine. 2000;25:1148-1156.

16. Meerding WJ, Bonneux L, Polder JJ, Koopmanschap MA, van der Maas PJ. Demographic and epidemiological determinants of healthcare costs in Netherlands: Cost of illness study. BMJ. 1998;317:111-115.

17. Nygren A, Berglund A, von Koch M. Neck-and-shoulder pain, an increasing problem. Strategies for using insurance material to follow trends. Scand J Rehabil Med Suppl. 1995;32:107-112.

18. Oostenbrink JB, Bouwmans CAM, Koopmanschap MA, Rutten FFH. Handleiding voor kostenonderzoek, methoden en standaard kostprijzen voor economische evaluaties in de gezondheidszorg. Amstelveen: College voor zorgverzekeringen; 2004.

19. Picavet HS, Schouten JS. Musculoskeletal pain in the Netherlands: Prevalences, consequences and risk groups, the DMC(3)-study. Pain. 2003;102:167-178.

20. Turk DC. The role of demographic and psychosocial factors in transition from acute to chronic pain. In 8th World Congress on Pain, Progress in Pain Research and Management. Seattle, WA: IASP Press; 1997.

21. van der Windt DA, Koes BW, Boeke AJ, et al. Shoulder disorders in general practice: prognostic indicators of outcome. $\mathrm{Br} \mathrm{J}$ Gen Pract. 1996;46:519-523.

22. van Hout BA, Al MJ, Gordon GS, Rutten FF. Costs, effects and C/Eratios alongside a clinical trial. Health Econ. 1994;3:309-319.

23. van Loenen AC. Farmacotherapeutisch Kompas. Amstelveen: College voor zorgverzekeringen; 2003.

24. Waddell $\mathrm{G}$. The back pain revolution. London: Churchill Livingstone; 1998:103-117; 351-367.

25. Weiser S, Cedraschi C. Psychosocial issues in the prevention of chronic low back pain - A literature review. Baillieres Clin Rheumatol. 1992;6:657-684.

26. Winters JC, De Jongh AC, van der Windt DAWM et al.. NHG-standaard schouderklachten. Huisarts en Wetenschap. 1999;42:222-231. 


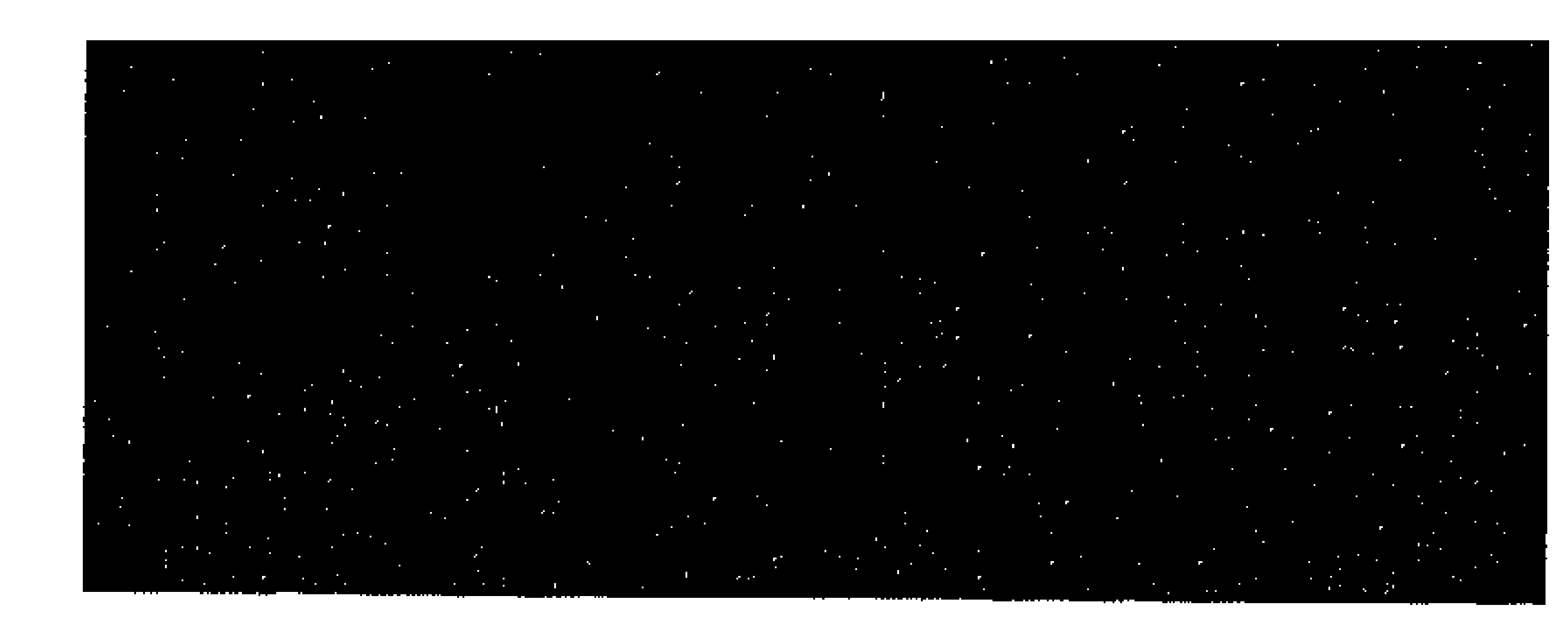

\section{Patient recruitment}

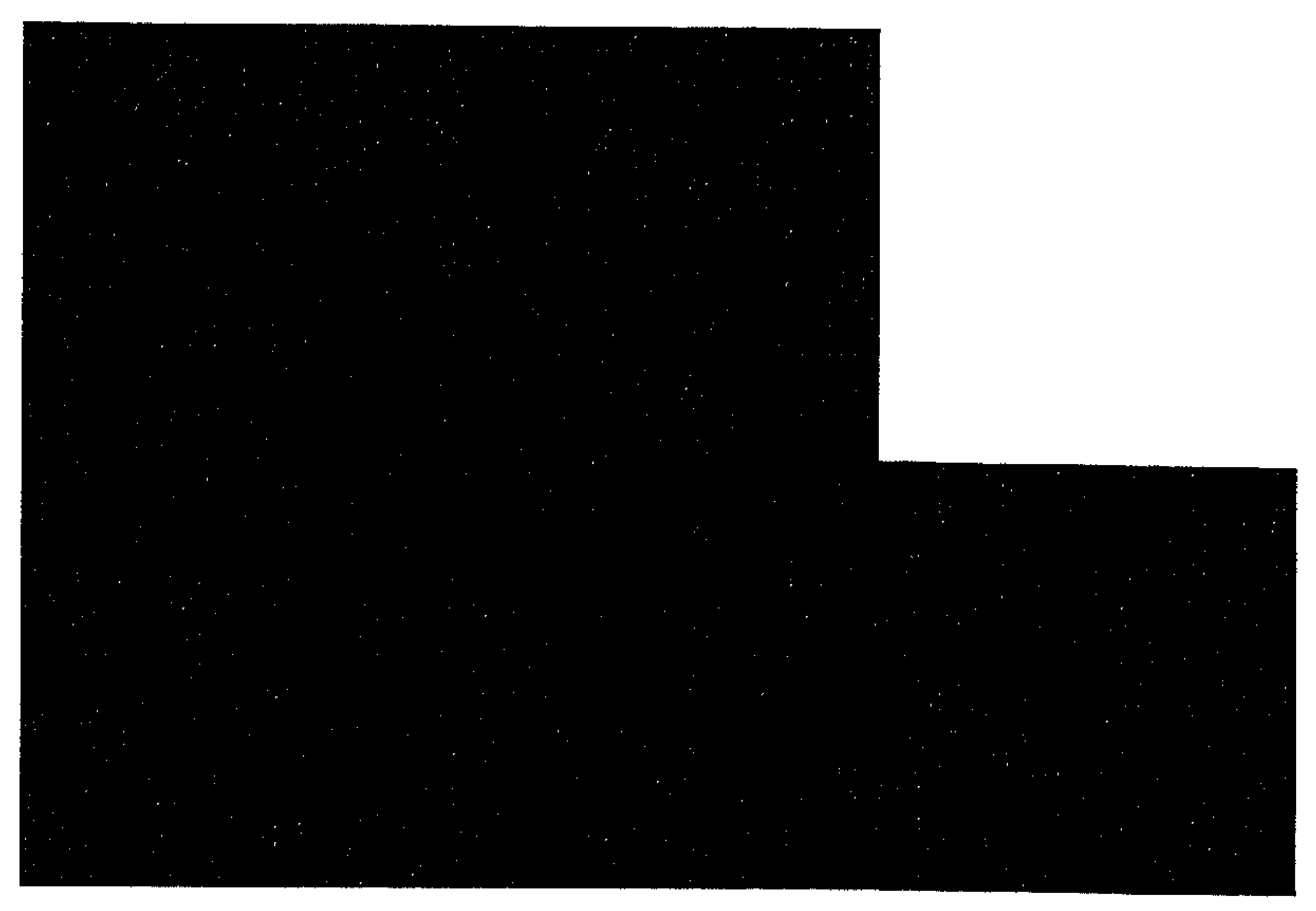

Submitted as:

De Bruijn C, De Bie RA, Geraets J, Goossens M, van den Heuvel W, van der Heijden G, Dinant GJ. Patient recruitment a practical approach and its effect on outcome. Submitted. 


\section{ABSTRACT}

Background: The sample size of a randomised clinical trial (RCT) weighs heavily on the patient recruitment effort needed to successfully complete the trial.

Aim: This paper describes the recruitment strategies used in the so-called EAP trial and evaluates its effect on outcome.

Design of the study: The EAP trial evaluates the effectiveness of the education and activation program (EAP) in combination with usual care (EAP group) compared to usual care alone (UC group) in patients with shoulder complaints.

Setting: Patients were recruited both during regular general practice consultations and through advertisements in local newspapers.

Methods: Multilevel analysis was used to study the effect of recruitment strategy on outcome measured as 'patient perceived recovery' after 26 weeks.

Results: The recruitment strategies used in this RCT have no significant effect on outcome.

Conclusions: Recruiting patients through advertisements is a valid alternative for the recruitment of patients by GPs with no effect on outcome. 


\section{INTRODUCTION}

Embedded in the design of a randomised clinical trial (RCT) is usually a planned sample size needed for sufficient statistical power. This sample size weighs heavily on the patient recruitment effort needed to successfully complete the trial. In confirmation of 'Lasagna's Law', actual recruitment often falls short of expectations, which may threaten the completion of the trial [1]. The literature offers many possible causes of this phenomenon and suggestions for coping with it [2-5].

Patient recruitment in general practice often requires the active participation of general practitioners (GPS). However, it should be noted that a GP's primary objective is to treat patients rather than to recruit patients for research. A wide variety of strategies is available to promote the recruitment of patients by GPs $[4,6,7]$. The choice of strategy to optimise patient recruitment depends on the available time and resources. This paper describes the strategies we used to optimise GP and patient recruitment in an RCT evaluating the effectiveness of an education and activation program (EAP) in patients with shoulder complaints (SCs) in general practice, the so-called EAP trial.

A particular characteristic of the EAP trial was that patients were recruited both during regular GP consultations and through advertisements in local newspapers. This paper describes specifically the effect of the recruitment methods on baseline characteristics and outcome.

\section{METHODS}

\section{The EAP trial}

\section{Background}

With usual care, half of all newly presented shoulder complaints in general practice last for at least six months. To reduce this proportion of persistent SCs, we have developed a new treatment protocol, called EAP, which aims to prevent the development of inadequate cognitions and maladaptive behaviours known to play a role in the persistence of musculoskeletal disorders [8-10]. 


\section{Study design}

The EAP trial is a randomised clinical trial in the Netherlands, evaluating the effectiveness of the EAP in combination with usual care (EAP group) compared to usual care alone (UC group) in patients with SCs that have persisted for less than 12 weeks. The EAP was administered by trained GPs, or by one ambulant therapist if no trained GP was available near the patient's home.

Demographic and specific disease variables were documented at baseline. Process variables documented at baseline were shoulder pain, measured with the Shoulder Pain Score (SPS)[11], functional limitations in activities of daily living, measured with the 16-item Shoulder Disability Questionnaire (SDQ) [12], severity of the main complaint measured with a visual analogue scale, the generic health related quality of life, rated on the EQ-5D [13], and catastrophising and coping with pain, rated on subscales of the Pain Coping and Cognition List [14].

Main outcome was measured as 'patient perceived recovery' 17 after 6 and 26 week, measured on a 7-point ordinal scale ranging from 'very much worsened' to 'very much improved' [15]. Patients were considered recovered when they reported to be 'much improved' or 'very much improved' on this scale. Additionally, patients who, in answer to a dichotomous question ${ }^{18}$, reported to be cured were also considered recovered, since the concept of 'cured' surpasses that of 'very much improved'.

Power calculations indicated that 164 patients were needed to detect a difference in recovery rate of $22 \%$ (alpha $=0.05$ and power $=80 \%$ ), which was assumed to be clinically relevant.

The design of this study has been described in detail elsewhere [16]. The Medical Ethics Committee of the Institute for Rehabilitation Research Hoensbroek, in association with Rehabilitation Foundation Limburg, approved the design of the study. Funding was obtained from the Netherlands Organisation for Scientific Research.

\footnotetext{
${ }^{17}$ Question: What do you think of your shoulder complaints in the past six months?

The complaints have: very much worsened ........ very much improved.

${ }^{18}$ Question: Are you fully recovered from your SCs? Yes/no.
} 


\section{Patients}

Patients older than 18 years, living in the south of the Netherlands and suffering from SCs that had persisted for up to three months (acute) were included. In addition, only newly presented episodes of SCs were considered, that is, patients who had not consulted their GP for SCs in the previous three months and had not been treated for their SCs in the previous three months. Reasons for exclusion were: other episodes of SCs in the 12 months preceding the consultation with the GP, prior fractures and/or surgery of the shoulder, known or suspected referred pain from internal organs, SCs with a confirmed extrinsic cause, inability to complete a questionnaire independently and presence of dementia or other severe psychiatric abnormalities.

\section{Recruitment calculation}

The annual incidence of SCs as seen by GPs in the Netherlands lies between 15 and 25 patients per 1000 registered general practice patients [17]. With an average of 2350 patients enlisted per GP, a GP is expected to be consulted by a minimum of $35((2350 / 1000) * 15)$ patients with SCs per year. Allowing for $75 \%$ of these patients to be excluded due to patient refusal or not meeting the inclusion criteria, 8 patients per general practice centre per year should be eligible for inclusion in the EAP trial. With a recruitment period of 18 months and 15 general practice centres participating in the EAP trial, the intended study population of 164 patients was assumed to be within easy reach.

\section{Recruitment}

\section{Phases in the recruitment process}

Several phases can be distinguished in the recruitment process. The first phase was the recruitment of GPs willing to participate in the EAP trial. The next phase was the recruitment of patients by these GPs. The focus in this phase was on optimising the conditions for the GPs to recruit all eligible patients. Because recruitment by GPs fell short of expectations, patients were simultaneously recruited using advertisements in local newspapers. Obtaining informed consent and willingness to be randomised were also part of the recruitment process.

The following paragraphs elaborate on the various phases in the recruitment process. 


\section{Recruitment of GPs}

GPs were recruited by sending them an initial letter of introduction, followed by a personal phone call to make an appointment in which the design and protocol of the EAP trial were further discussed. The letter of introduction was accompanied by a brief information leaflet on the EAP trial. The information given during the appointment was tailored to the GPs' interests and available time focusing on patient recruitment. Appointments with the GPs were made preferably outside visiting hours, to ensure their undivided attention.

Initially, only GPs with previous expertise in RCTs were contacted by postal mail. If the success rate of this approach proved insufficient, all GPs within a radius of $100 \mathrm{~km}$ from the research centre were to be contacted. To divide the workload of the researcher and to make the best use of each GP's available attention, they were contacted in weekly 'batches' of 25 .

\section{Patient recruitment by GPs}

Since lack of time during the consultation is often mentioned as one of the main barriers to recruiting patients in general practice, the patient recruitment procedure in the consultation room was designed to minimise the time the GP needed [18]. GPs had to point out the existence of the EAP trial to patients with newly presented SCs, check the inclusion and exclusion criteria and forward the patients' personal data by fax to the research centre. The patients had to give written permission to forward their personal data to the research centre. Patients were then contacted within 2 weeks by a research assistant.

An information leaflet was available for the patients, offering further information about the EAP trial. The GPs were advised to refer patients to the research centre for further information about the EAP trial. This minimised the time spent on explaining the EAP trial during consultations.

Several actions were undertaken to optimise patient recruitment by the GPs. General promoting activities comprised monthly newsletters, frequent visits, small gifts and accredited courses. Furthermore, some specific actions were used in individual cases. These mostly related to minor modifications of the recruitment procedure, such as instructing a doctor's assistant how to inform the patient about the EAP trial and how to obtain written permission after a GP had pointed out the existence of the trial. A more radical alteration to the recruitment procedure gave GPs the opportunity to contact patients afterwards 
by letter if they had forgotten to mention the EAP trial during the consultation. For this purpose, the GPs were provided with a standardised letter.

\section{Patient recruitment through advertisements}

An advertisement was placed in local newspapers, calling on patients with SCs to participate in a trial. Patients responding to the advertisement were first screened by telephone for inclusion and exclusion criteria. Patients meeting the inclusion criteria were subsequently visited by a GP who was employed by the EAP trial (referred to below as the EAP-GP). The EAP-GP provided these patients with a regular consultation for SCs, including a complete history check, and checked the inclusion and exclusion criteria again. If patients met all criteria, the EAP-GP informed a research assistant, who contacted the patients within two weeks. The patients were then referred to their own GP for further treatment of the SCs.

The patients' own GPs were informed by the research centre that a patient of theirs had applied for participation in the EAP trial. Furthermore, the GPs were asked if they foresaw any problems with this patient's participating in a trial. The patients had to consent to their GP being contacted to be eligible for participation.

\section{Informed consent and randomisation}

As soon as the personal data of an eligible patient had been sent to the research centre, a research assistant contacted the patient to make an appointment within two weeks. At this appointment, the patient received further information about the EAP trial. The research assistant informed the patient about the randomisation procedure and checked the inclusion and exclusion criteria. If the inclusion criteria were met and the patient had given written informed consent, the patient was randomised. Having a research assistant take care of the informed consent and randomisation procedure reduced the workload of the GPs in the consultation room.

\section{Statistics}

Differences between patients recruited by GPs and patients recruited using advertisements were analysed with an independent samples t-test for continuous baseline characteristics and with the chi-square test for categorical baseline characteristics. 
Patients attending the same GP cannot be assumed to be fully independent. Similarly, different observations for the same patient with SCs cannot be assumed to be independent either. Logistic multilevel analysis was used to address this dependency due to clustering of data and to analyse the effect of recruitment strategy on patient-perceived recovery. Three levels of variance were distinguished: GPs, subjects and measurements.

Time of measuring was represented in the model by two dummy variables for the measurements at 6 and 26 weeks. Catastrophising at baseline was entered in the model as a confounders since it showed a significant difference at baseline between treatment groups ( $p=0.022$; not presented in this paper). Finally, the interaction effect between the treatment group and the time of measuring and the interaction effect between recruitment strategy and the time of measuring were included in the model.

The multilevel analyses resulted in estimates (and standard errors) of the fixed and random effects. Wald chi-square tests were used to determine the statistical significance of the estimates in the logistic multilevel analyses. Estimates that did not reach the required level of significance were excluded from the model in a top-down procedure, except for the group effect and the effect of the recruitment strategy, leaving out the least significant estimates first. Estimates were converted to odds ratios (ORs) with their $95 \%$ confidence intervals (Cls). Multilevel analyses were performed with MLwiN (version 1.10) $[19,20]$.

\section{RESULTS}

\section{Recruitment of GPs}

Before the patient recruitment started, 220 GPs with previous expertise in RCTs were contacted. As patient recruitment failed to meet our expectations 6 months after it had started, an additional 140 GPs with previous expertise were contacted. Eventually, 360 experienced GPs were contacted by letter and by telephone, of whom 23 agreed to make an appointment and 18 (5\%) actually participated in the trial.

Since patient recruitment continued to fall short of expectations 12 months after the start of the trial, we also contacted GPs who were less experienced in RCT participation and who were located within a radius of $100 \mathrm{~km}$ from the research centre. Over a period of 8 months, 120 GPs were additionally contacted. This 
resulted in a further 11 GPs participating in the EAP trial. The various efforts undertaken for the recruitment of GPs are presented in Figure 1.

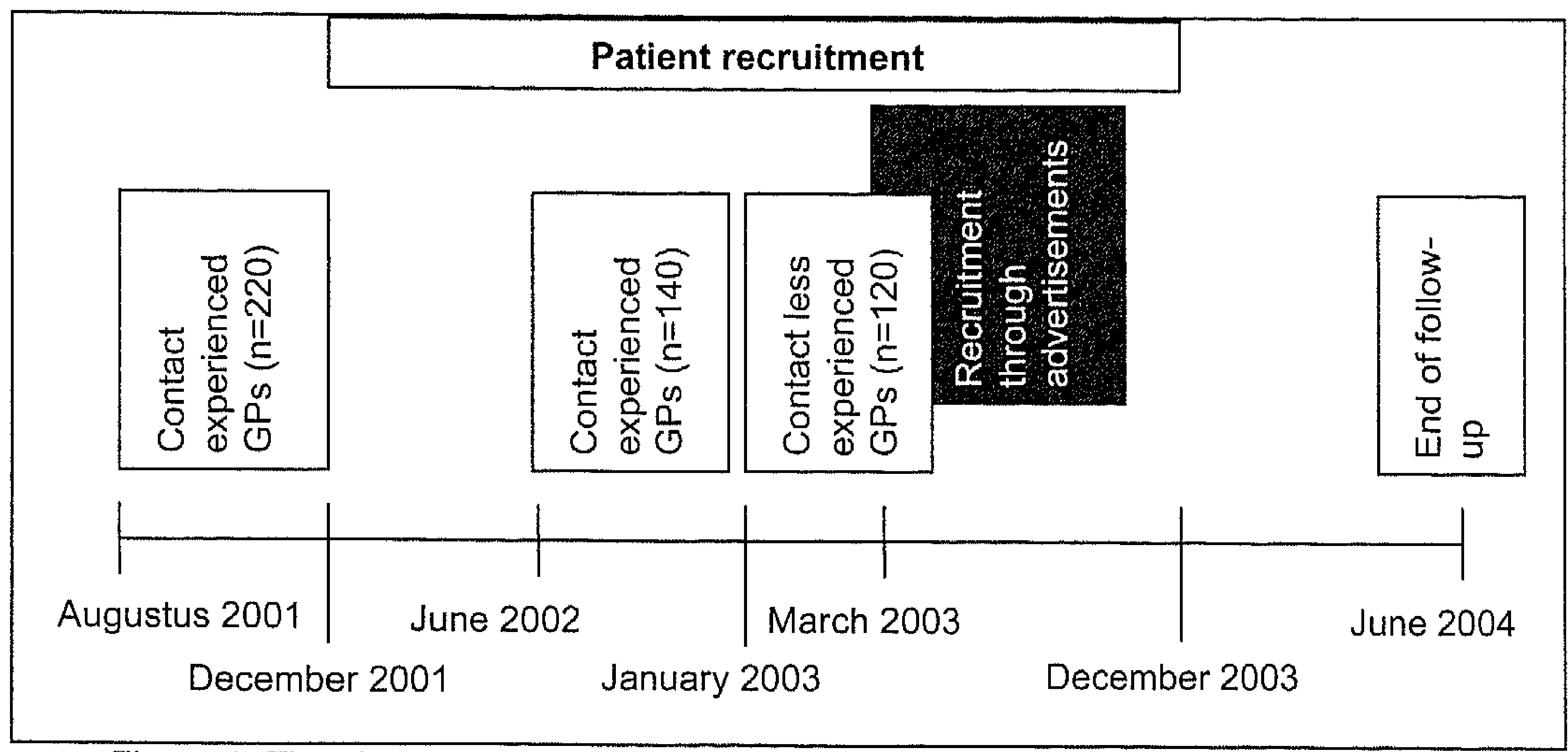

Figure 1: Time line of recruitment for the EAP trial

\section{Patient recruitment}

Patient recruitment started on December $10^{\text {th }} 2001$, and was planned to last for 18 months. Participating GPs referred few patients to the EAP trial during the first 6 months. As the additional experienced GPs were recruited, patient recruitment started to increase in the second half of 2002. Yet, by the end of 2002 , only 30 patients had been included in the trial.

To increase patient recruitment, additional activities were started during the first few months of 2003. In addition, the recruitment period was extended by 6 months, to December 2003. The additional activities included the recruitment of additional GPs and preparations for the open recruitment of patients using advertisements. The newly recruited GPs created a peak in the patient recruitment in March 2003 (15 new patients included) after which recruitment by GPs returned to an average of nearly 3 patients per month until the end of the recruitment period. GPs referred a total of 133 patients for participation in the EAP trial, 74 of whom were actually included in the trial. The reasons for which 59 patients were excluded from the trial are shown in table 1. 


\begin{tabular}{lc}
\hline Reason for exclusion & Number of patients \\
\hline Treated for their SCs in the preceding three months & 2 \\
\hline Inability to complete a questionnaire independently & 4 \\
\hline Referred pain from internal organs & 2 \\
\hline No more SCs & 5 \\
\hline Treatment preference & 2 \\
\hline Content of EAP & 2 \\
\hline Unknown/not interested & 42 \\
\hline
\end{tabular}

Table 1: Reasons for exclusion

The average number of patients included per GP was 2.6, with a minimum of 0 and a maximum of 10 included patients. Four GPs were very active in recruiting patients and included together 33 patients (45\%).

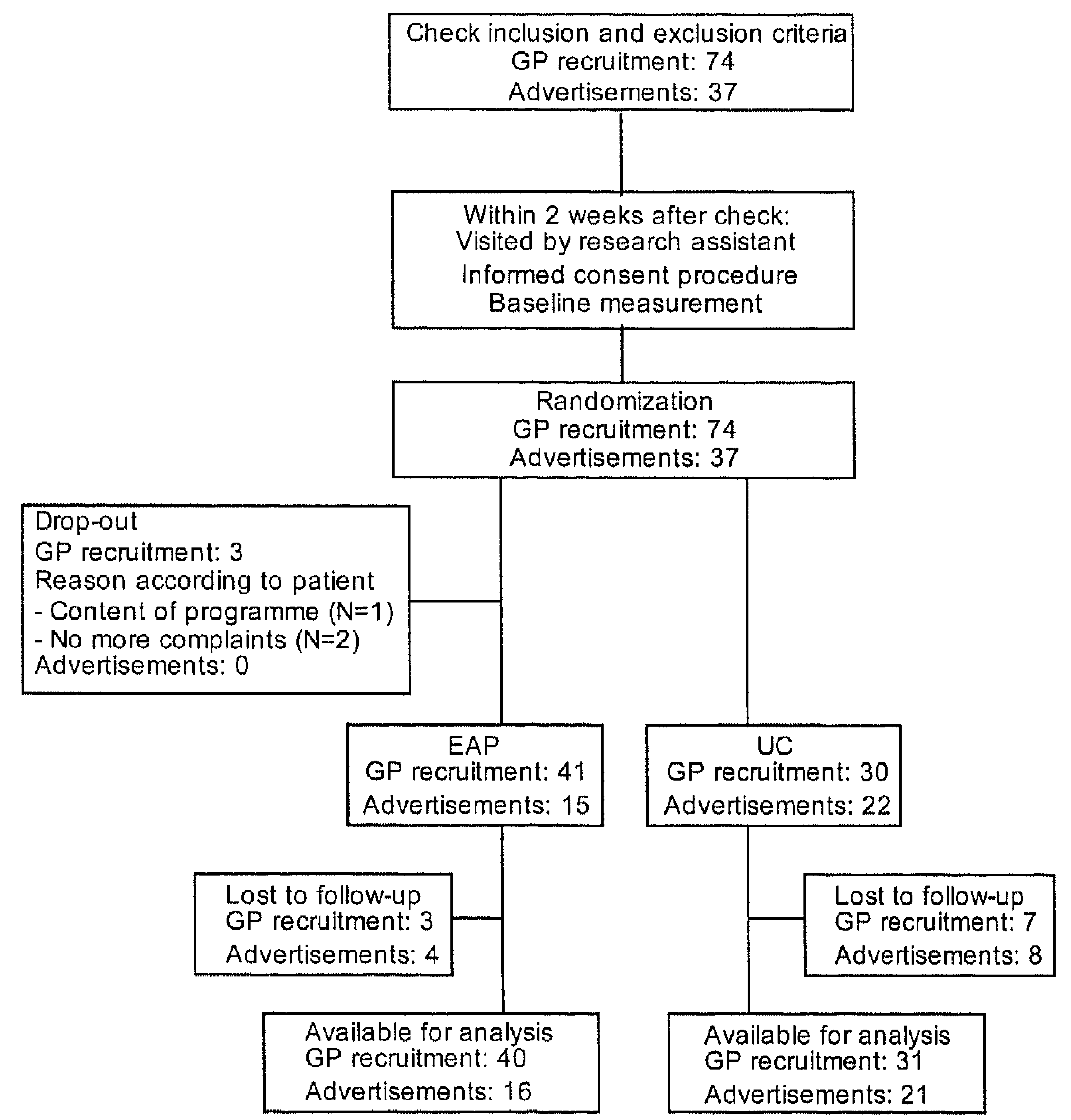

Figure 2: Flow chart 
The first advertisement calling on patients with SCs to participate in a trial was placed in a local newspaper in March 2003. Subsequently, new advertisements were placed in local newspapers covering several regions on a weekly basis, until November 2003. In total, 64 patients responded to the advertisements. Of these, 44 met the selection criteria, as ascertained by a telephone interview. The subsequent visit by the EAP-GP resulted in the final inclusion of 37 patients. Seven patients were excluded by the EAP-GP. Four of these had exceeded the maximum allowed duration of the SCs, one patient had had a fracture of the shoulder in the past and two patients had SCs from extrinsic causes.

Recruitment by GPs and through advertisements resulted in a total of 111 patients being included in the EAP trial over a period of two years (figure 2).

\begin{tabular}{|c|c|c|c|c|}
\hline & $\begin{array}{r}\text { Recruitment } \\
\text { by } \\
\text { GP }\end{array}$ & $\begin{array}{r}\text { Recruitment } \\
\text { through } \\
\text { advertisements }\end{array}$ & $95 \% \mathrm{Cl}$ & p-value \\
\hline Number & 71 & 37 & & \\
\hline \multicolumn{5}{|l|}{ Demographic variables } \\
\hline - Age (years) (SD) & $47.3(15.4)$ & $52.5(11.0)$ & $-10.9-0.4$ & 0.068 \\
\hline - Gender $\hat{O}(\%)$ & 39 & 32 & & 0.216 \\
\hline \multicolumn{5}{|l|}{ Specific disease variables } \\
\hline - Pain intensity (mean and SD) & $3.8(2.4)$ & $4.1(2.3)$ & $-1.3-0.9$ & 0.702 \\
\hline - Onset (quick) (\%) & 50 & 49 & & 0.894 \\
\hline $\begin{array}{l}\text { - Affected shoulder } \\
\text { (Left/right/both shoulders) (\%) }\end{array}$ & $7 / 83 / 10$ & $3 / 89 / 8$ & & 0.589 \\
\hline $\begin{array}{l}\text { - Prior episodes of SC of } \\
\text { at least } 1 \text { week }(\%)\end{array}$ & 44 & 51 & & \\
\hline \multicolumn{5}{|l|}{ Process variables } \\
\hline - SPS (mean and SD) & $18.5(4.5)$ & $18.3(5.2)$ & $-1.7-2.2$ & 0.798 \\
\hline - SDQ (mean and SD) & $64.2(24.1)$ & $63.8(24.7)$ & $-9.4-10.1$ & 0.938 \\
\hline $\begin{array}{l}\text { - Main complaints } \\
\text { (mean and SD) }\end{array}$ & $7.4(2.2)$ & $7.7(2.0)$ & $-1.1-0.6$ & 0.543 \\
\hline - Euroqol (mean and SD) & $.7(.2)$ & $.7(.2)$ & $-0.1-0.0$ & 0.324 \\
\hline - Catastrophising (\% very low) & 42 & 30 & & 0.224 \\
\hline - Coping (\% very low) & 14 & 3 & & 0.091 \\
\hline
\end{tabular}

Table 2: Baseline characteristics 


\section{Baseline characteristics and 'patient perceived recovery'}

Comparison of baseline values showed no significant differences between the two recruitment methods. P-values ranged from .949 for 'onset' to .068 for 'age'.

Estimates with their standard errors and levels of significance for the logistic multilevel analyses are presented in table 3. Data were interpreted by converting estimates to odds ratios.

\begin{tabular}{lcrrr}
\hline Variable & Estimate (SE) & OR & $95 \% \mathrm{Cl}$ & p-value \\
\hline Fixed parameter & & & & \\
\hline Treatment group & $0.71(0.65)$ & 2.03 & {$[0.57 ; 7.24]$} & 0.1368 \\
\hline Recruitment strategy & $-0.99(0.68)$ & 0.37 & {$[0.10 ; 1.40]$} & 0.0728 \\
\hline Time dummy 1 (6 weeks) & $1.29(0.45)$ & 3.63 & {$[1.51 ; 8.76]$} & 0.0023 \\
\hline Time dummy 2 (26 weeks) & $2.70(0.50)$ & 14.88 & {$[5.58 ; 39.65]$} & 0.0000 \\
\hline
\end{tabular}

Table 3: Results of the logistic multilevel analysis of patient-perceived recovery

The top-down procedure resulted in the exclusion of the interaction terms from the logistic model. This implies that the potential effect of treatment group was similar for both post measurements. In the final analysis model, the group effect $(p=0.1368)$ and the effect of the recruitment strategy $(p=0.0728)$ on patient-perceived recovery were not significant. A significant effect was found for time dummy 1 and time dummy 2, indicating a significant effect on PPR of the time elapsed since baseline. Baseline levels of catastrophising did not have a significant effect on the PPR and were excluded from the final analysis model.

\section{DISCUSSION}

\section{Recruitment of GPs}

Recruiting GPs was a persistent issue during the EAP trial. The 480 GPs contacted for participation resulted in only 29 GPs (6\%) consenting to participate in the trial. Moreover, getting initial consent from a GP to participate in the trial was no guarantee for active patient recruitment by that GP. It required regular visits and reminders to keep GPs focused on the trial. 


\section{Patient recruitment by GPs}

The anticipated number of 8 patients per GP per year was never reached. The reason why patient recruitment during the first 6 months fell far short of expectations may have been that several of the GPs were also participating in other trials. Participating in more than one trial increases the workload for a GP, possibly resulting in a lower recruitment rate per trial. The second group of experienced GPs was therefore asked to participate in the EAP trial only if they were not participating in other trials at that moment. Patient recruitment increased after these GPs started recruiting.

Although GPs were asked to go on recruiting eligible patients for the entire duration of the EAP trial, actual patient referral peaked during the first three months after the first contacts with the GPs. Recruitment then decreased or ceased altogether. Small improvements in recruitment rates were achieved by means of a newsletter, visits and small gifts, but never regained the level of the first three months. GPS participating in the EAP trial received no financial reward for recruiting patients, since there was no budget for this. In view of this, it is actually remarkable and admirable that participating GPs managed to include 74 patients without being financially compensated for their efforts.

A substantial part (44\%) of the patients referred to the research centre by the GPs $(n=133)$ were excluded from the EAP trial for a variety of reasons, which are presented in table 1. The unknown/not interested category may have been caused by the time that elapsed between consulting the GP and being contacted by a research assistant. Although the majority of the patients were contacted within two days after consulting their GP, this delay may have given them time to reflect on and decide against participation in a trial. Furthermore, declining participation is easier during a telephone call with an 'anonymous' research assistant than face-to-face with their own GP. This downside of the recruitment procedure, however, was offset by the advantage of a reduced workload for the GPs, which resulted in a possible higher referral rate. Another advantage of this procedure was that it provided insight into a process that usually takes place behind closed doors in the consultation room, if GPs are responsible for the inclusion of patients and the documentation of patients refusing participation. 


\section{Patient recruitment through advertisements}

Patient recruitment through advertisements was started because actual recruitment by GPS fell short of the anticipated numbers. Since, however, recruitment by advertisement introduced the risk of recruitment bias, we ensured that the selection criteria used during the recruitment through advertisements were exactly the same as the criteria used by GPs. Also, a GP employed by the EAP trial (EAP-GP) provided the patients responding to the advertisements with a regular consultation on their SCs. This ensured that patients responding to the advertisements and patients recruited by GPs were managed in a similar way. The main difference with patients recruited by GPs was that patients responding to advertisements had not decided beforehand to visit a GP for their SCs, and an advertisement was used to persuade these patients to consult a GP, in this case the EAP-GP.

\section{Changes in the recruitment process}

Changes in or additions to the recruitment process, such as the recruitment by advertisement we used, require preparation time. Effective monitoring of actual recruitment is needed to anticipate setbacks and increase the preparation time. Special attention should be paid to changes in the recruitment process that require approval by a medical ethics committee, which takes extra time.

\section{Recruitment strategy and outcome}

Baseline characteristics of patients recruited by GPs and those recruited through advertisements showed no significant differences. This does not, however guarantee that recruitment bias was absent, since the baseline questionnaire of the EAP trial was not intended to detect differences between patients recruited by different methods. The multilevel analysis, however, showed that recruitment had no effect on outcome either as the effect of the recruitment strategy in the multilevel model was not significant.

\section{Effectiveness of the EAP}

Although the focus of this paper was not on the effectiveness of the EAP, the multilevel model shows no significant $(p=0.1368)$ effect of the EAP on outcome. This is in accordance with our previous findings that showed also no effect of the EAP. 


\section{Choosing a recruitment strategy}

This study shows that the recruitment strategies used in this RCT have no significant effect on either baseline characteristics or outcome. This makes both strategies a valid strategy for the recruitment of patients. Consequently, choosing a recruitment strategy could be based on practical considerations such as available time and available financial resources instead of methodological considerations.

\section{CONCLUSIONS}

Beating 'Lasagna's Law' proved to be a demanding task in the completion of the EAP trial. Patient recruitment by GPs fell short of expectations and had to be remedied by the recruitment of additional GPs and by patient recruitment through advertisements. The referral rate by GPs was highest in the three months following the first contacts with the GPs. Instead of recruiting GPs for the whole duration of the EAP trial, it might in retrospect have been more effective to recruit GPs willing to refer a fixed number of patients over a threemonth period. This could have made participation in the EAP trial more acceptable for the GPs. Additionally, the extra efforts needed to keep GPs involved in the trial for the whole trial period could have been used for the recruitment of more GPs, with each recruiting fewer patients.

Recruiting patients through advertisements is a valid alternative for the recruitment of patients by GPs with no effect on outcome. Although some additional actions and investments are needed for this strategy such as the deployment of an ambulant GP, recruitment through advertisements offers the researcher more control over the recruitment strategy and makes him or her less dependent on GPs. 


\section{REFERENCES}

1. Gore SM. Assessing clinical trials--first steps. Br Med J (Clin Res Ed) 1981;282(6276):1605-7.

2. Tognoni G, Alli C, Avanzini F, Bettelli G, Colombo F, Corso R, et al. Randomised clinical trials in general practice: lessons from a failure. Bmj 1991;303(6808):969-71.

3. van der Windt DA, Koes BW, van Aarst M, Heemskerk MA, Bouter LM. Practical aspects of conducting a pragmatic randomised trial in primary care: patient recruitment and outcome assessment. $\mathrm{Br} \mathrm{J}$ Gen Pract 2000;50(454):371-4

4. Ross S, Grant A, Counsell C, Gillespie W, Russell I, Prescott R. Barriers to participation in randomised controlled trials: a systematic review. J Clin Epidemiol 1999;52(12):1143-56.

5. Peto V, Coulter A, Bond A. Factors affecting general practitioners' recruitment of patients into a prospective study. Fam Pract 1993;10(2):207-11.

6. Bell-Syer SE, Moffett JA. Recruiting patients to randomized trials in primary care: principles and case study. Fam Pract 2000;17(2):187-91.

7. Foy R, Parry J, Duggan A, Delaney B, Wilson S, Lewin-Van Den Broek NT, et al. How evidence based are recruitment strategies to randomized controlled trials in primary care? Experience from seven studies. Fam Pract 2003;20(1):83-92.

8. Linton S. A systematic review of psychological risk factors for back and neck pain. Spine 2000;25:1148-1156.

9. Turk DC. The role of demographic and psychosocial factors in transition from acute to chronic pain. In: Jensen TS, Turner JA, Z. W-H, editors. 8th World Congress on Pain, Progress in Pain Research and Management; 1997: IASP Press; 1997. p. 185-213.

10. Weiser $S$, Cedraschi C. Psychosocial issues in the prevention of chronic low back pain - a literature review. Bailliere's Clinical Rheumatology 1992;6(3):657-684.

11. Winters J, Sobel J, Groeniers K, Arendzen J, Jong BM-D. A shoulder pain score: a comprehensive questionnaire for assessing pain in patients with shoulder complaints. Scandinavian Journal of Rehabilitation Medicine 1996;28:163-167. 
12. Heijden GJMGvd, Leffers P, Bouter LM. Development and responsiveness of the shoulder disability questionnaire. Journal of Clinical Epidemiology 1999.

13. Brooks R. EuroQol: The current state of play. Health Policy 1996;37:53-72.

14. Berg SS-vd, Vlaeyen J, Kuile Mt, Spinhoven P, Breukelen Gv, KoleSnijders A. Pijn coping en cognitie lijst. In; 1999.

15. Windt DAvd, Koes BW, Boeke AJ, Deville W, Jong BAD, Bouter LM. Shoulder disorders in general practice: prognostic indicators of outcome. Br J Gen Pract 1996;46(410):519-23.

16. Bruijn CD, de Bie R, Geraets J, Goossens M, Koke A, van den Heuvel $W$, et al. Evaluation of an education and activation programme to prevent chronic shoulder complaints: design of an RCT [ISRCTN71777817]. BMC Fam Pract 2005;6(1):7.

17. Sobel JS, Winters JC. Shoulder complaints in general practice: Rijksuniversiteit Groningen; 1996.

18. Prout $\mathrm{H}$, Butler $\mathrm{C}$, Kinnersley $\mathrm{P}$, Robling M, Hood K, Tudor-Jones R. A qualitative evaluation of implementing a randomized controlled trial in general practice. Fam Pract 2003;20(6):675-81.

19. Rasbash J, Browne W, Goldstein H, Yang M, Plewis I, Healy M, et al. A user's guide to MLwiN (Second Edition). London: Institute of Education University of London; 2000.

20. Rasbash J, Browne W, Healy M, Cameron B, Charlton C. MLwiN. In. 1.10.0007 ed. London: Multilevel Models Project Institute of Education; 2001. 


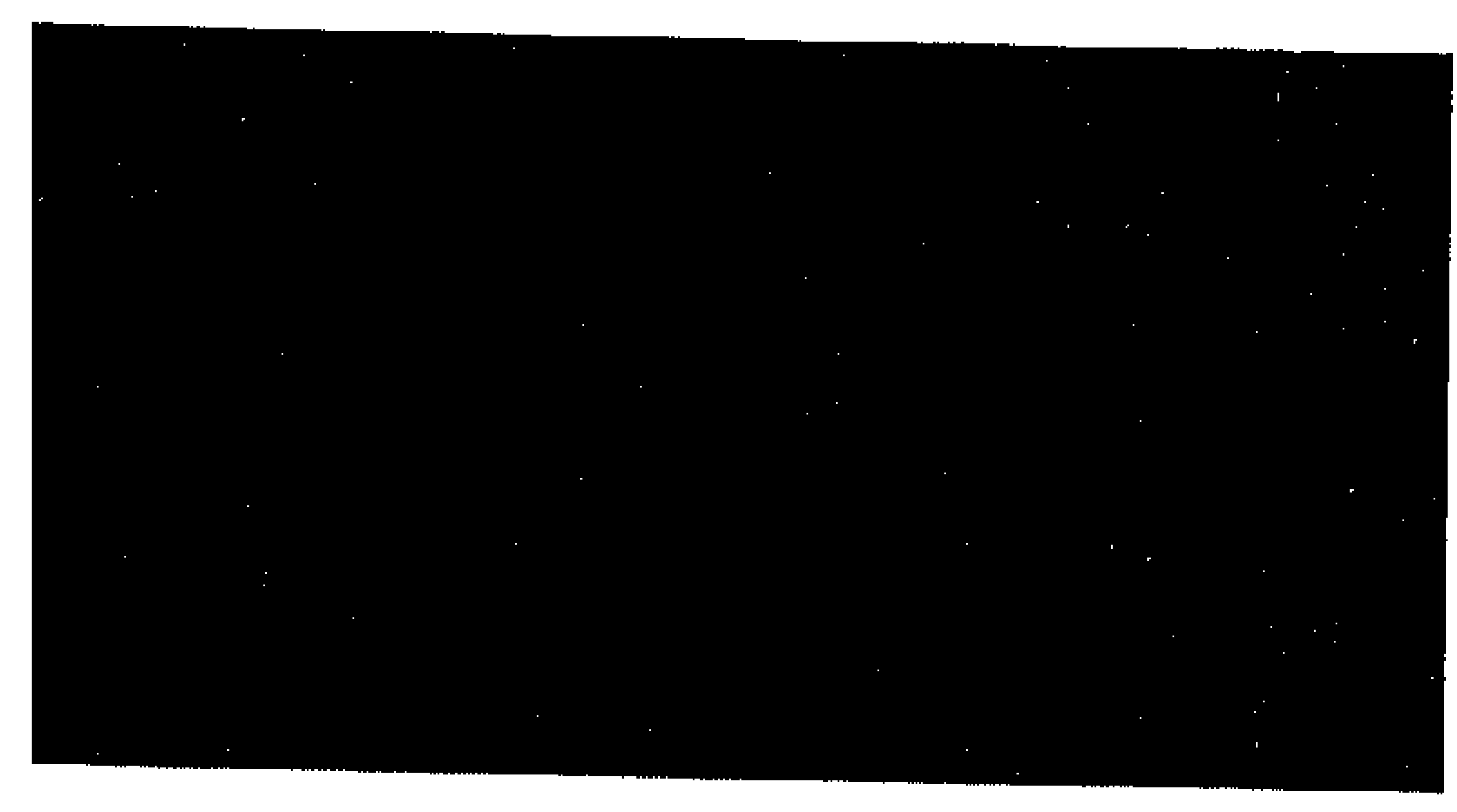

General discussion
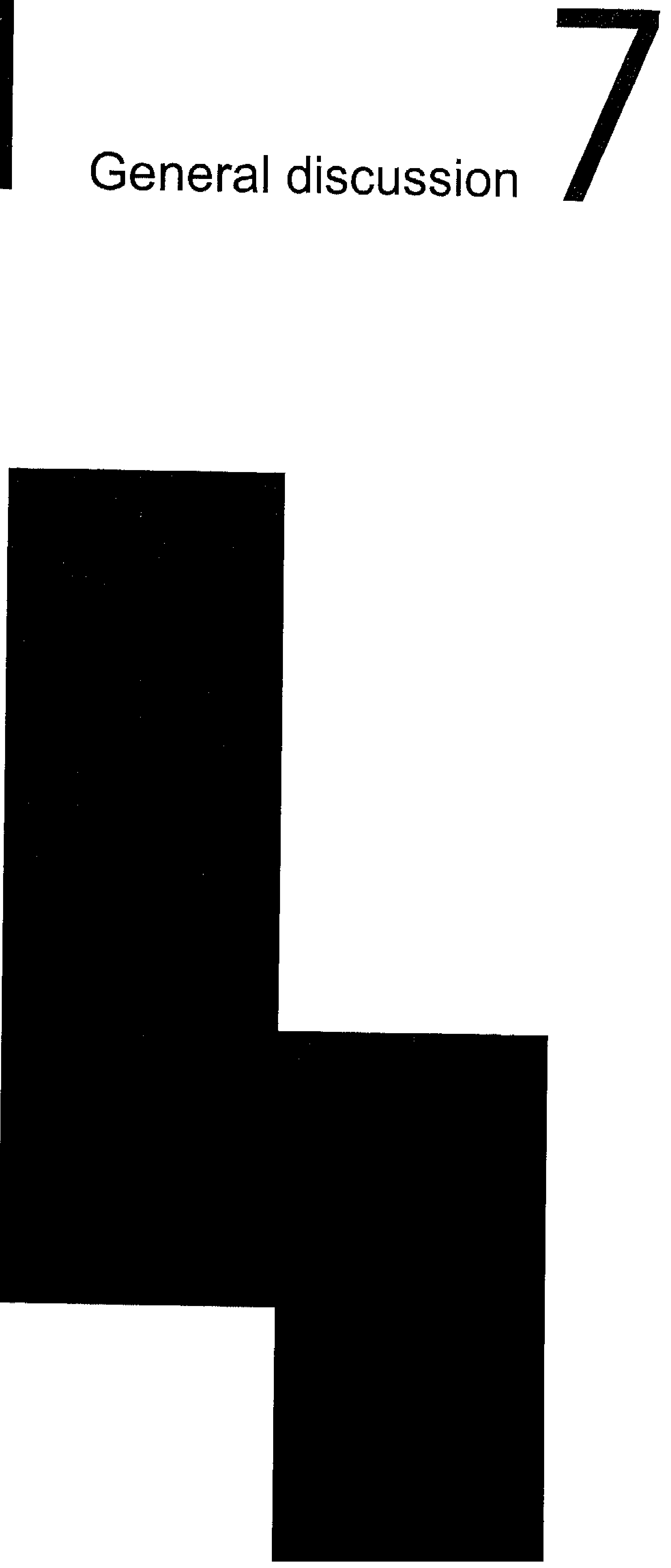


\section{INTRODUCTION}

This chapter starts with a summary of the main findings of the randomised clinical trial (RCT) evaluating the effectiveness of the Education and Activation Programme (EAP) in reducing the proportion of patients reporting persistent shoulder complaints (SCs) after six months. This summary is followed by a reflection on methodological and practical issues, while overall conclusions and recommendations are presented in the final section of the chapter.

\section{MAIN FINDINGS}

The EAP as an addition to usual care (UC) failed to show a significant effect on functional limitations or patient-perceived recovery after 6 and 26 weeks when compared to UC alone. Functional limitations were, however, found to be significantly and positively related to catastrophising at baseline. An analysis of videotaped consultations showed that GPs administering the EAP performed below the desired level, while GPs in the UC group were already using key features of the EAP in daily practice [1]. This has probably resulted in a smaller than anticipated difference between treatments in the EAP and UC groups.

No significant difference in mean total costs was found between the EAP and UC treatment groups [2], while considerable investments would be needed to increase the probability of the EAP being cost-effective. It was thus concluded that the EAP is not cost-effective at this moment.

A particularly interesting finding of the study is that recruiting patients for a study through advertisements is a valid alternative to recruitment by GPS during consultation hours, and has no effect on outcome.

\section{METHODOLOGICAL CONSIDERATIONS}

\section{Performing a trial in clinical practice}

The EAP trial was designed to evaluate the effectiveness of the EAP as used in clinical practice. The advantage of this setting is that an intervention can, if found to have a favourable effect, be easily embedded in daily practice. A disadvantage is, however, that it is difficult to pinpoint a reason if no effect is found. Anticipating this disadvantage, we monitored factors potentially affecting 
outcome, such as recruitment strategy and the quality of EAP administration in daily practice, which was measured using videotaped consultations.

\section{Outcome measures}

The EAP as an addition to UC addresses biological as well as psychological and social factors involved in SCs, and the chosen outcome measures preferably had to be able to assess changes in all these factors. In addition, since patients may perceive changes in biological or psycho-social factors differently, the outcome measures also had to be able to measure differences in patient perception.

We used two outcome measures, the Shoulder Disability Questionnaire (SDQ) and patient-perceived recovery, and we have to conclude in retrospect that only patient-perceived recovery met the above criteria for a suitable outcome measure [3]. It offered patients the opportunity to indicate their perception of the changes and to offer their interpretation of the importance/weight of the various factors.

Another argument in favour of patient-perceived recovery as an outcome measure is that it reflects the patient's perception of the success of an intervention. We considered the intervention to be successful if the patients considered the intervention to be successful. Whether the success of the intervention can be attributed to changes in biological, psychological or social factors is relevant from a scientific rather than a clinical point of view.

The predefined items of the (SDQ) restricted the patients' answering options to activities of daily living described by the items [4]. It cannot be ruled out, however, that these items are not applicable to individual patients and thus not relevant from the patient's point of view.

\section{Rationale for a multilevel analysis approach}

The statistical analyses proposed in our original design for the RCT referred to an independent samples t-test for continuous outcome variables and the chisquare test for categorical outcome variables. Although straightforward and easy to understand, we felt with hindsight that these statistical analyses were not appropriate for our study, due to a number of problems that arose during data collection. The first assumption for t-test and chi-square statistics is to have complete cases without missing values. In our trial, however, we were confronted with missing values despite our best effort to collect all data. 
Imputation had to be used to substitute missing values before we could apply ttesting and chi-square testing. Imputation uses available data to substitute missing values, based on assumptions about the behaviour of the data and possibly resulting in overestimation or underestimation of the outcome.

Another disadvantage of the statistical analyses proposed in our original RCT design is the assumption of independence. This assumption was violated in this study, since outcomes of patients attending the same GP cannot be considered to be fully independent. Furthermore, measurements for the same patient at different times are also dependent.

For these reasons, the actual statistical analyses used in this study deviated from those proposed in the original design. The multilevel analyses we eventually used enabled us to overcome some of the problems we faced with the originally intended analyses. Multilevel analyses are able to use the available data without the need to impute missing data while retaining the necessary power. Also, a multilevel analysis can be used to adjust for dependent outcome variables.

\section{PRACTICAL CONSIDERATIONS}

\section{Diagnosing Shoulder Complaints}

The activation part of the EAP focuses on gradually increasing activities of daily living, despite the pain. Some causes of SCs however, do not benefit from gradually increasing activities. Even more, some SCs are likely to deteriorate when activated to early. Therefore, patients were excluded from the RCT if the SCs were diagnosed with a (suspected) extrinsic cause such as a cuff rupture. This diagnosis was made by the GPs participating in the selection of patients for this RCT.

\section{Changing the attitudes of general practitioners}

One of the findings of our analysis of videotaped consultations was that GPs administering the EAP performed below the desired level, despite their training. This raises the question why the GPs did not administer the EAP in accordance with the training they had received. One explanation may be the modest quality and short duration of the training programme. Another explanation may be the practical applicability of the intervention in daily practice. Although we cannot and do not rule out that these explanations may 
have contributed to the discrepancy between the EAP as it was trained and as it was administered, another explanation may have contributed more to this discrepancy.

Administering the EAP adequately requires a change in attitude from a biomedical to a biopsychosocial approach to SCs. This change in attitude may not have been given enough attention in the design and implementation of the study. GPs were allocated to either UC or EAP based on their personal preferences, which, however, appeared not to guarantee an adequate attitude in the EAP study. Although participating GPs endorsed the benefits of the biopsychosocial model, actually applying this model to patients with SCS instead of a biomedical approach proved to be a drastic change that not all GPs were able to achieve.

The Pain Attitude and Beliefs Scale questionnaire is developed to distinguish between a biomedical and a biopsychosocial treatment orientation of low back pain in physiotherapists[5]. This questionnaire has been adapted for this RCT to distinguish between treatment orientation of SCs in GPs. All GPs participating in the RCT completed this questionnaire. The analysis of these questionnaires is not yet completed.

\section{Recruitment strategies}

Recruitment during regular general practice consultations proved to be a demanding task for both the GPs and the researcher. GPs needed to interrupt their regular consultations to inform the patients about the trial, while the researcher needed to remind the GPs regularly to do so. In contrast, recruiting patients through advertisements requires no involvement of the GPs. The researcher is in control of the recruitment process as he decides the dates when the advertisements will appear. This offers the researcher the opportunity to plan the recruitment of patients more efficiently.

However, recruiting patients through advertisements did involve some additional efforts. Patients responding to the advertisement were first screened by telephone for inclusion and exclusion criteria. Patients meeting the inclusion criteria were subsequently visited by a GP who was employed by the EAP trial. This GP provided eligible patients with a regular consultation for SCs, including a complete history taking and another check of the inclusion and exclusion criteria. The patients' own GPs were informed by the research centre that one of their patients had applied for participation in the EAP trial. The additional 
efforts needed to recruit patients through advertisements were, however, easily compensated by not having to remind the GPs about the trial.

Since using two different recruitment strategies introduces the risk of bias, we evaluated the effect of recruitment strategy on outcome by entering recruitment as a variable in the multilevel analysis. We found no effect of recruitment strategy on outcome.

\section{Ambulant therapist}

A substantial proportion of the patients have received the EAP from the ambulant therapist. Multivariate analysis (not presented in this thesis) showed no effect of the therapist on outcome variables. The ambulant therapist was trained and coached by a GP and a behavioural therapist to ensure the quality of the EAP. Training comprised ten treatment sessions with simulated patients that were evaluated. Regular meetings were organized to evaluate the EAP sessions with actual patients.

\section{GENERAL CONSIDERATIONS}

\section{Who should preferably diagnose and treat SCs?}

While a GP is often the first healthcare contact for patients with newly developed SCs in the Netherlands, it could be questioned whether a GP is also the most suitable healthcare provider to treat the SCs. Referral for further treatment to other healthcare providers in primary care, such as practice nurses and physiotherapists, may be an option.

Whereas the GP is more of a generalist, other healthcare providers often specialise in particular fields of healthcare, such as musculoskeletal disorders. This specialisation and the extra time that these specialists can invest per treatment make them a good alternative to treatment by a GP. With the right training, we expect these healthcare providers to be able to administer the EAP just as well as GPs.

On the other hand, an advantage of patients with SCs being treated by GPS is that GPs are often familiar with their patients' complete medical history, allowing them to relate the SCs to a particular patient's general health status. Another advantage is that, as generalists, GPs are trained to screen for a broad range of conditions that could possibly be accompanied by SCs, or cause SCs. These advantages would make GPs ideally suited to treating 
patients with SCs, if they were not limited by the time they have available in their daily routine.

\section{CONCLUSIONS AND RECOMMENDATIONS}

\section{EAP in daily general practice}

Based on the results of this trial, it can be concluded that the Education and Activation Programme (EAP) for patients with shoulder complaints (SCs) should not be implemented in daily general practice in its present form. This study represents a first attempt to apply a biopsychosocial treatment approach to patients with SCs. At the start of this study, little was known about specific psychosocial factors involved in the development of chronic SCs, although psychosocial factors in general were known to play a role in the development of chronic musculoskeletal diseases. The psychosocial factors addressed by the EAP did not result in a change in outcome when compared to usual care (UC).

\section{Catastrophising as a determinant}

The relation between catastrophising and functional limitations in patients with SCs suggests that an intervention focusing specifically on a reduction of catastrophising may be more successful in reducing functional limitations in the long term. Further research is needed, however, to evaluate the effect of catastrophising and other psychosocial variables on the course of SCs. This would provide relevant information for the development of a more adequate intervention but was beyond the scope of this thesis focussing on the effectiveness of the EAP.

\section{Choice of outcome measures}

In retrospect, the Shoulder Disability Questionnaire (SDQ) is not very appropriate as an outcome measure in a study evaluating the effectiveness of a biopsychosocial intervention such as the EAP. Patient-perceived recovery is more appropriate as an outcome measure, as it offers patients the opportunity to report their perception of the changes and to indicate their interpretation of the importance/weight of the various factors. 


\section{Quality of the EAP administration}

The EAP was introduced to the GPs during a short training session. Increasing the length of the training programme by adding more role-plays, and organising more refresher and evaluation meetings might have increased the quality of the training and might have resulted in a better quality of administration of the EAP. The fact that available time in daily general practice is limited may also have resulted in a less than optimal performance. Further study is needed to evaluate the effect of this pressure of time on the quality of EAP administration. In the future, special attention should be paid to the attitude of the participating GPs, especially if a new intervention requires a different attitude on their part towards the complaints that are being investigated, irrespective of the nature of the complaints.

\section{Recruitment strategies}

Patients participating in the EAP trial were recruited both during regular general practice consultations and through advertisements in local newspapers. The absence of a significant effect of the recruitment strategy on outcome means that the choice of recruitment strategy can be based on practical considerations. The additional efforts needed to recruit patients through advertisements are easily compensated by not having to remind the GPs about the trial. In retrospect, recruiting patients by advertisements alone would have been a good option in our trial, possibly resulting in more patients being included and more control over the recruitment strategy.

\section{Deployment of other healthcare providers}

Before embedding a new, relatively time-consuming, therapy for musculoskeletal conditions in general practice, alternatives should be considered that employ other healthcare providers. We overlooked this option when we designed the EAP trial. We recommend that other researchers do consider the deployment of other healthcare providers before embedding a new treatment in general practice. This recommendation is supported by the results of a review that Huibers et al. [6] performed. They found no conclusive evidence that psychosocial interventions administered by GPs are more effective than usual care. In contrast, psychosocial interventions by healthcare providers other than the GPs have shown to be more effective than usual care. 


\section{Pain is inevitable. Suffering remains optional.}

We stated in the Introduction to this thesis that suffering is only optional if a patient is provided with tools to cope with the suffering. Our trial showed that from a medical point of view, the Education and Activation Programme is not such a tool. It should be stressed, however, that suffering remains optional. Although further study is needed to find a scientifically valid tool, patients should meanwhile continue to search for their own tools to confront the suffering. 


\section{REFERENCES}

1 De Bruijn C, de Bie R, Geraets J, Goossens M, Koke A, van den Heuvel W, et al. General practitioners apply the usual care for shoulder complaints better than expected--analysis of videotaped consultations. BMC family practice. 2007;8:13.

2 De Bruijn C, Goossens M, de Bie R, Ament A, Geraets J, Dinant GJ. Cost-effectiveness of an education and activation program for patients with acute and subacute shoulder complaints compared to usual care. International journal of technology assessment in health care. 2007 Winter;23(1):80-8.

3 Windt DAvd, Koes BW, Boeke AJ, Deville W, Jong BAD, Bouter LM. Shoulder disorders in general practice: prognostic indicators of outcome. Br J Gen Pract. 1996;46(410):519-23.

4 Heijden GJMGvd, Leffers $P$, Bouter LM. Shoulder disability questionnaire design and responsiveness of a functional status measure. Journal of Clinical Epidemiology. 2000;53:29-38.

5 Houben RM, Ostelo RW, Vlaeyen JW, Wolters PM, Peters M, Stompvan den Berg SG. Health care providers' orientations towards common low back pain predict perceived harmfulness of physical activities and recommendations regarding return to normal activity. European journal of pain (London, England). 2005 Apr;9(2):173-83.

6 Huibers MJ, Beurskens AJ, Bleijenberg G, van Schayck CP. Psychosocial interventions by general practitioners. Cochrane database of systematic reviews (Online). 2007(3):CD003494. 


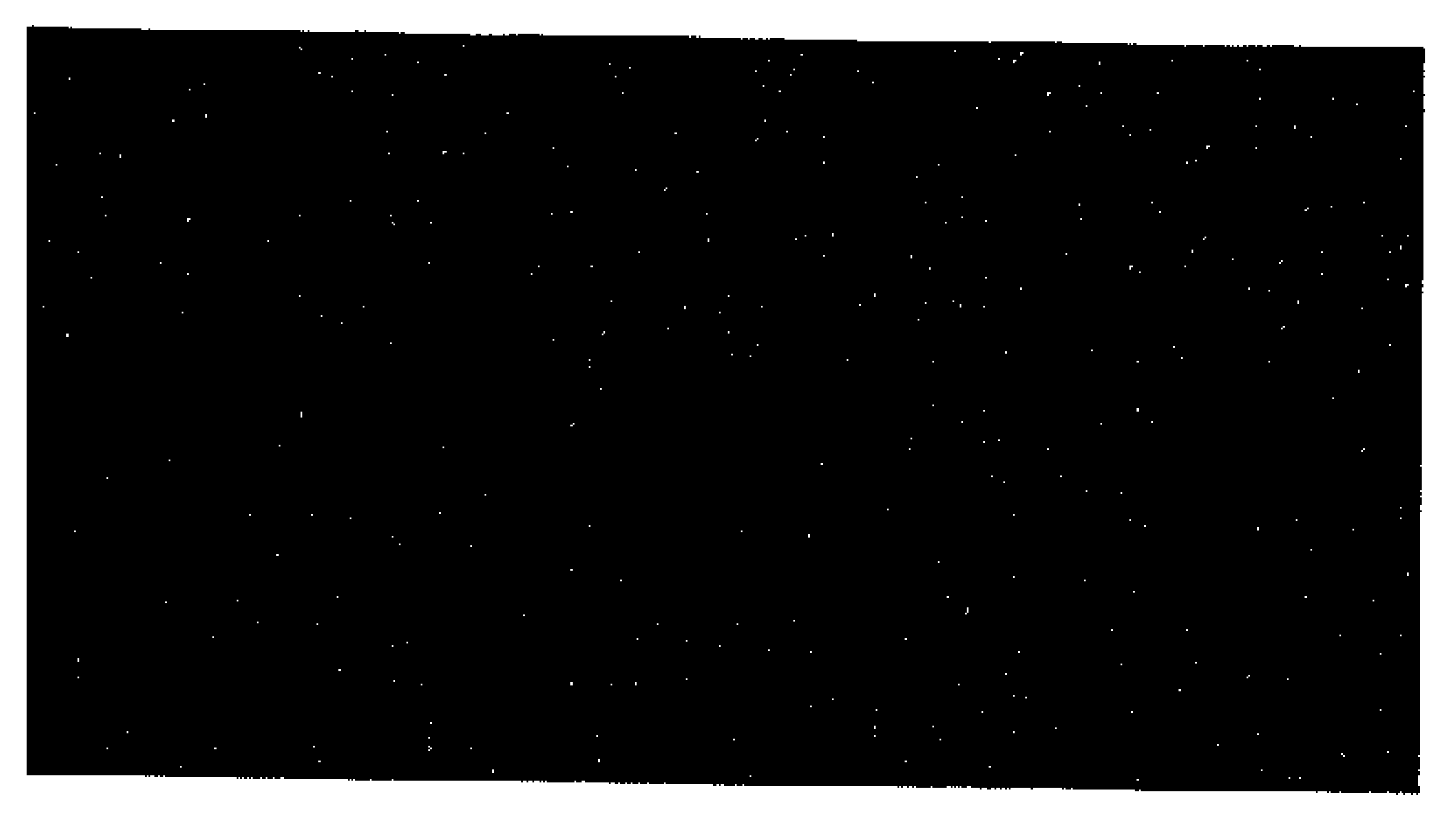

Summary

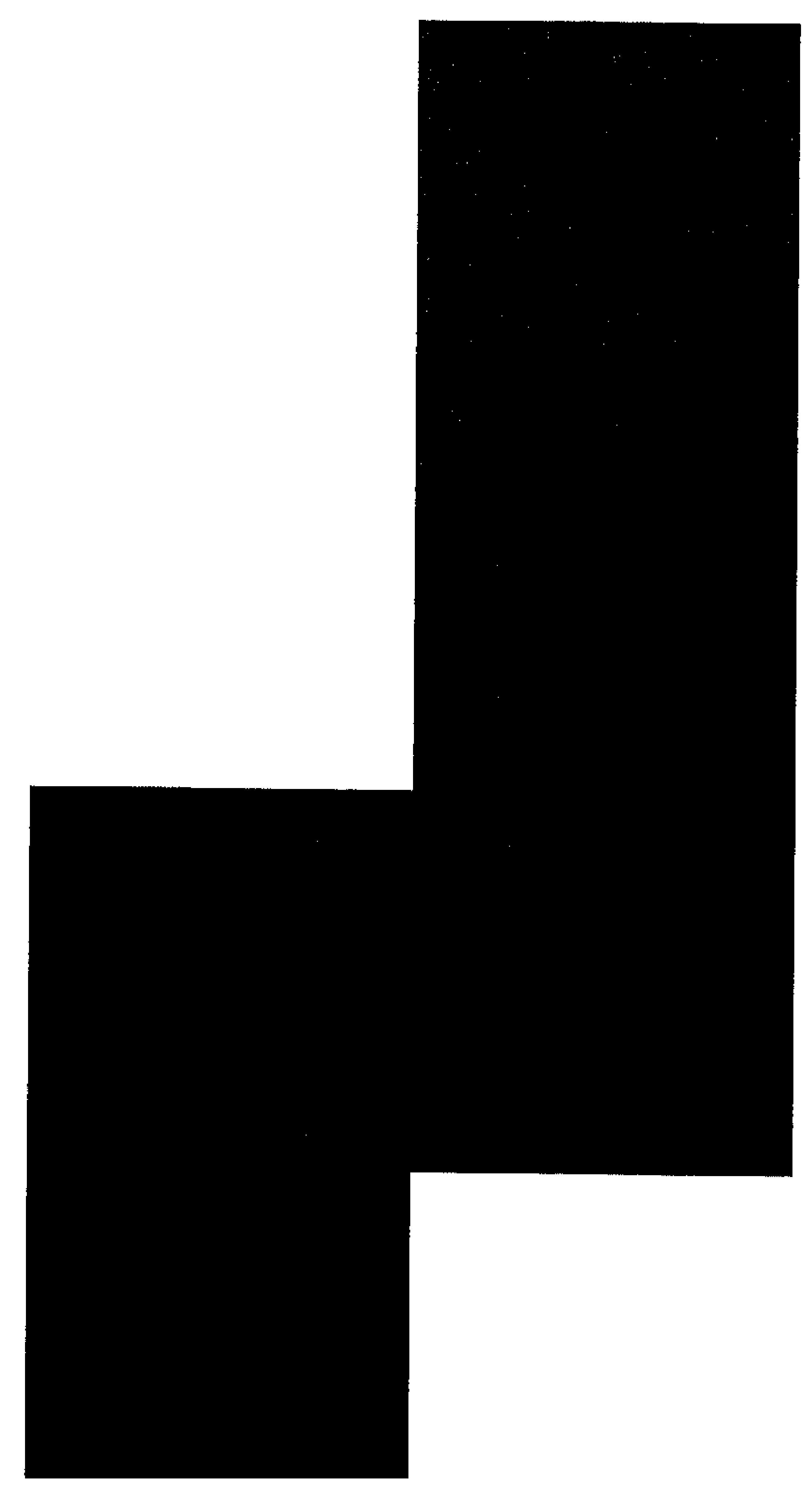


The annual incidence of shoulder complaints (SCs) in patients seen by general practitioners (GPs) in the Netherlands lies between 15 and 25 cases per 1000 patients registered with a GP. Half of these patients report persistent SCs after six months, in spite of usual care (UC), which is characterized by a mainly biomedical approach.

Psychosocial factors may cause a patient to develop inadequate cognitions and maladaptive behaviours, which are known to play a role in the persistence of musculoskeletal disorders such as SCs. To reduce the proportion of patients reporting chronic SCs after six months, a new intervention has been developed. This intervention, the education and activation programme (EAP), aims to prevent the development of inadequate cognitions and maladaptive behaviours in the early stages of the SCs.

To evaluate the effect of the EAP on the prevention of chronic SCs 26 weeks after the first presentation in general practice, a randomized clinical trial (RCT) was designed and implemented.

Chapter 1 presents the rationale behind the EAP, resulting in the main research questions.

'Pain is inevitable. Suffering is optional.' That is what the Dalai Lama ${ }^{19}$ once said about pain. However, many patients may disagree, as suffering is only optional if a patient is provided with tools to confront the suffering. Whereas the biomedical approach offers patients few such tools, the introduction of the biopsychosocial model by Engel initiated the development of new treatments, providing patients with tools to confront the suffering themselves. The biopsychosocial model suggests that not only biological determinants but also psychosocial determinants play a role in disease or illness. Previous studies have indicated that therapies aimed at coping with psychosocial determinants are promising instruments for the prevention of chronic musculoskeletal pain. The EAP is such a therapy and complements the biomedical approach in the usual care (UC) of SCs.

The RCT was designed to answer the main research question:

Is EAP in addition to UC more effective in reducing the proportion of patients reporting persistent SCs after six months than UC alone?

\footnotetext{
${ }^{19}$ Spiritual and political leader of Tibet and Nobel Peace Prize winner
} 
Additional research questions were concerned with the programme's costeffectiveness, comparing the observed difference in costs with the clinical effectiveness, and with the performance of trained GPs, using videotaped consultations. We also evaluated the effect of the patient recruitment strategy on outcome.

Chapter 2 describes the design of the RCT and the content of the EAP. Patients who had suffered from SCs for less than three months were recruited in general practice and through open recruitment. Only newly presented episodes of SCs were considered, that is, patients who had not consulted their GP and had not been treated for their SCs in the preceding three months. Patients were allocated at random to either EAP as an addition to UC, or to UC only. A trained GP or a trained therapist administered the EAP.

The EAP consists of a minimum of two sessions and a maximum of six followup sessions over a period of six weeks. Each session may last up to 20 minutes. The first part of the EAP has an educational purpose, and focuses on information about the origin, nature and prognosis of the SCs, possible interventions and their effects, the impact on activities of daily living and its consequences, and the patient's own opportunities to contribute to recovery. This information is tailored to patients' questions and needs and is based on the information available in the Dutch College of General Practitioners' practice guideline for SCs. The second part of the EAP consists of a time-contingent activation programme, based on principles of operant learning. It focuses on gradually increasing activities of daily living, despite the pain.

Primary outcome measures were patient-perceived recovery and functional limitations in activities of daily living, assessed by a 16-item questionnaire, the shoulder disability questionnaire (SDQ). The outcome measures were recorded at 6,12 and 26 weeks after randomization. The SDQ was also used at baseline. A cost diary was used to assess health care utilization, direct nonmedical costs and indirect costs.

The RCT was part of the Dutch Shoulder Disability Study, a comprehensive prognostic cohort study on SCs, with randomized controlled interventions in sub-cohorts. The Dutch Shoulder Disability Study was funded by the Netherlands Organisation for Scientific Research (ZonMw)

Previous studies had shown that the actual performance of GPs is not directly related to their competence. This implies that training GPs to implement a 
newly developed intervention may not or only partly result in the desired performance in daily practice. We therefore studied the performance of five trained GPs administering the EAP and five GPs administering UC, using videotaped consultations of the GPs treating a standardized patient. The female standardized patient simulating the SCs in this study had received a two-hour instruction during which her role had been developed by means of role-plays.

Chapter 3 describes the results of this video analysis. The aim of the video analysis was to obtain some idea of the performance of the trained GPs. The number of key features of the EAP that was present in the consultations was used as an indication of the GPs' performance and their adherence to the EAP. In addition, videotaped consultations by the GPS in the UC group were analyzed for the presence of key features of the EAP. The aim of this analysis was to see whether features exclusively attributed to the EAP were already embedded in daily general practice. The videotaped consultations were evaluated by two blinded observers using a checklist to score the presence of key features of the EAP.

A comparison of the groups at item level for the key features showed that the proportion of key features observed in the consultations by the EAP group equalled or exceeded that in the UC group for all but one key feature.

Neither the GPs in the EAP group nor those in the UC group reached acceptable scores on the EAP checklist, while GPs in the UC group performed above expectation. This can be explained by experiences with a similar approach in low back pain and irritable bowel syndrome.

It must be noted that observing the presence of key features in the treatment provides no information on the quality of the way they are administered, and this quality may well have differed between the two study groups.

In summary, this RCT found that the GPs who were administering the EAP performed below the desired level of performance, while GPs in the UC group were already using key features of the EAP in their daily routine. This resulted in a smaller difference than anticipated between the UC and EAP groups, which may have affected the outcome of the RCT. However, the impact of this difference also depends on the quality of the administration of the key features, which was not assessed by the checklist. 
The main results of the RCT described in chapter 2 are presented in chapter 4. Patients with SCs present at rest or elicited by movement and lasting no longer than 3 months were allocated at random to either the EAP as an addition to UC, or to UC only. Measurements were taken at baseline and after 6 and 26 weeks, and were analyzed by means of multilevel analysis for the group effect. The EAP was administered by GPs or by an ambulant therapist. Patients in the UC group were given UC by their own GP.

The first primary outcome measure was patient-perceived recovery. Patients were considered recovered when they reported to be 'much improved' or 'fully recovered', on a 7-point ordinal scale, six weeks after randomization. The second primary outcome measure was a change in functional limitations of activities of daily living. This outcome measure was assessed by the 16-item shoulder disability questionnaire (SDQ), with a standardized scoring range of 0 to 100 . A lower score on this questionnaire implies lower levels of functional limitations.

Results of patients attending the same GP cannot be assumed to be fully independent. Similarly, results of different observations for the same patient with SCs cannot be assumed to be independent either. This dependency was addressed by using multilevel analysis, due to clustering of data. The effect of treatment group was analyzed by means of linear multilevel analysis if SDQ was the outcome variable and logistic multilevel analysis if patient-perceived recovery was the outcome variable. Three levels of variance were distinguished: GPs, subjects and measurements.

The multilevel analyses resulted in estimates of the fixed and random effects. Likelihood ratio test statistics were used to determine whether the estimates were statistically significant in the linear multilevel analyses. Wald chi-square tests were used to determine the statistical significance of the estimates in the logistic multilevel analyses. Estimates that did not reach the required level of significance were excluded from the model in a top-down procedure, except for the intervention variable, leaving out the least significant estimates first. For the logistic multilevel analysis, these estimates were converted to odds ratios with their $95 \%$ confidence intervals.

Linear multilevel analyses of the SDQ scores resulted in a final model in which the EAP turned out to have no significant effect on functional limitations. Catastrophizing at baseline and baseline SDQ scores were significantly and positively related to SDQ scores at both post-intervention measurements. Time 
was significantly and negatively related to SDQ scores, suggesting that SDQ score, representing the level of functional limitations, decreases as time progresses.

Logistic multilevel analyses of the patient-perceived recovery resulted in a final model with a non-significant effect of the EAP on patient-perceived recovery. We found a significant effect on patient-perceived recovery of the time elapsed since baseline. Baseline levels of catastrophizing did not have a significant effect on the patient-perceived recovery and were excluded from the final analysis model.

Multilevel analysis using either SDQ scores or patient-perceived recovery as the outcome variable failed to show a significant effect of EAP after 6 and 26 weeks.

A coincidental finding of this study was the relation between catastrophizing at baseline and functional limitations. This relation suggests that an intervention focusing specifically on catastrophizing may be more successful in reducing functional limitations in the long term. In contrast, the EAP addresses catastrophizing as one of several psychosocial determinants of SCs. The effect of an intervention focusing on catastrophizing may be improved by selecting patients with elevated levels of catastrophizing at baseline.

SCs constitute the second most prevalent group of musculoskeletal disorders after low back pain. The economic burden in terms of costs of healthcare use and costs due to work absenteeism underlines the need for a costeffectiveness analysis of the interventions involved. Chapter 5 presents the results of the cost-effectiveness analysis that was conducted alongside the RCT evaluating the effect of EAP. The aim of the cost-effectiveness analysis was to compare the total costs incurred over a period of 26 weeks in both study groups. Additionally, the observed difference in costs was related to the clinical effectiveness (patient-perceived recovery after 26 weeks) in the two study groups, using bootstraps.

Cost data were collected from a societal perspective, using a cost diary assessing direct healthcare costs and direct non-health-related costs.

The clinical outcome measure was analyzed according to the intention-to-treat principle. Between-group changes since baseline were analyzed using the chisquared test. Additional analysis was conducted on imputed data. The 'last- 
observation-carried-forward' method was used to impute missing values in clinical outcomes.

The primary cost-effectiveness analysis was performed on imputed cost data. Missing cost data were replaced using last-value-carried-forward imputation for individual cost data. Since cost data per patient are typically highly skewed, we used bootstrap estimation to derive a $95 \%$ confidence interval for the mean difference in total costs due to SCs and the mean difference in clinical effectiveness between the groups. Bootstrap estimation is based on random sampling (1000 replications) with replacement of a number of the patients in the RCT, using the original data.

The incremental cost-effectiveness ratios (ICERs), calculated by dividing the difference in direct costs for the two treatment groups by the difference in effect between the two groups, were calculated for each bootstrap replicate. The bootstrapped cost-effect pairs were graphically represented on a costeffectiveness plane. Acceptability curves showed the probability that a treatment is cost-effective at a specific ceiling ratio.

Patient-perceived recovery between the study groups showed no significant difference for patients for whom complete cost data was available. Nor was there a significant difference in patient-perceived recovery between the treatment groups for patients for whom imputed cost data was available.

The ICER for the comparison of patient-perceived recovery between the study groups was $€ 8501$. This implies that an investment of $€ 8501$ is needed for every additional recovered patient in the EAP group, compared to the UC group, after 26 weeks.

Mean ICER after 1000 bootstrap replications was $€ 7933$ (95\% confidence interval $€ 675-€ 15192)$. The majority (82\%) of the cost-effect pairs for patientperceived recovery were located in the north-east quadrant of the costeffectiveness plane, suggesting that the EAP is more effective but at higher costs. Sixteen percent of the cost-effect pairs were located in the north-west quadrant, implying that the EAP is less effective at higher costs (inferior). The incremental cost-effectiveness acceptability curve for patient-perceived recovery showed that at a cost ceiling ratio of $€ 10,000$, the probability that the EAP is cost-effective is $53 \%$.

The EAP is an early intervention intended to prevent the development of chronic SCs. Additional costs incurred for all patients with a new episode of SCs should be compensated by costs avoided in the future by patients likely to 
develop chronic SCs at baseline. In this study, however, the future was restricted to a period of 26 weeks. Avoided costs beyond this period are not known from the literature, nor were they recorded in this study. Since our conclusions are thus based on a period of 26 weeks, it should be noted that accounting for the costs avoided after this period might have altered the conclusions.

The outcome measure chosen in this study has rarely been used in costeffectiveness studies, and the literature offers few opportunities for comparison. Final conclusions on the cost-effectiveness of EAP should therefore be based on common sense rather than comparison with other studies.

Additional costs of $€ 10,000$ to achieve a probability of $53 \%$ that the EAP is cost-effective are simply too high for such a low probability. Furthermore, these additional costs are needed to help only one additional patient in the EAP group recover, which is not a clinically relevant improvement. A clinically relevant improvement was defined in the RCT as a number needed to treat of 4.5 , and achieving this improvement would require an even greater investment. Clinical outcomes show even more clearly that this clinical effectiveness was not achieved in the present study (NNT=9). Based on this, we consider the EAP not to be cost-effective when compared to UC.

In confirmation of 'Lasagna's law', actual recruitment often falls short of expectations, which may threaten the completion of an RCT. Chapter 6 describes the strategies we used to optimize GP and patient recruitment in the RCT, comprising monthly newsletters, frequent visits, small gifts and accredited courses. Patients were recruited both during regular GP consultations and through advertisements in local newspapers. Recruitment by advertisement was used since recruitment by GPs fell short of expectations. The effect of the two recruitment strategies on outcome was evaluated by entering recruitment strategy as a variable in a multilevel analysis.

Since lack of time during consultations is often mentioned as one of the main barriers to recruiting patients in general practice, the patient recruitment procedure in the consultation room was designed to minimize the time needed by the GPs.

Recruitment by advertisement was organized by placing an advertisement in local newspapers, calling on patients with SCs to participate in the RCT. 
Patients responding to the advertisement were first screened by telephone for inclusion and exclusion criteria, after which those meeting the inclusion criteria were visited by a GP who was employed by the research team. This GP provided these patients with a regular consultation for SCs, including a complete history check, and checked the inclusion and exclusion criteria again. If patients met all criteria, the GP informed a research assistant, who contacted the patients within two weeks. The patients were then referred to their own GP for further treatment of the SCs.

The final analysis model of the multilevel analysis with recruitment strategy as a variable showed no significant effect of the recruitment strategy on outcome,making both strategies valid for the recruitment of patients. Consequently, choosing a recruitment strategy could be partly based on practical considerations such as available time and available financial resources, instead of methodological considerations only.

Chapter 7 presents a reflection on methodological and practical issues.

The RCT was designed to evaluate the effectiveness of the EAP as used in clinical practice. The advantage of this setting is that an intervention can, if found to have a favourable effect, be easily embedded in daily practice. A disadvantage is, however, that it is difficult to pinpoint a cause if no effect is found. Anticipating this disadvantage, we monitored factors potentially affecting outcome, such as recruitment strategy and the administration of EAP in daily practice, which was assessed using videotaped consultations.

Since the statistical analyses proposed in the original design of the RCT had certain shortcomings, we eventually used multilevel analyses, since these are able to cope with missing values and adjust for dependent outcome variables. Correct administration of the EAP requires a change in attitude on the part of the GPs, from a biomedical to a biopsychosocial approach to SCs. Although participating GPs endorsed the benefits of the biopsychosocial model, actually applying this model to patients with SCs instead of a biomedical approach proved to be a drastic change that not all GPs were able to achieve.

While a GP is often the first healthcare contact for patients with newly developed SCs in the Netherlands, it could be questioned whether a GP is also the most suitable healthcare provider to treat the SCs. Referral for further treatment to other healthcare providers in primary care, such as practice nurses and physiotherapists, may be an option. 
Based on the results of this RCT, it can be concluded that the EAP in its present form should not be implemented for patients with SCs in routine general practice. This study represents a first attempt to apply a biopsychosocial treatment approach to patients with SCs. At the start of this study, little was known about specific psychosocial factors involved in the development of chronic SCs, although psychosocial factors in general were known to play a role in the development of chronic musculoskeletal diseases. Addressing the psychosocial factors that the EAP focuses on did not result in a change in outcome when compared to UC. 


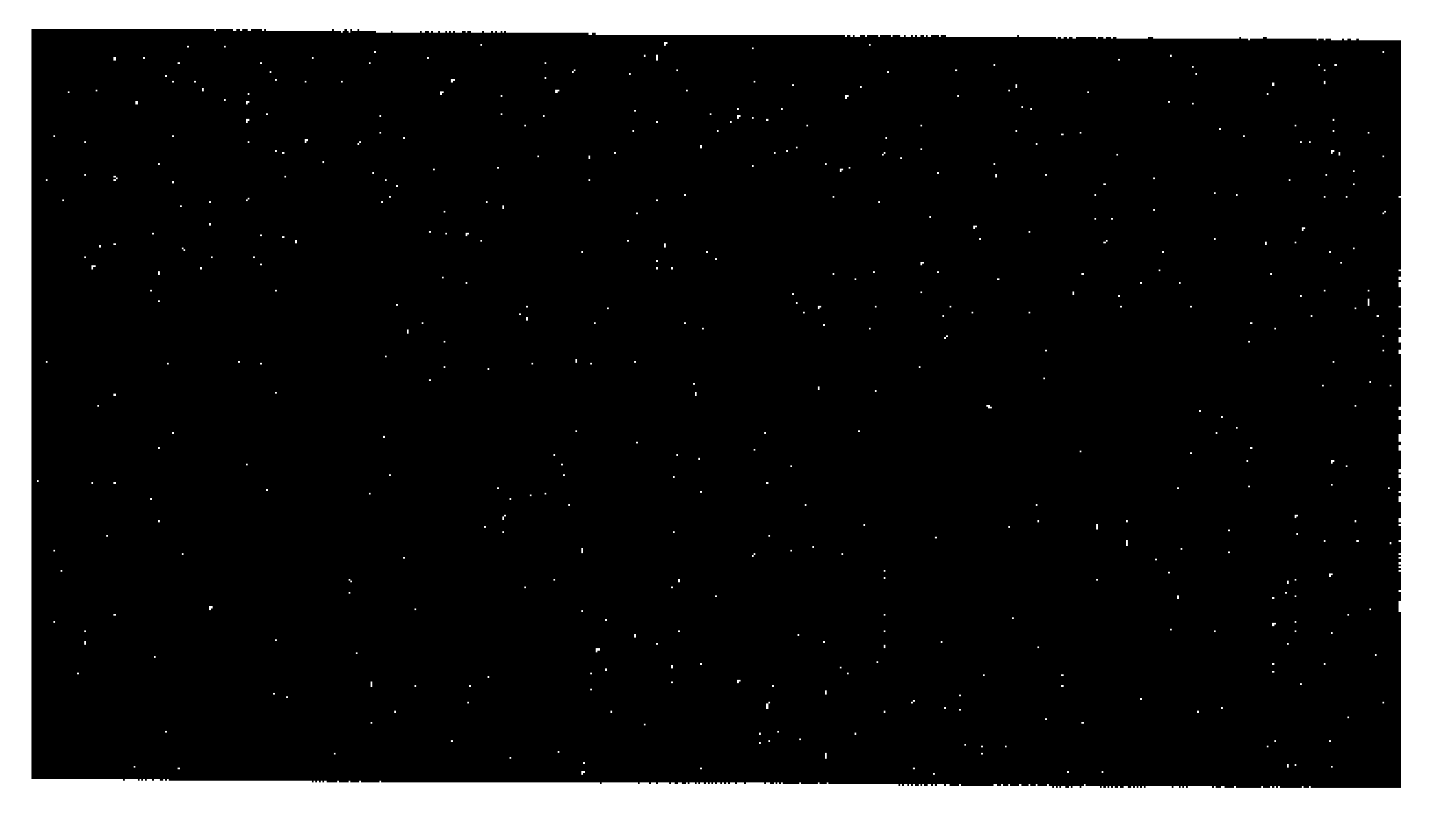

Samenvatting

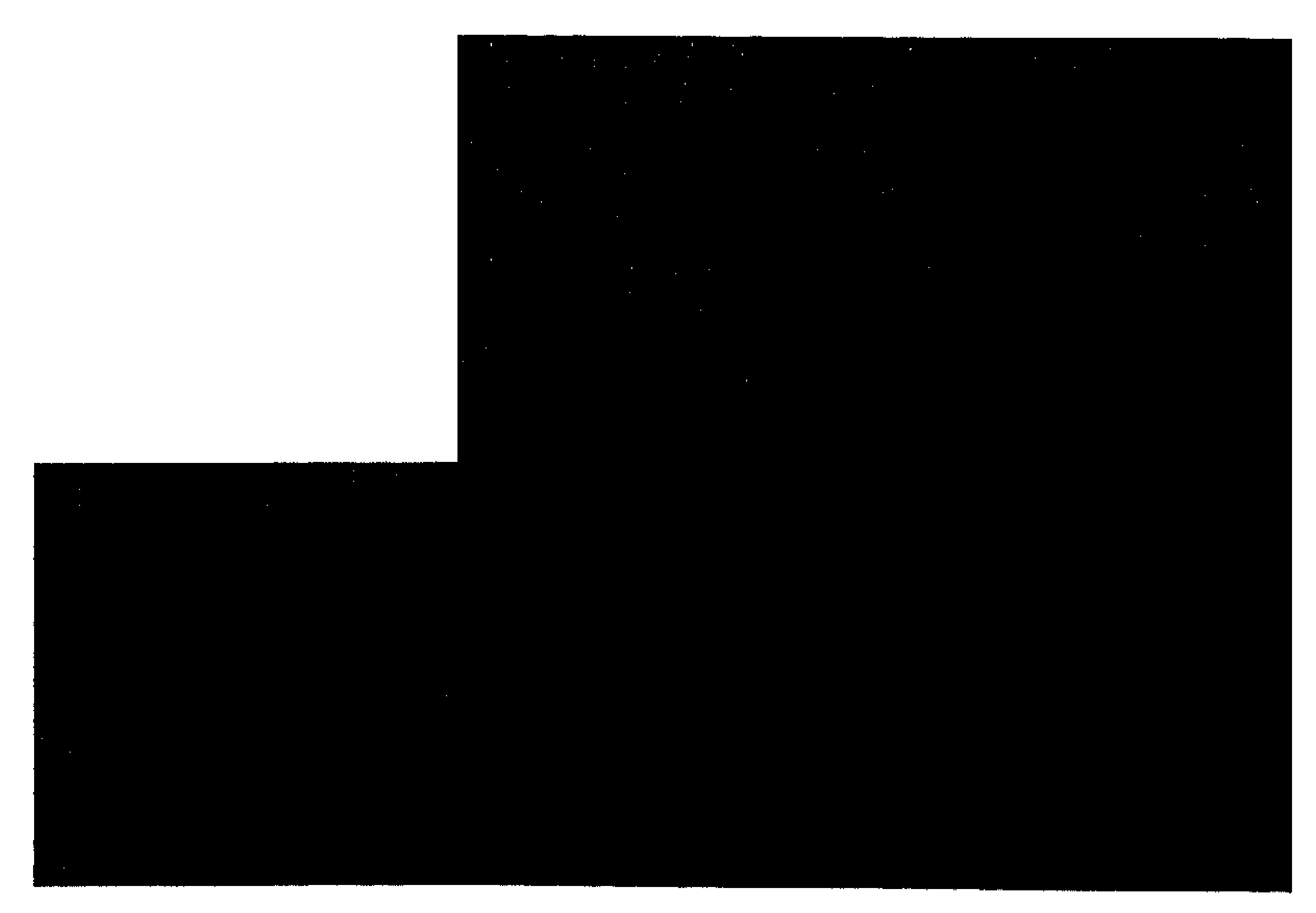


De jaarlijkse incidentie van schouderklachten in de huisartsenpraktijk ligt tussen de 15 en 25 gevallen per 1000 geregistreerde patiënten. De helft van deze patiënten heeft ook na de gebruikelijke behandeling zes maanden later nog klachten. Kenmerkend voor de gebruikelijke behandeling is de biomedische benadering van de schouderklachten.

Psychosociale factoren kunnen er toe leiden dat een patiënt ten opzichte van de schouderklacht onjuiste cognities en niet adequaat gedrag ontwikkelt. Het is bekend dat onjuiste cognities en niet adequaat gedrag een rol spelen bij het aanhouden van skeletspieraandoeningen, waaronder veel schouderklachten. Ter preventie van aanhoudende schouderklachten na zes maanden is een nieuwe behandeling ontwikkeld. Deze behandeling, het Educatie en Activatie Programma (EAP), heeft als doel het ontstaan van onjuiste cognities en niet adequaat gedrag te voorkomen kort na het ontstaan van de schouderklachten.

Een gerandomiseerde klinisch onderzoek (GKO) is opgezet en uitgevoerd om het effect van EAP te bestuderen op het voorkómen van chronische schouderklachten, 26 weken na de eerste presentatie van de klachten in de huisartsenpraktijk.

In hoofdstuk 1 worden de rationale achter EAP, alsmede de primaire vraagstelling beschreven.

De Dalai Lama ${ }^{20}$ zei eens: 'Pijn is onvermijdelijk. Lijden is een keuze.' Toch zullen veel patiënten het hier niet mee eens zijn. Immers, lijden is alléén een keus als de patiënt hulpmiddelen en vaardigheden krijgt aangereikt waarmee hij of zij het lijden kan verminderen. De gebruikelijke biomedische behandeling biedt de patiënt weinig hulpmiddelen en vaardigheden in deze. Met de introductie van het biopsychosociaal model van Engel werden nieuwe behandelingen ontwikkeld die patiënten wél de hulpmiddelen en vaardigheden boden om zelf het lijden aan te kunnen pakken. Uitgangspunt van het biopsychosociale model is dat naast biologische oorzaken ook psychosociale variabelen een rol spelen bij ziekte. Uit eerdere studies is gebleken dat behandelingen die zich richten op het leren omgaan met de psychosociale variabelen waardevolle instrumenten zijn bij het voorkómen van chronische skeletspieraandoeningen. EAP is een dergelijke behandeling en daarmee een aanvulling op de gebruikelijk, biomedische behandeling van schouderklachten.

${ }^{20}$ Spiritueel en politiek leider van Tibet en Nobelprijs winnaar. 
Het GKO is opgezet om de primaire vraagstelling te beantwoorden: Is EAP als aanvulling op de gebruikelijke behandeling effectiever in het verminderen van het aandeel patiënten met schouderklachten na 6 maanden dan alléén de gebruikelijke behandeling?

Daarnaast zijn vraagstellingen gedefinieerd die zich richten op de kosteneffectiviteit van het programma en de prestaties van de getrainde huisartsen. Voor de kosteneffectiviteit werden gevonden verschillen in kosten vergeleken met de klinische effectiviteit van EAP. De prestaties van de huisartsen zijn bekeken met behulp van video opnamen van consulten. Daarnaast is het effect van de manier van patiënten werven op de uitkomst van het onderzoek bestudeerd.

De opzet van het GKO en de inhoud van EAP zijn beschreven in hoofdstuk 2 . Patiënten met minder dan drie maanden schouderklachten werden door de eigen huisarts benaderd voor deelname aan het GKO, dan wel opgeroepen middels een open werving. Alleen nieuwe (episodes van) schouderklachten kwamen in aanmerking voor inclusie in het onderzoek. Het laatste impliceerde dat patiënten in de drie voorgaande maanden voor deze klacht niet bij de huisarts mochten zijn geweest én dat de schouderklachten in de 3 voorgaande maanden niet waren behandeld door eerstelijns hulpverleners. Vervolgens werden de patiënten op basis van het toeval toegewezen aan de groep die de gebruikelijke behandeling kreeg of de groep die naast de gebruikelijke behandeling ook EAP kreeg aangeboden.

EAP bestaat uit twee behandelingen gevolgd door maximaal zes vervolgbehandeling gedurende een periode van totaal zes weken. Elke behandeling kan tot maximaal twintig minuten duren. Het eerste deel van EAP heeft een educatief doel waarbij de focus ligt op informatie over het ontstaan en de prognose van schouderklachten, de effectiviteit van mogelijke behandelingen en de gevolgen voor activiteiten in het dagelijks leven. Daarnaast wordt de patiënt geïnformeerd over de mogelijkheden die hij of zij zelf heeft om bij te dragen aan het herstel. De informatie was afkomstig uit de Standaard Schouderklachten van het Nederlands Huisartsen Genootschap, aangepast aan de informatiebehoefte van de individuele patiënt. Het tweede deel van EAP bestond uit een activerings programma dat is gebaseerd op de principes van operante conditionering. Hierbij worden de activiteiten in het 
dagelijks leven stapsgewijs in de tijd opgevoerd zonder rekening te houden met de pijn.

De primaire uitkomsten waren het door de patiënt ervaren herstel en de verandering van functionele beperkingen in het dagelijks leven. Het laatste werd bepaald met behulp van de 16 items van de 'Shoulder Disability Questionnaire' (SDQ). De uitkomsten werden 6, 12 en 26 weken na toewijzing aan de groepen gemeten. De SDQ werd ook afgenomen op baseline. Patiënten hielden een kostendagboek bij om het zorggebruik en directe nietmedische en indirecte kosten vast te leggen.

Het GKO was onderdeel van het Nederlands Schouderklachten Onderzoek (NSO). Het NSO bestond uit een prognostische cohortstudie waarin GKO's zijn ondergebracht in subcohorten. Het NSO is gesubsidieerd door de Nederlandse organisatie voor gezondheidsonderzoek en zorginnovatie (ZonMw).

De prestatie van huisartsen hangt niet direct samen met hun kennis en vaardigheden, zo is gebleken uit eerdere studies. Dit betekent dat huisartsen die een training hebben gevolgd om een nieuwe behandeling te geven, niet automatisch de getrainde behandeling op de bedoelde manier uitvoeren. Daarom hebben we de prestaties bestudeerd van vijf huisartsen die EAP (EAP groep) en vijf huisartsen die de gebruikelijke behandeling gaven (GB groep). Daartoe werden video-opnames gemaakt van consulten waarin de tien huisartsen een gestandaardiseerde vrouwelijke simulatiepatiënt behandelden. De simulatiepatiënt speelde dat ze schouderklachten had. Zij had hiervoor een twee uur durende instructie, inclusief rollenspelen, gevolgd.

De resultaten van de video-opnames worden beschreven in hoofdstuk 3. Het aantal op de video gescoorde sleutelkenmerken van EAP werd gebruikt als een indicatie voor de prestaties van de huisartsen, alsmede de mate waarin ze EAP toepaste. Daarnaast werd gekeken of huisartsen die de gebruikelijke behandeling gaven sleutelkenmerken van EAP toepasten. Het doel hiervan was om te onderzoeken of sleutelkenmerken die exclusief werden toebedeeld aan EAP tevens in de gebruikelijke behandeling werden verweven. De videoopnames zijn geëvalueerd door twee geblindeerde observatoren die een checklijst gebruikten om de sleutelkenmerken van EAP te scoren.

Een vergelijking tussen de twee groepen liet zien dat het aantal sleutelkenmerken in de EAP groep gelijk of groter was dan het aantal sleutelkenmerken in de groep huisartsen die de gebruikelijke behandeling 
gaven, met uitzondering van één kenmerk (n.l. uitleggen aan de patiënt wat het doel van de behandeling is).

Huisartsen in de EAP groep en de GB groep slaagden er beiden niet in een acceptabel aantal sleutelkenmerken te scoren, terwijl huisartsen in de GB groep boven verwachting presteerden. Een verklaring voor dat laatste kunnen eerder opgedane ervaringen zijn met gelijksoortige behandelingen bij patiënten met lage rugklachten en vage buikklachten.

Overigens moet worden genoemd dat het toepassen van sleutelkenmerken tijdens een behandeling geen informatie geeft over de kwaliteit waarmee de kenmerken worden uitgevoerd. De kwaliteit kan verschillend zijn geweest tussen de groepen.

Samengevat blijkt uit deze analyse dat huisartsen die EAP gaven niet de gewenste prestaties leverden. Daar staat tegenover dat huisartsen die de gebruikelijke behandeling gaven toch al sleutelkenmerken toepassen in de dagelijkse praktijk. Het resultaat hiervan is dat het verschil tussen de twee groepen kleiner was dan verwacht. Mogelijk heeft dit de uitkomsten van het GKO beïnvloed, hoewel de kwaliteit van het toepassen van de sleutelkenmerken in de analyse van de primaire uitkomstmaten niet werd meegenomen.

De resultaten van het GKO worden gepresenteerd in hoofdstuk 4. Patiënten met niet langer dan drie maanden bestaande schouderklachten in rust of tijdens beweging werden op basis van het toeval toegewezen aan twee behandelingen: EAP als aanvulling op gebruikelijke behandeling of alleen de gebruikelijke behandeling. Metingen werden uitgevoerd op baseline en na 6 en 26 weken. Huisartsen of een ambulante therapeut gaven EAP; de gebruikelijke behandeling werd gegeven door de eigen huisarts van de patiënt.

De eerste primaire uitkomstmaat was het door de patiënt ervaren herstel. Na 6 weken werden patiënten die op een 7-punts ordinale schaal aangaven dat ze veel verbeterd óf volledig waren hersteld, als hersteld beschouwd. De tweede primaire uitkomstmaat (de verandering van functionele beperkingen in het dagelijks leven) werd bepaald met behulp van de 16 items van de 'Shoulder Disability Questionnaire' (SDQ). De gestandaardiseerde score van deze vragenlijst ligt tussen de 0 en 100 waarbij een lage score een indicatie is voor weinig functionele beperkingen. 
Patiënten die afkomstig zijn van dezelfde huisarts zullen naar verwachting niet onafhankelijk van elkaar reageren op de EAP of de gebruikelijke behandeling. Hetzelfde geldt voor herhaalde metingen aan dezelfde patiënt. Multilevel analyse houdt rekening met deze afhankelijkheid, door gebruik te maken van clusters. Het effect van EAP werd geanalyseerd door middel van een lineaire multilevel analyse voor de SDQ en een logistische multilevel analyse voor het door de patiënt ervaren herstel. Hierbij werden drie niveaus van variantie onderscheiden: huisartsen, patiënten en metingen.

Het resultaat van multilevel analyses bestaat uit schattingen van de 'fixed' en 'random' effecten. De statistische significantie van deze schattingen werd voor de lineaire multilevel analyse bepaald met behulp van de Likelihood-ratio-test. Bij de logistische multilevel analyse werd hiervoor gebruik gemaakt van de Wald-chi-kwadraat test. Schattingen die niet significant waren werden uit het multilevel model verwijderd, met uitzondering van het effect van EAP. Hierbij werden de minst significante schattingen als eerste uit het model gehaald. Bij de logistische multilevel analyse werden de schattingen omgezet in odds ratio's met de bijbehorende $95 \%$ betrouwbaarheidsintervallen.

De logistische multilevel analyse van het door de patiënt ervaren herstel liet geen significant effect van EAP zien. Wel was er een significant effect van de tijd te zien op een toename van het ervaren herstel na 6 en 26 weken. Catastroferen op baseline had geen significant effect op het ervaren herstel.

Het uiteindelijke model voor de lineaire multilevel analyse voor de SDQ liet zien dat EAP geen effect had op functionele beperkingen. Catastroferen op baseline was wel significant en positief gerelateerd aan de scores op de SDQ na 6 en 26 weken. Er werd voorts opnieuw een statistisch significant effect gevonden voor een afname van functionele beperkingen in de tijd.

Samenvattend liet de multilevel analyse geen significant effect zien van EAP op de primaire uitkomstmaten na 6 en 26 weken.

De relatie tussen catastroferen op baseline en functionele beperkingen was een toevalsbevinding van het GKO. Deze relatie wekt de indruk dat een behandeling die zich specifiek richt op catastroferen meer kans van slagen heeft bij het voorkomen van functionele beperkingen op de lange termijn. In EAP is catastroferen slechts één van de psychosociale factoren. Het effect van een behandeling die zich richt op catastroferen kan nog meer worden vergroot door patiënten te selecteren die op baseline al een verhoogde mate van catastroferen laten zien. 
Schouderklachten zijn na lage rugklachten de meeste voorkomende groep van skeletspieraandoeningen. De gerelateerde kosten voor gezondheidszorg en de kosten ten gevolge van werkverzuim maken duidelijk dat er behoefte is aan een kosteneffectiviteitanalyse van EAP. De resultaten van deze analyse worden gepresenteerd in hoofdstuk 5. Voor een analyse van de totale kosten werden de studiegroepen onderling vergeleken gedurende een periode van 26 weken. Verder zijn kosten afgezet tegen het door de patiënt ervaren herstel (eerste primaire uitkomstmaat) in de twee groepen. Hierbij is gebruik gemaakt van 'bootstraps'.

Kosten zijn vanuit een maatschappelijk standpunt benaderd, gebruikmakend van een kostendagboek. In het kostendagboek zijn directe kosten voor de gezondheidszorg en kosten die niet gerelateerd zijn aan de gezondheid vastgelegd.

De klinische uitkomst is geanalyseerd volgens het 'intention-to-treat' principe. Hierbij zijn de verschillen tussen de groepen ten opzicht van baseline met behulp van de chikwadraattoets getoetst. Daarnaast is een analyse uitgevoerd op geïmputeerde klinische data. Hierbij is de laatst opgegeven waarde gebruikt om ontbrekende meetwaarden van de klinische uitkomst te imputeren.

De primaire kosteneffectiviteitanalyse is uitgevoerd op geïmputeerde kostgegevens. Ontbrekende gegevens over de kosten zijn geïmputeerd door de laatst opgegeven waarde te gebruiken. Kostgegevens vertonen normaal gesproken een scheve verdeling (een minderheid van de patiënten geneert het grootste deel van de totale kosten). Daarom is een schatting met behulp van bootstraps gebruikt om $95 \%$ betrouwbaarheidsintervallen te bepalen voor het gemiddelde verschil in totale kosten ten gevolge van schouderklachten en het gemiddelde verschil van de klinische uitkomstmaten tussen de groepen. De bootstrap-schatting is gebaseerd op willekeurige steekproeven (1000 herhalingen) waarbij gegevens van een aantal patiënten uit het GKO werden vervangen door originele data.

De 'Incremental Cost-Effectiveness Ratios' (ICERs) worden berekend door het verschil in kosten tussen de twee groepen te delen door het verschil in klinisch effect tussen de groepen. De ICERS werden bepaald voor elke herhaling van de bootstrap. De kosteneffectparen worden grafisch weergegeven in een kosteneffectiviteitkwadrant. Een 'acceptability curve' laat de kans dat een behandeling kosteneffectief is zien bij een bepaald waarde van de ICER. 
Er werd geen verschil gevonden tussen de groepen ten aanzien van het door de patiënt ervaren herstel. Hierbij is eerst gekeken naar patiënten waarvan alle kostengegevens beschikbaar waren. Hetzelfde resultaat werd gevonden voor patiënten waarvoor geïmputeerde kostengegevens beschikbaar waren.

De ICER waarmee het door de patiënt ervaren herstel werd vergeleken tussen de groepen bedroeg $€ 8501$ na 26 weken. Dit betekent dat voor elke extra herstelde patiënt in de EAP groep ten opzichte van de groep die de gebruikelijke behandeling krijgt een investering nodig is van $€ 8501$.

De gemiddelde ICER na 1000 bootstrap herhaling bedroeg $€ 7933$ met een betrouwbaarheidsinterval van $€ 675$ tot $€ 15192$. De meerderheid $(82 \%)$ van de kosteneffectparen lagen in het noordoostelijke kwadrant van het kosteneffectiviteit kwadrant. Dit wijst erop dat de EAP effectiever is tegen hogere kosten. Zestien procent van de kosteneffectparen lagen in het noordwestelijke kwadrant: minder effectief tegen hogere kosten. De incrementele 'acceptability curve' laat zien dat de kans $53 \%$ is dat EAP kosteneffectief is wanneer als de maximale waarde voor kosten $€ 10000$ wordt aangehouden.

EAP is bedoeld als een vroege behandeling gericht op het voorkomen van chronische schouderklachten. Door het voorkomen van chroniciteit moeten extra kosten die zijn geïnvesteerd in patiënten met nieuwe schouderklachten in de toekomst terugverdiend worden. De toekomst reikt in dit onderzoek echter slechts tot 26 weken. Uit de literatuur en uit dit onderzoek is niet te achterhalen hoeveel kosten worden uitgespaard na afloop van deze periode.

De klinische uitkomstmaat die in deze kosteneffectiviteitstudie is gebruikt, wordt door anderen zelden gebruikt. De literatuur biedt dan ook nauwelijks mogelijkheden ter vergelijking.

De klinische relevantie is in het GKO vastgesteld op een 'numbers-needed-totreat' (NNT) van 4,5. Om deze drempel te behalen is een nog grotere investering dan 10000 euro nodig. Los daarvan laten de klinische uitkomsten van het GKO zien dat de genoemde drempel niet is behaald (NNT=9). Op basis hiervan stellen we dat EAP niet kosteneffectief is ten opzichte van de gebruikelijke behandeling.

De wet van Lasagna wordt vaak bevestigd wanneer in een patiëntgebonden onderzoek de gerealiseerde rekrutering tegenvalt ten opzichte van de verwachte rekrutering. Dit is een bedreiging voor het slagen van een GKO. In 
hoofdstuk 6 wordt beschreven welke strategieën wij hebben gebruikt om de rekrutering van zowel huisartsen als patiënten te optimaliseren. Hierbij is gebruik gemaakt van maandelijkse nieuwsbrieven, regelmatige praktijkbezoeken, kleine cadeaus en geaccrediteerde cursussen. Patiënten werden gerekruteerd door huisartsen tijdens het spreekuur en middels advertenties in lokale weekbladen. De advertenties werden ingezet omdat de rekrutering door de huisarts erg tegenviel. Het effect van de twee rekruteringsstrategieën op de uitkomstmaten is geëvalueerd door de rekruteringsstrategie mee te nemen als een variabele in een multilevel analyse. Tijdgebrek wordt vaak genoemd als voornaamste bezwaar bij het rekruteren van patiënten tijdens het spreekuur. Daarom was de procedure voor de rekrutering tijdens het spreekuur zo opgesteld dat de benodigde tijd tot een minimum werd beperkt.

Via advertenties in lokale weekbladen werden patiënten opgeroepen om mee te doen aan het GKO. Patiënten die reageerden op de advertenties werden eerst telefonisch gescreend op de in- en uitsluitcriteria. Patiënten die voldeden aan deze criteria werden vervolgens bezocht door een huisarts die daartoe werd aangesteld door de studiegroep. Deze huisarts voerde het gebruikelijke consult bij schouderklachten uit, met inbegrip van een nauwgezette evaluatie van de medische voorgeschiedenis van de patiënt. Ook controleerde deze huisarts nogmaals de in- en uitsluitcriteria. Nadat de patiènt definitief aan alle criteria voldeed, informeerde de huisarts de onderzoeksassistente. De assistente nam vervolgens binnen twee weken contact op met de patiënt. Voor de verdere behandeling werden de patiënt daarna doorverwezen naar de eigen huisarts.

In het definitieve model van de multilevelanalyse waarin de rekruteringsstrategie als variabele was meegenomen, werd geen significant effect gezien van de rekruteringsstrategie op de uitkomstmaten. Derhalve lijken beide strategieën geschikt om patiënten te rekruteren. We concluderen dat de keuze voor een rekruteringsstrategie gedeeltelijk op praktische gronden (beschikbare hoeveelheden tijd en budget) kan worden gemaakt.

Een reflectie op methodologische en praktische aandachtspunten wordt gegeven in hoofdstuk 7.

Het doel van het GKO was het evalueren van het effect van EAP in de dagelijkse huisartspraktijk. Het voordeel van onderzoek in deze setting is dat 
een succesvolle behandeling in principe succesvol in dezelfde setting kan worden geïmplementeerd. Een nadeel is dat het moeilijker wordt om een verklaring te vinden voor een eventueel ontbrekend effect. Anticiperend op dit nadeel hebben we een aantal factoren die van invloed kunnen zijn op de uitkomstmaten in de gaten gehouden. Zo is onder andere gekeken naar het effect van de rekruteringsstrategie en het correcte gebruik van EAP in de praktijk. Voor dit laatste zijn video-opnamen van behandelingen gemaakt.

De statistische analyse zoals die was voorgesteld bij de opzet van het GKO bleek enkele tekortkomingen in zich te hebben. Daarom is uiteindelijk gebruik gemaakt van een multilevelanalyse, die immers beter rekening houdt met ontbrekende waarden en onderling afhankelijke uitkomsten.

Om EAP goed te kunnen geven, moeten de huisartsen hun houding ten opzichte van schouderklachten veranderen. De biomedische benadering van schouderklachten moet veranderen in een biopsychosociale benadering. Hoewel de deelnemende huisartsen de voordelen van het biopsychosociale model onderkenden, bleek het op de juiste manier toepassen van dit model op patiënten met schouderklachten voor een aantal huisartsen een brug te ver.

Een huisarts is vaak de eerste schakel tussen een patiënt met schouderklachten en overige hulpverleners in gezondheidszorg. Het is echter de vraag of de huisarts ook de meest geschikte behandelaar is van patiënten met schouderklachten. Verwijzing naar andere behandelaars in de eerste lijn, zoals fysiotherapeuten of zelfs praktijkverpleegkundigen, is wellicht een optie.

De resultaten van het GKO rechtvaardigen de conclusie dat EAP in haar huidige vorm niet ingezet moet worden voor de behandeling door de huisarts van patiënten met schouderklachten. Met het in dit proefschrift beschreven onderzoek is mogelijk een eerste stap gezet op weg naar meer biopsychosociale behandeling van patiënten met schouderklachten. Bij de opzet van dit onderzoek was nog weinig bekend over specifieke psychosociale factoren die van invloed zijn op het ontstaan van chronische schouderklachten. Wel was bekend dat in het algemeen psychosociale factoren een rol spelen bij chronische skeletspieraandoeningen. De manier waarop EAP de psychosociale factoren aanpakt, bleek echter niet geschikt om een verandering te bewerkstelligen in de uitkomst in vergelijking met de gebruikelijke behandeling. 


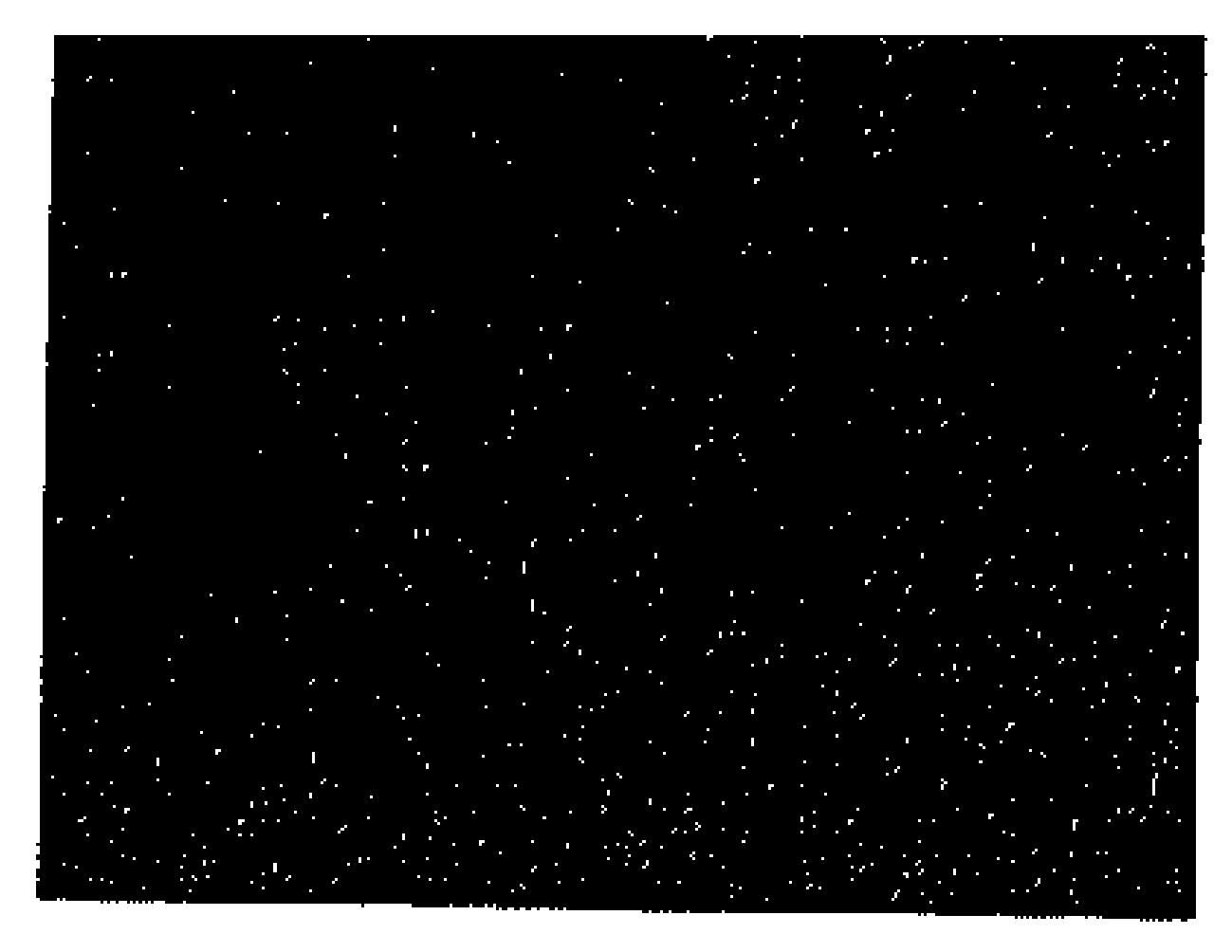

Dankwoord

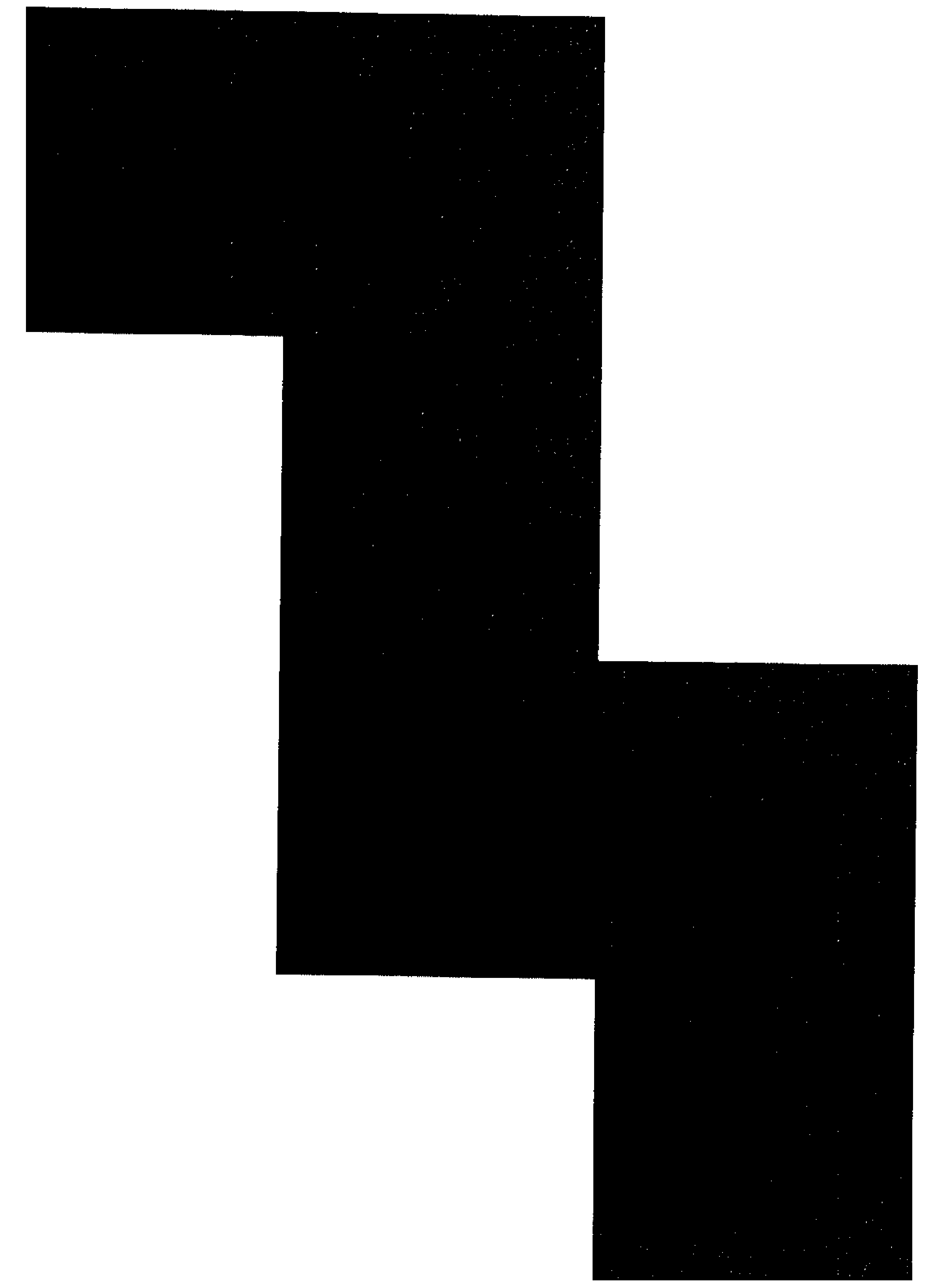


Het maken van dit proefschrift ging niet zonder slag of stoot. Dat blijkt wel uit de tijd die ik nodig heb gehad om tot de afronding te komen. In de afgelopen jaren heb ik geregeld steun en aanmoediging van collega's, vrienden en familie gekregen om door te gaan. Zonder hun hulp was dit boekje er zeker niet gekomen.

Er zijn een aantal mensen die ik in het bijzonder wil bedanken. In de eerste plaats mijn promotoren: Wim, Rob en Geert-Jan. Jullie hielden de grote lijn van mijn activiteiten in de gaten en stuurden mij zonodig bij.

Wim, je was vooral betrokken bij de opzet en de uitvoering van het onderzoek en hebt ervoor gezorgd dat er een stevig fundament werd gelegd voor de analyse en verslaglegging.

Rob, na het vertrek van Geert werd jij mijn begeleider. Als de instroom van de patiënten weer eens tegenviel, zorgde jij ervoor dat ik vertrouwen bleef houden in een goed afloop. Bovendien is jouw relativerende humor verhelderend bij de aanpak van problemen.

Geert-Jan, vanaf het begin was je bij het onderzoek betrokken. Jij voelt als geen ander aan wanneer ik een duwtje in de rug nodig heb. Vooral de laatste jaren zorgde jij ervoor dat ik bleef doorgaan. De afspraken met jou in Maastricht bleken altijd nuttig, zelfs als ik voor mijn gevoel niet veel nieuwe inbreng had. De stand van zaken op een rijtje zetten kan namelijk heel verhelderend zijn. Ik ging altijd met een goed en opgeruimd gevoel weer naar huis om de volgende stap te zetten.

Geert, als co-promotor en begeleider in het eerste jaar heb je mij de kans geboden om weer het wereldje van de wetenschap binnen te stappen. $\mathrm{Na}$ je vertrek bij het iRv hield je vanuit Utrecht een oogje in het zeil. Marielle, formeel was je de begeleidster van Jacques maar ik zie je toch ook een beetje als mijn begeleidster. Je bood altijd een luisterend oor en dacht mee over de aanpak van het onderzoek. 
Jacques, Gert en Ton: jullie waren me alle drie te snel af met promoveren. Het Limburgs kwartiertje heeft me genekt. Maar nu is het Nederlands

Schouderonderzoek dan écht klaar. Helaas lust ik nog steeds geen bier, maar ook met een colaatje was het altijd gezellig met jullie.

Natalie, Jeanne, Marianne, Sabine. Jullie waren de onderzoeksassistenten die ervoor zorgden dat de hele logistiek op rolletjes liep en de patiënten bleven meedoen. Albère, je was nauw betrokken bij de inhoud van de EAP. Ik voelde me altijd gesteund door jouw kennis en ervaring als behandelaar, trainer en onderzoeker.

Olga, Jos, Chantal, Manon, Judith en Jacques. Jullie waren allemaal supergezellige collega's en vrienden waarbij ik graag ging 'buurten'.

Daarnaast wil ik alle collega's van het iRv bedanken, de leden van de projectgroep, de leden van de leescommissie en natuurlijk alle huisartsen en patiënten die hebben deelgenomen aan het onderzoek.

Pap en mam, bedankt voor alles. Xavier en Jörn, super dat jullie mijn paranimfen willen zijn.

Tenslotte Bianca, mijn meisje en Sander, ons manneke. Bianca, jij weet hoe zwaar het soms écht is geweest en dat ik dan niet de leukste persoon ben om mee samen te leven. Jij bent de echte volhouder! En Sander: je bent het mooiste cadeautje van mijn leven.

Bedankt! 


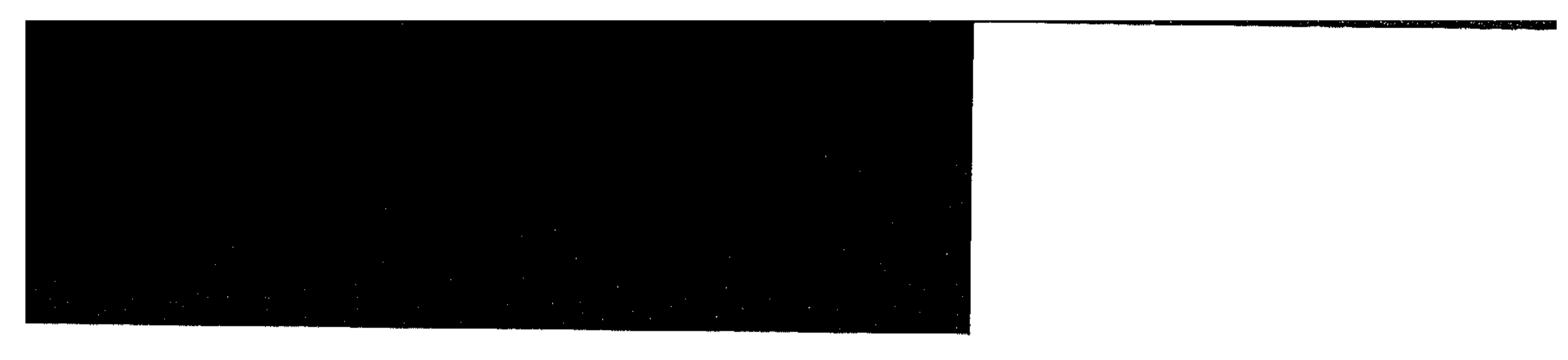

About the author

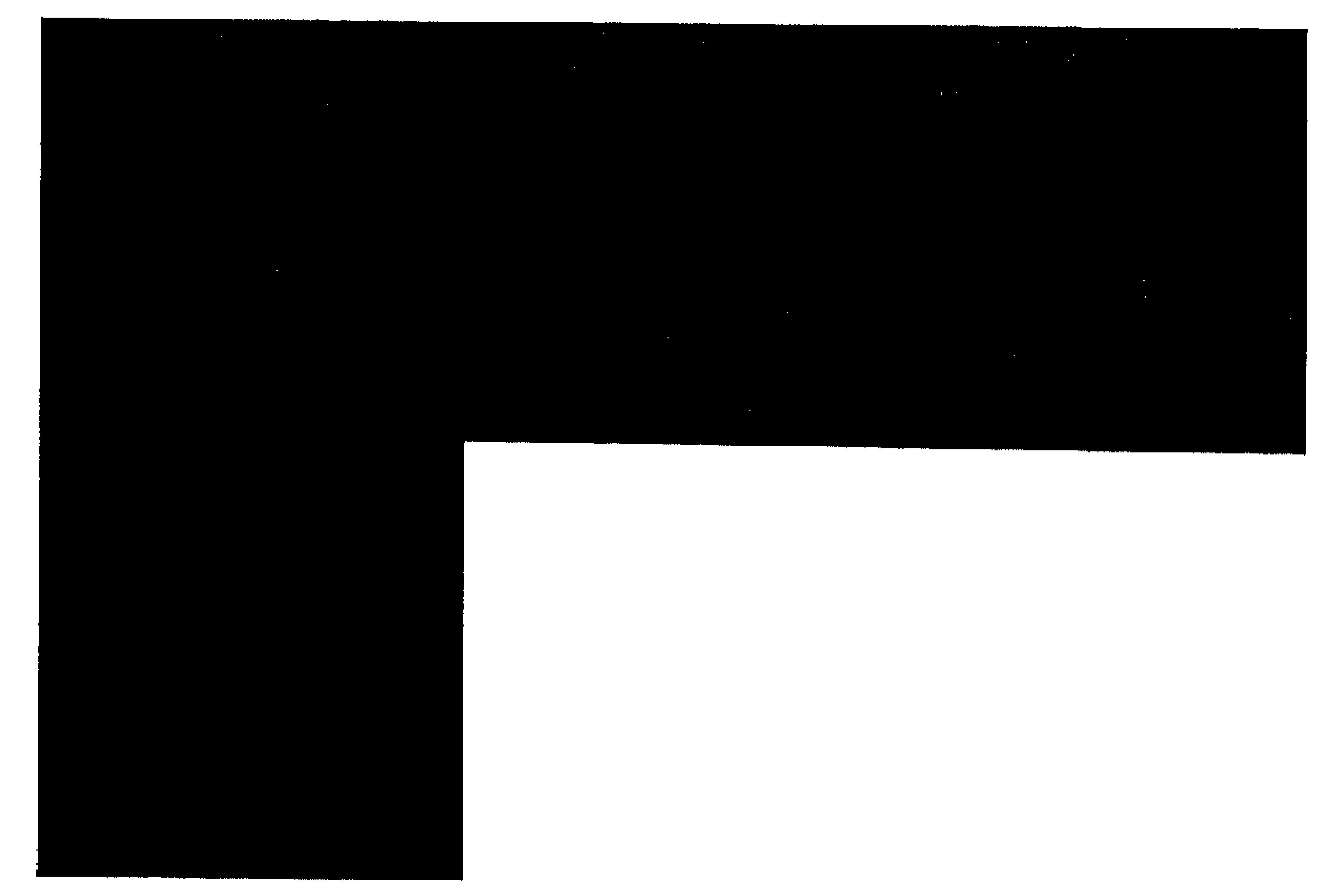


Camiel De Bruijn was born on June 19, 1972 in Sittard, the Netherlands and grew up in Buchten. He obtained his Gymnasium diploma in 1990. He then started his study in Health Sciences at Maastricht University and graduated in 1996. He worked as a parcel post deliverer from 1996 until 1999. In 1999 he was research assistant at Novartis after which he started as a PhD-student in 2000. He started as a statistical researcher at Statistics Netherlands in 2006. $\mathrm{He}$ is living together with Bianca Fraats and became father of their son Sander in 2007. 